
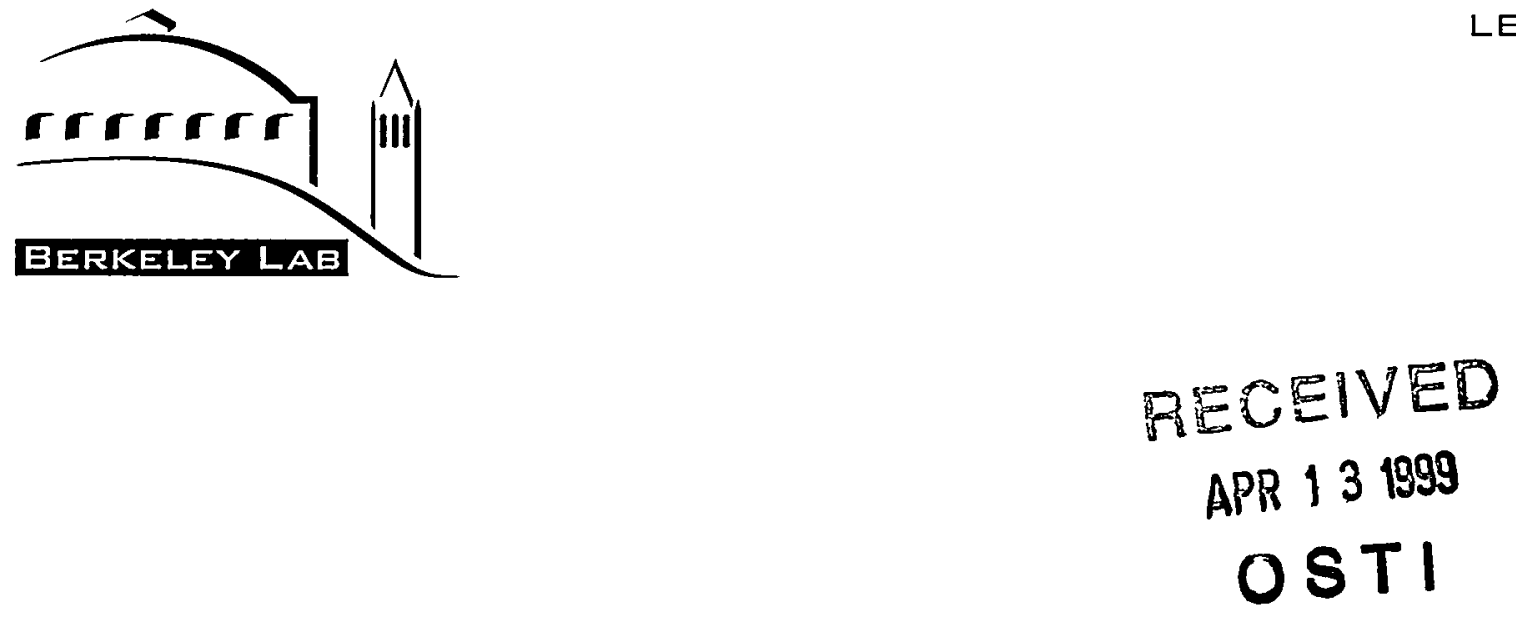

CURRENT WIRK IN ENERGY ANALYSIS

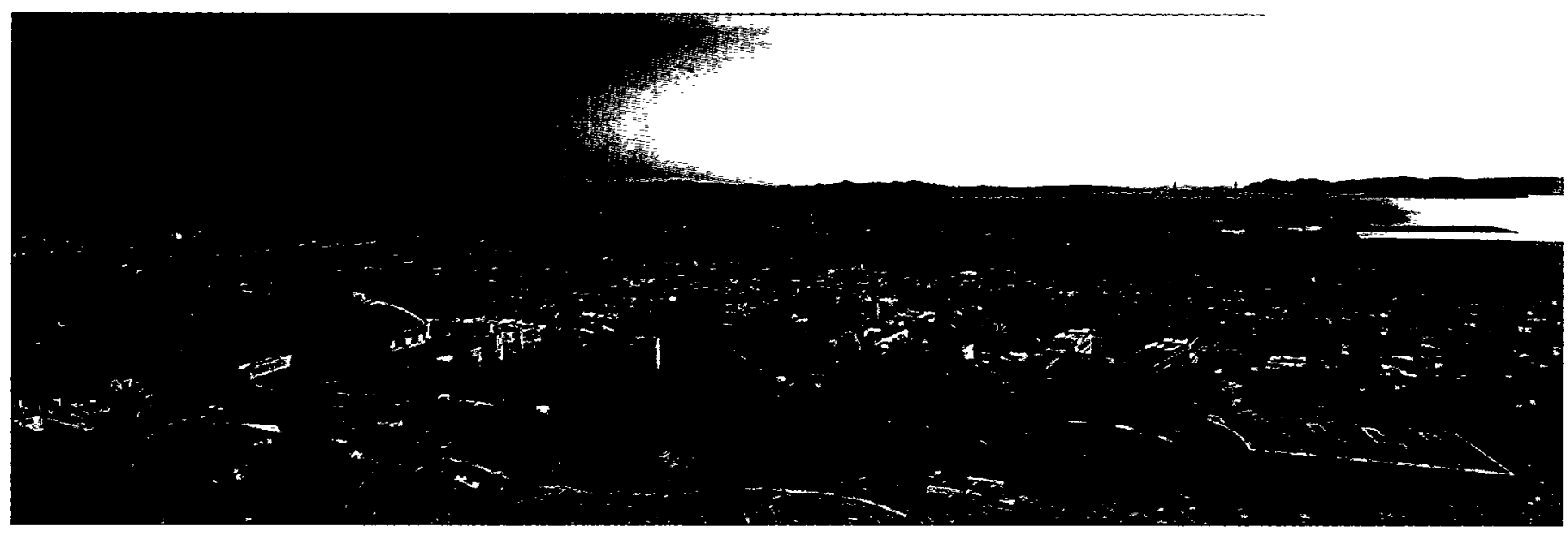

ENVIRINMENTAL ENERGY TECHNDLOGIES DIVISION MAREH 1998 


\section{DISCLAIMER}

This document was prepared as an account of work sponsored by the United States Government. While this document is believed to contain correct information, neither the United States Government nor any agency thereof, nor The Regents of the University of California, nor any of their employees, makes any warranty, express or implied, or assumes any legal responsibility for the accuiacy, completeness, or usefulness of any information, apparatus, product, or process disclosed, or represents that its use would not infringe privately owned rights. Reference herein to any specific commercial product, process, or service by its trade name, trademark, manufacturer, or otherwise, does not necessarily constitute or imply its endorsement, recommendation, or favoring by the United States Government or any agency thereof, or The Regents of the University of California. The views and opinions of authors expressed herein do not necessarily state or reflect those of the United States Government or any agency thereof, or The Regents of the University of California.

Available to DOE and DOE Contractors from the Office of Scientific and Technical Information

P.O. Box 62, Oak Ridge, TN 37831

Prices available from (615) $576-8401$

Available to the public from the National Technical Information Service

U.S. Department of Commerce

5285 Port Royal Road, Springfield, VA 22161

Ernest Orlando Lawrence Berkeley National Laboratory is an equal opportunity employer.

Printed on recycled paper using soy-based ink.

Prepared for the U.S. Department of Energy under Contract No. DE-AC03-76SF00098. 


\section{DISCLAIMER}

Portions of this document may be illegible in electronic image products. Images are produced from the best available original document. 
LBNL-41073

\title{
CURRENT WORK IN ENERGY ANALYSIS
}

\author{
Environmental Energy Technologies Division \\ Ernest Orlando Lawrence Berkeley National Laboratory \\ University of California \\ Berkeley, California 94720 \\ phone - 510.486.4000 \\ fax -510.486 .6996$ \\ web - http:/ / eetd.lbl.gov/EA
}

LBNL reports that are downloadable from our Web site are noted as such in the References. Unless otherwise directed, go to our Home Page and choose the Publications button, which calls up our publication search engine. Search for the document by entering its LBNL number and then clicking the Find button. At the foot of the page presented on your screen for that document, click on the word "downloadable." 



\section{Preface}

Ernest Orlando Lawrence Berkeley National Laboratory (Berkeley Lab) -is the oldest of seventeen National Laboratories owned and managed by the United States Department of Energy. It is located in California above the campus of the University of California at Berkeley. A panoramic view of the Lab, campus, and San Francisco Bay graces the cover of this report. The efforts of the 3000-plus men and women who make up Berkeley Lab are dedicated to solving problems to improve the way we live while also investigating and unraveling the secrets of the universe.

Berkeley Lab was founded as a high energy physics laboratory in 1931 by Ernest Orlando Lawrence, the University of California Berkeley professor who invented the cyclotron. Today, six decades later, the achievements of this Lab can be viewed as having contributed significantly to the history of science. Ernest Lawrence was the first of nine Nobel prize winners at the Lab. His cyclotron led to a Golden Age of particle physics and revolutionary discoveries about the nature of the universe. The Lab also houses a world center for accelerator and detector innovation and design, is the birthplace of nuclear medicine and a center of invention for medical imaging, is where lipoproteins were first isolated, is where it was determined that the ratio of high-density to low-density lipoproteins is a strong indicator of heart disease risk, is where the theory was developed that dinosaurs had been killed off by a massive comet or asteroid that had slammed into the Earth, and is where the chemical laser was invented. Lab scientists conduct work in high energy physics, astrophysics, accelerator and fusion research, life sciences, physical biosciences, chemical sciences, materials sciences, earth sciences, information and computing sciences, and environmental energy technologies.

The last of these topics is the focus of the Environmental Energy Technologies Division, one of the Lab's thirteen technical divisions. It is broadly charged with developing innovative approaches for more efficient energy use and advanced options for energy conversion, storage, and distribution; investigating the atmospheric and biospheric effects of energy technologies and remediation options; analyzing national and international energy use; transferring research results to the private sector and to government and other decision-makers; applying its accumulated expertise to national problems related to energy; and contributing to the education of scientists and engineers. The match of the Division's expertise to national needs is the central criterion for judging the priorities of its activities.

The Environmental Energy Technologies Division houses the Energy Analysis Department, a group of 100 people who provide data and analysis for understanding how people use energy and for supporting the development of rational energy policy. This report presents the results of the Energy Analysis Department's efforts over the period 1996 and 1997. 



\section{Introduction}
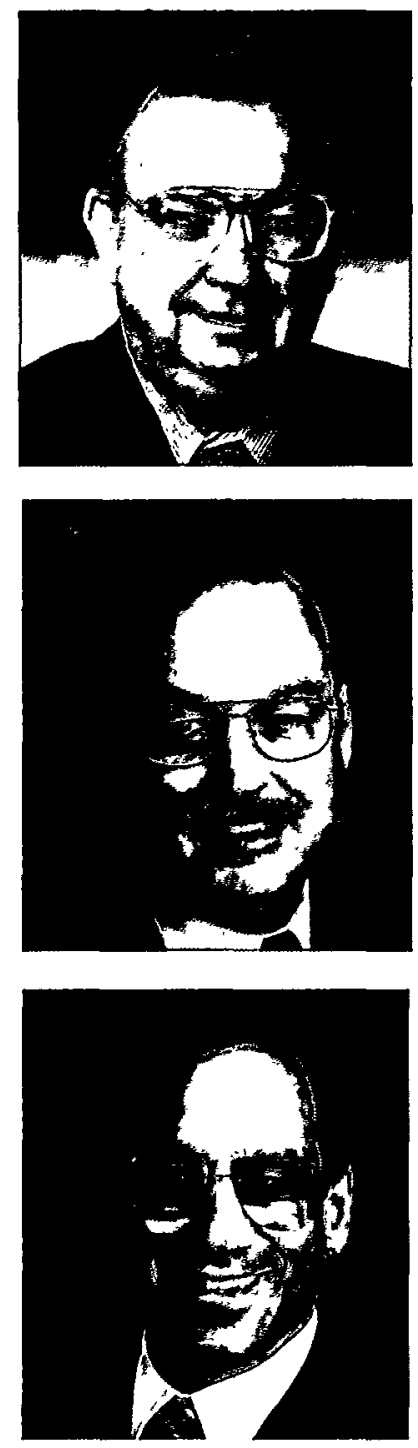

\section{Activities and Accomplishments}

7 The Environmental Energy Technologies Division performs R\&D to create new technology for using and converting energy at very high efficiency and at low environmental impact. The Division also carries out extensive analyses supporting the development of sound energy policies and programs, as well as studying ways to reduce environmental impacts. I look to the Division to do work that makes a difference in the real world.

Charles V. Shank, Director, Berkeley Laboratory

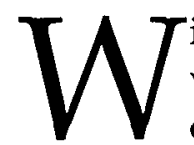
ithin the Division, the Energy Analysis Department provides the understanding of energy use that enables us to develop better energy technologies. It also provides analysis to inform government decisionmakers on matters related to energy policy. As a result, our society uses energy at least a little more efficiently.

\section{Mark D. Levine, Division Director}

erkeley Lab is home of the largest program of energy efficiency analysis anywhere within the National Laboratory system, perhaps anywhere in the world. This analytical work is mostly done in the Environmental Energy Technologies Division's Energy Analysis Department. We are a group of 100 researchers, technicians, and support staff, perhaps best known for combining an excellence in research with an exceptionally strong dedication to public service. Our mission is stated here:

Berkeley Lab's Energy Analysis Department informs governments and international institutions on energy-related issues to help them formulate energy and environmental policies. We do this by generating and interpreting information on the supply and consumption of energy, on technologies, on management practices, and on economic and environmental impacts.

Znergy analysis at the Lab dates back to the mid- and late 1970s, in the wake of the 1973 and 1979 oil Zshocks, when scientists at the Lab turned their attention to two new and important themes. We first broke away from the tradition of analyzing energy consumption in the aggregate and, instead, worked to separately understand each energy end use. Over the ensuing two decades we have identified and analyzed about 100 end uses of energy in buildings and many others in industrial settings. We also developed and popularized the concept known as "supply curves of saved energy," charts showing the amount of energy that can be saved from energy-efficiency investments as a function of the cost per unit of energy saved. Supply curves have drawn attention to the enormous cost-effectiveness of energy conservation and have become a standard tool for energy analysts and policymakers. 
Over the past 20 years, we have collected the data to allow future use of each end use to be forecast independently. We have assessed the potential of our country and the world as a whole to use energy more efficiently. We have analyzed the mechanisms by which each energy-consuming device uses and wastes energy, sometimes leading directly to improvements in the technology. Our analyses of technology, engineering practices, and economic impacts have allowed our government to set cost-effective energy performance standards for refrigerators, freezers, fluorescent lamp ballasts, air conditioners, ovens and ranges, dishwashers, clothes washers, and dryers. Our analyses have led to many of the target energy performance levels for our government's ENERGY STAR ${ }^{\circledR}$ program and other voluntary energy-efficiency partnerships with the private sector. We have evaluated the effectiveness of utility sector regulation to stimulate energy efficiency and, as the electricity sector is restructured, have worked to protect energy efficiency and other public goods traditionally delivered by utility companies. We have conducted analyses to support our government's policy on climate change and have worked with over 60 industrialized and cleveloping countries to support their policy development as well.

Over the years, we have maintained a steady attention to energy efficiency despite large fluctuations in public interest and apparent need. Perhaps the primary benefit is that, in time of need, energy data and analytical tools are available. Now appears to be such a time, as the nations of the world assemble to address potential threats to our well-being posed by climate change. Energy consumption is certainly the root human contribution to climate change, and energy efficiency is the centerpiece of all strategies to mitigate its impact.

We at Berkeley Lab are poised to respond to the challenge. We have been actively engaged in climate change analysis for the past six years, conducting "country studies" of greenhouse gas mitigation strategies, participating prominently in the world's assessment of the problem by the Intergovernmental Panel on Climate Change (IPCC), and facilitating projects in the U.S. and around the world designed to reduce greenhouse gas emissions. Most of the work we are currently performing is targeted at climate change issues.

There are a few exceptions where our attention is turned more toward urban smog than climate change. Our assessment of urban heat islands is an example. The traditional approach to combatting urban smog is to reduce air pollutant emissions. Our research has shown another cost-effective option is to reduce the urban ambient temperature by using reflective roofs and pavements and planting more vegetation. Our research also shows that, in order to control urban smog, eliminating malfunctioning catalytic converters in new cars is as important as maintenance inspections and adjustments in older cars. We also show that "fee-bates" (revenue neutral penalties for buying gas-guzzling cars and associated rewards for buying energy-efficient ones) would be effective in promoting efficiency and reducing pollution.

This report describes the work we have been doing most recently. One of our proudest accomplishments is the publication of Scenarios of U.S. Carbon Reductions, an analysis of the potential of energy technologies to reduce carbon emissions in the U.S. This analysis, described on pages 1 and 2, played a key role in shaping the U.S. position on climate change in the Kyoto Protocol negotiations. Our participation in the fundamental characterization of the climate change issue by the IPCC is described on page 4 . We are also especially proud of our study of "leaking electricity," described on page 42, which is stimulating an international campaign for a one-watt ceiling for standby electricity losses from appliances. This ceiling has the potential to save twothirds of the $5 \%$ of U.S. residential electricity currently expended on standby losses.The 54 vignettes contained in the following pages summarize results of research activities ranging in scale from calculating the efficacy of individual lamp ballasts to estimating the cost-effectiveness of the national ENERGY STAR $®$ labeling program, and ranging in location from a scoping study of energy-efficiency market transformation in California to development of an energy-efficiency project in the auto parts industry in Shandong Province, China. These are the intellectual endeavors of a talented team of researchers dedicated to public service. If you are interested in looking further into this research, obtaining copies of our reports, or just learning a little more about us, please visit us on the web at http://eetd.lbl.gov/EA 


\section{Program Staff During 1996 and 1997}

Stephen Wiel, Department Head

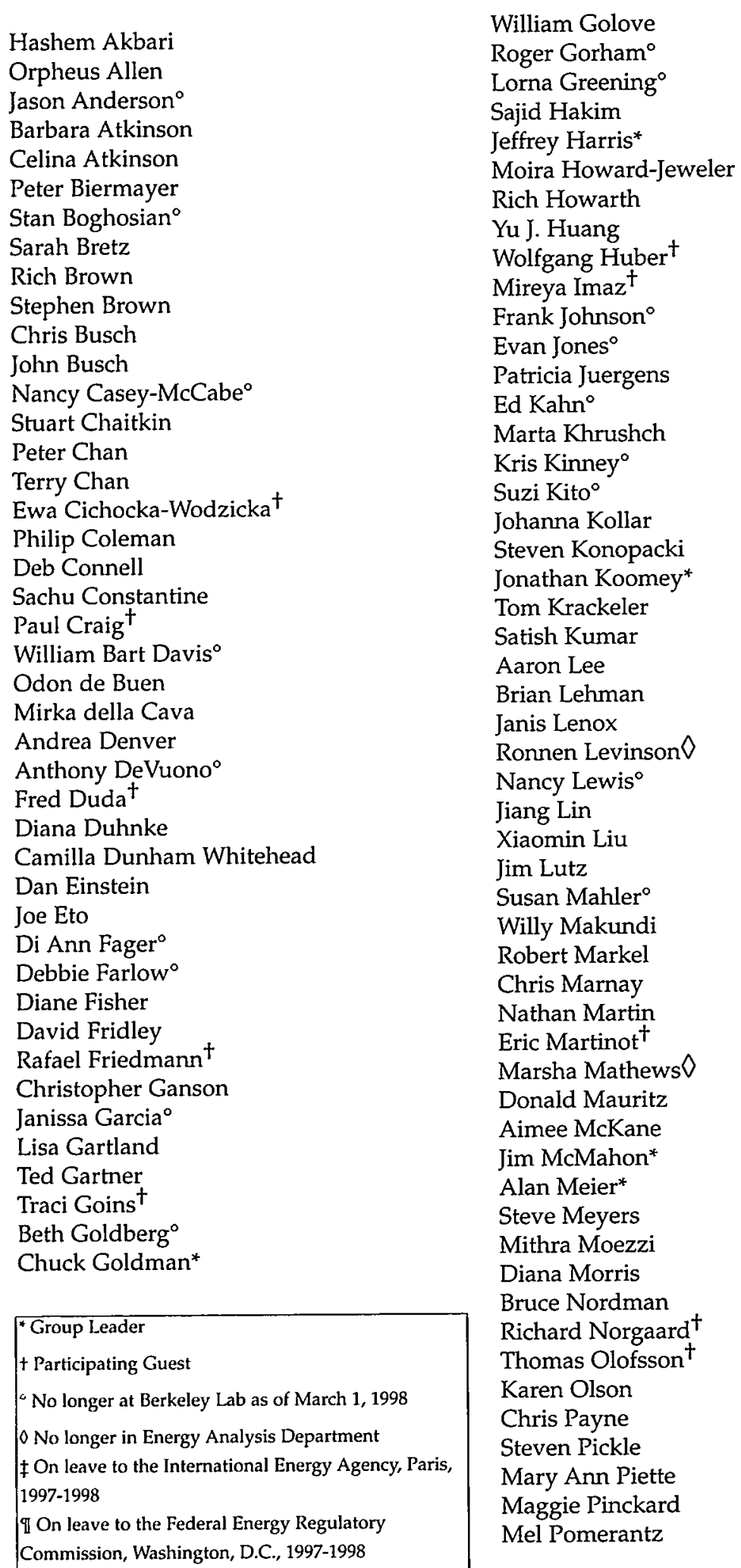

Brian Pon

Lynn Price

Stephen Puller ${ }^{\text {to }}$

Ned Raynolds

John Randolph $\bigcirc$

Wolf Read

R. Cooper Richey

Judy Roberson

Greg Rosenquist

Joyashree Roy ${ }^{\dagger}$

Glenn Saika

Marla Sanchez

Alan Sanstad

Jayant Sathaye*

Lee Schipper ${ }^{*} \ddagger$

Katja Schumacher

Osman Sezgen

Leslie Shown

Jonathan Sinton ${ }^{\circ}$

Henry Stadler ${ }^{\dagger}$

Jeff Stein

Steve Stoft II

Haider Taha

Alison ten Cate

Michael Ting

Kenneth Train ${ }^{\dagger}$

Isaac Turiel

Vestal Tutterow

Diana Urge-Vorsatz ${ }^{\circ}$

Ed Vine

Jeff Warner

Carrie Webber

Tom Wenzel

Daria Williams ${ }^{\circ}$

Ryan Wiser

Nan Wishner

Avis Woods ${ }^{t}$

Fu Qiang Yang

Chung Seok Yoo to

Hui Zhang

\begin{tabular}{|l|}
\hline LBNL Outstanding Performance \\
Award Recipients 1996-1997 \\
Rich Brown \\
Philip Coleman \\
Beth Goldberg \\
Patty Juergens \\
Aimee McKane \\
Diana Morris \\
Mary Ann Piette \\
Alison ten Cate \\
Ryan Wiser
\end{tabular}




\section{Global and National Energy and Greenhouse Gas Emissions Analysis}

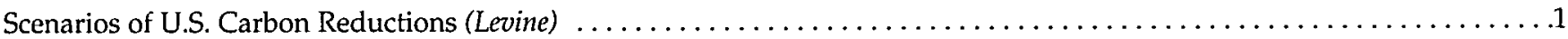

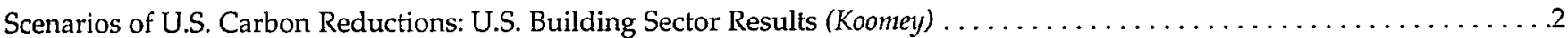

The Evolution of Carbon Dioxide Emissions from Energy Use in Industrialized Countries (Schipper) . . . . . . . . . . . . 3

\section{Climate Change Mitigation}

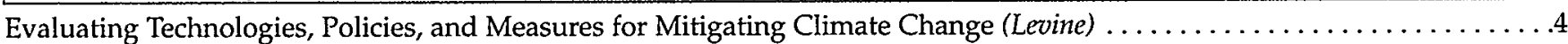

The Monitoring, Evaluation, Reporting, and Verification of Climate Change Mitigation Projects (Vine) ............

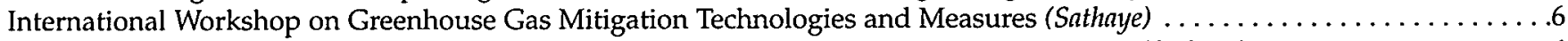

International Workshop on Monitoring and Verification of Sustainable Forest Management (Sathaye) $\ldots \ldots \ldots \ldots$

\section{China, India, and Other Partnerships}

Overview of Developing Countries' Concerns About Joint Implementation: Case Studies

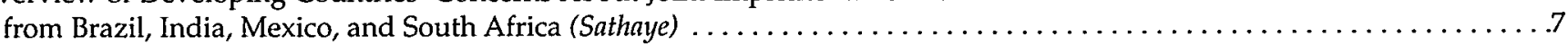

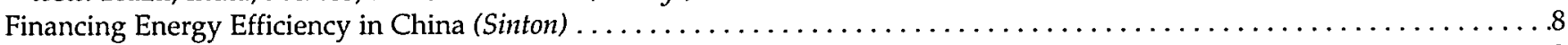

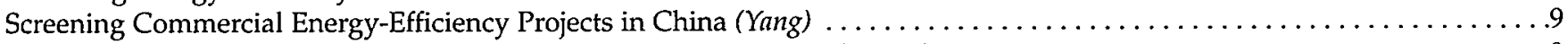

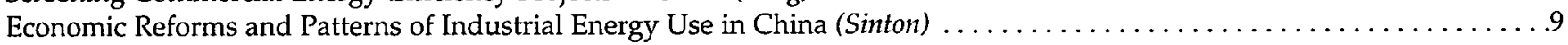

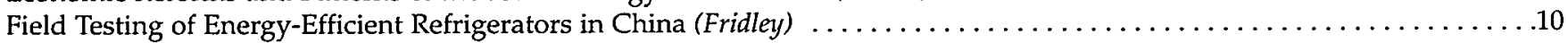

Improving Industrial Energy Efficiency Through New Banking Practices in India (Sathaye) $\ldots \ldots \ldots \ldots \ldots \ldots \ldots \ldots \ldots$

\section{Voluntary Government Programs}

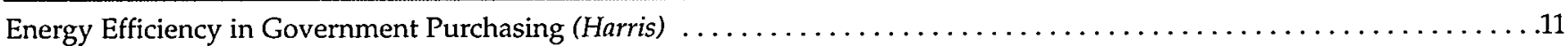

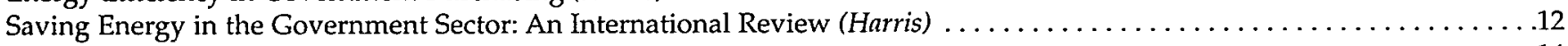

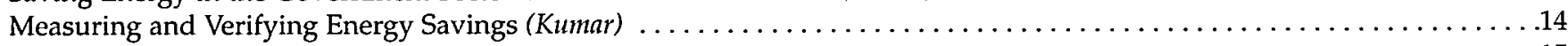

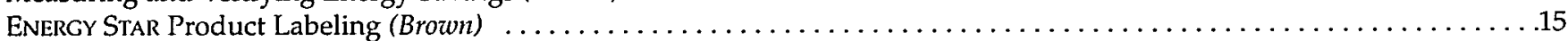

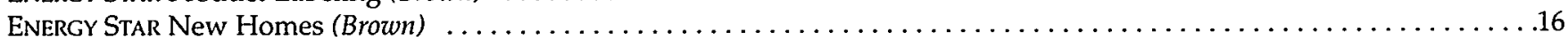

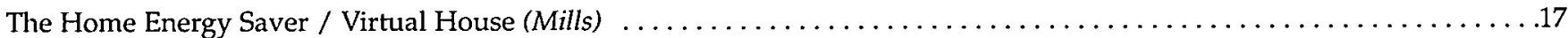

\section{Energy Efficiency Standards}

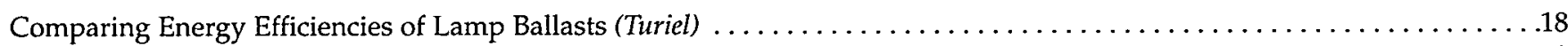

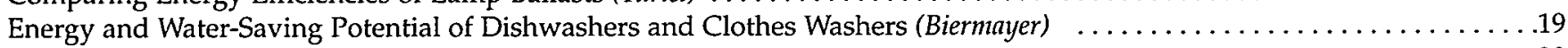

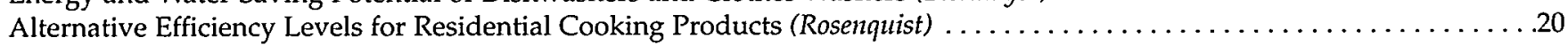

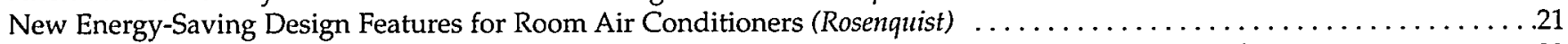

Effects of Appliance Standards on Product Price and Attributes: A Hedonic Pricing Model (Greening) ............22

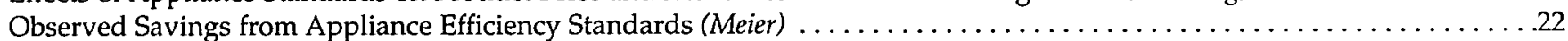

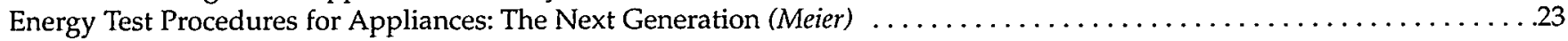

\section{Electricity Markets and Policy}

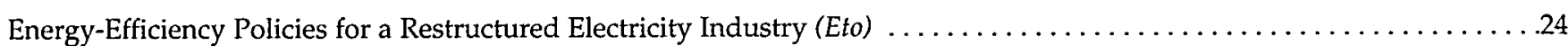

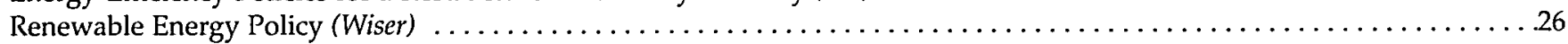

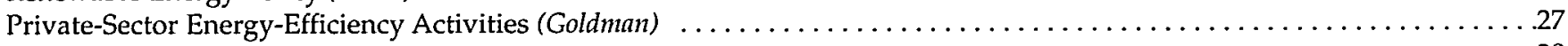

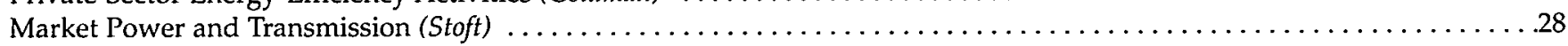

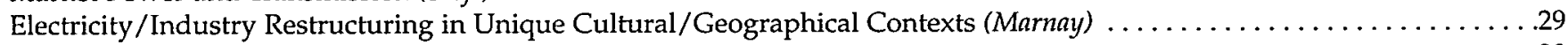

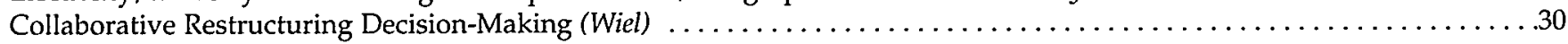

\section{Mitigation of Heat Islands}

Mesoscale Meteorological and Air Quality Impacts of Increased Urban Albedo and Vegetation (Taha) ..............31

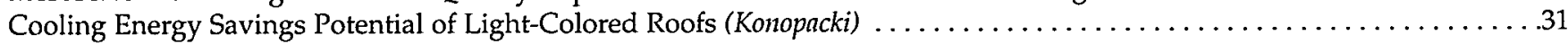

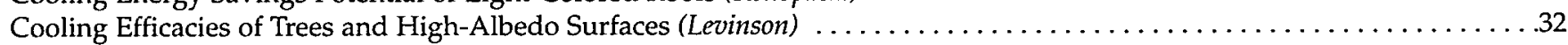




\section{Building Energy End-Use Forecasting}

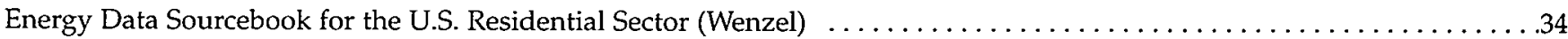

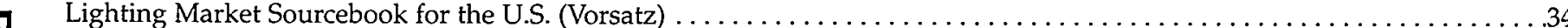

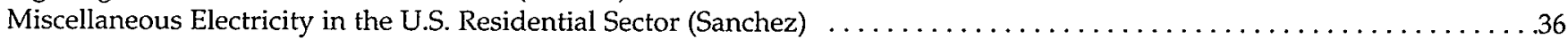

\section{Building Energy Measurement and Performance Analysis}

Integrated Information Technologies for Commercial Building Performance Assurance (Piette) . . . . . . . . . . . .37

Mandatory and Voluntary Approaches for Promoting Energy Efficiency in Residential Construction (Vine) . ..........39

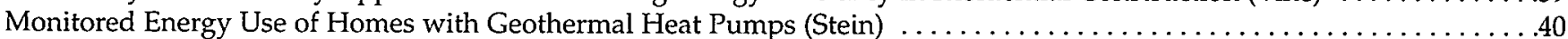

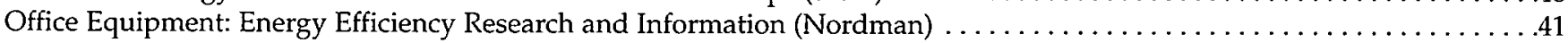

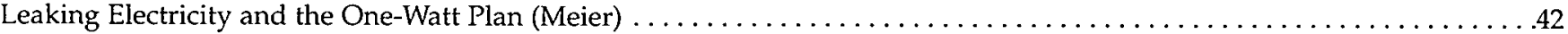

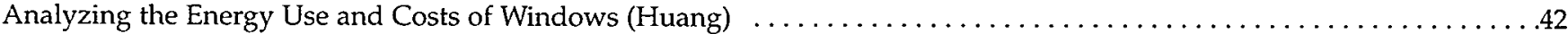

\section{Industrial Energy Analysis and Policy}

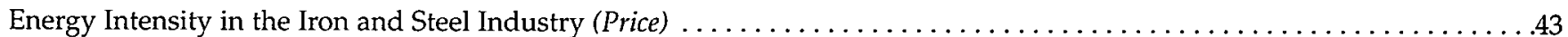

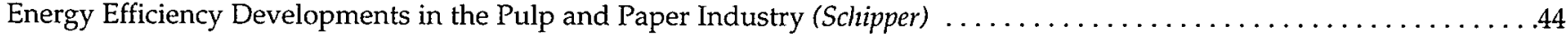

Decomposition Methods for Analyzing Aggregate Energy Intensity and Carbon Emissions Data (Greening) . . . . . . . . . .44

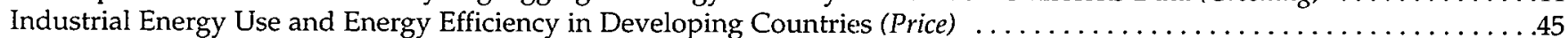

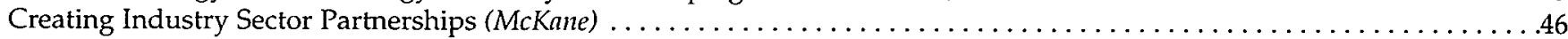

\section{-1 Transportation Energy Analysis}

International Trends in Carbon Dioxide Emissions from Passenger Transport (Schipper) . . . . . . . . . . . . . . .47

International Trends in Energy Use and Carbon Dioxide Emissions from Freight (Schipper) $\ldots \ldots \ldots \ldots \ldots \ldots$

Socioeconomic Factors Affecting Greenhouse-Gas Emissions from Personal Automotive Transportation (Greening) . . . . . . .48

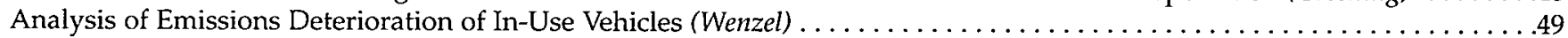

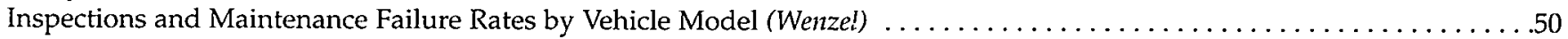


lobal and National Energy and Greenhouse Gas Emissions Analysis

\author{
Research analyzing national and global energy consumption, efficiency trends, and carbon flows; \\ analyzing the potential for improving efficiency and storing carbon; and supporting international cli- \\ mate change studies such as the Intergovernmental Panel on Climate Change assessments.
}

\section{Scenarios of U.S. Carbon Reductions}

\section{M.D. Levine, M. Brown (ORNL), J. Koomey, N. Martin, L. Price}

Scenarios of U.S. Carbon Reductions, a publication which played a prominant role in shaping the U.S. position taken at the 1997 Kyoto climate change negotiations, presents the results of a study conducted by five U.S. Department of Energy national laboratories that quantifies the potential for energy-efficient and low-carbon technologies to reduce carbon emissions in the U.S. The five national laboratories participating in the study were Argonne National Laboratory (ANL), Lawrence Berkeley National Laboratory (LBNL), National Renewable Energy Laboratory (NREL), Oak Ridge National Laboratory (ORNL), and Pacific Northwest National Laboratory (PNNL). LBNL and ORNL were the co-leaders of the effort.

The stimulus for this study derives from a growing recognition that any national effort to reduce the growth of greenhouse gas emissions must consider ways of increasing the productivity of energy use. To add greater definition to this view, we quantify the reductions in carbon emissions that can be attained by the year 2010 through the improved performance and increased penetration of efficient and low-carbon technologies. We also take a longer term perspective by characterizing the potential for future research and development to produce further carbon reductions over the next quarter century. As such, this report makes a strong case for the value of energy technology research, development, demonstration, and diffusion as a public response to global climate change.

Three overarching conclusions emerge from our analysis of alternative carbon-reduction scenarios. First, a vigorous national commitment to develop and deploy cost-effective energy-efficient and low-carbon technologies could reverse the trend toward increasing carbon emissions. Along with utility sector investments, such a commitment could halt the growth in U.S. energy consumption and accompanying carbon emissions so that levels in 2010 are close to those of 1997 (for energy) and of 1990 (for car- bon). It must be noted that such a vigorous national commitment would have to go far beyond current efforts. Second, if feasible ways are found to implement the carbon reductions, the cases analyzed in the study are judged to yield energy savings that are roughly equal to or greater than their costs. Third, a next generation of energy-efficient and low-carbon technologies promises to sustain an aggressive pace of carbon reductions over the next quarter century.

\section{Reference}

Interlaboratory Working Group. Scenarios of U.S. Carbon Reductions: Potential Impacts of Energy Technologies by 2010 and Beyond. Lawrence Berkeley National Laboratory and Oak Ridge National Laboratory Report Nos. LBNL-40533 and ORNL-444, 1997. Downloadable; http://eetd.lbl.gov/EE.html

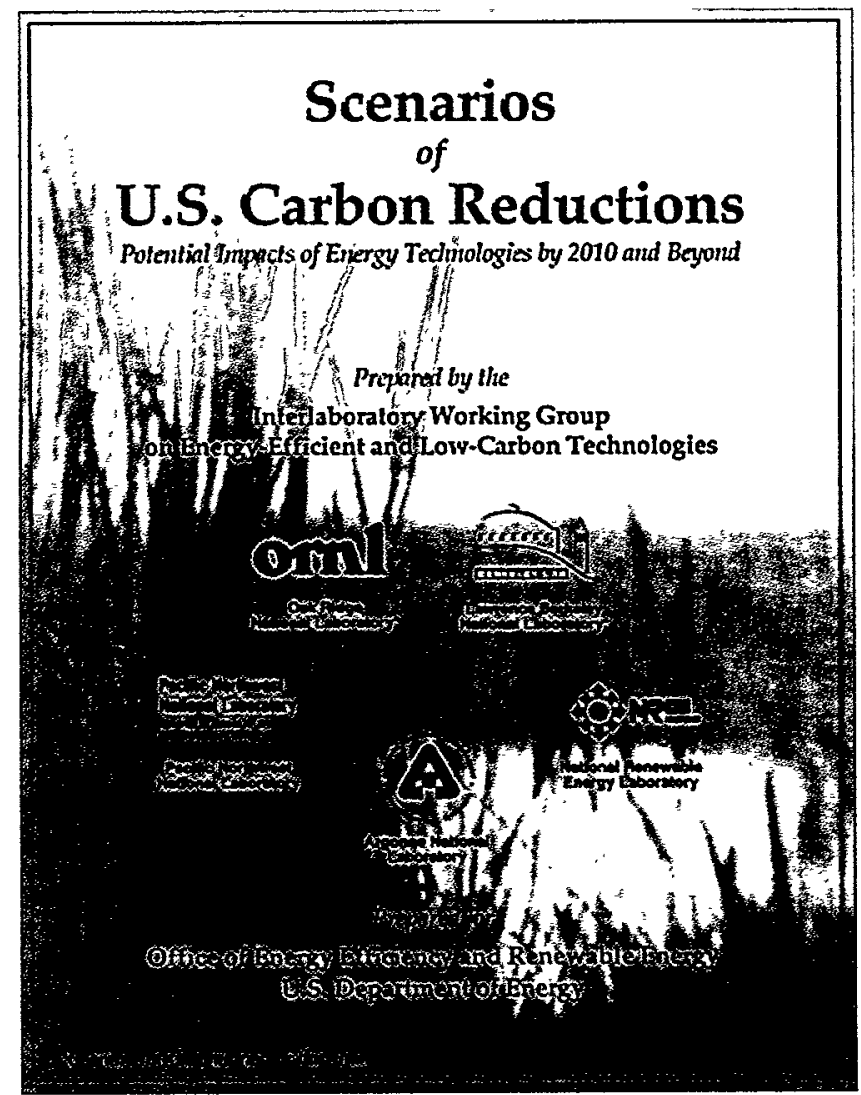


Scenarios of U.S. Carbon Reductions:

\section{U.S. Building Sector Results}

\section{J. Koomey, N. Martin, M. Brown (ORNL), L. Price, M.D. Levine}

Chapter Three of the Scenarios study focuses on the buildings sector. In the U.S., energy consumption in buildings for lighting, space heating, cooling, refrigeration, and electricity for electronics and other equipment, accounts for nearly one-third of total primary energy consumption and related greenhouse gas emissions. The cost of delivering all energy services in buildings (such as hot food, lighted offices, and warm homes) amounts to over $\$ 220$ billion in 1997 .

This chapter of the report describes results of analyzing the costs of reducing carbon emissions in buildings. We calculate energy, carbon, and dollar savings associated with adoption of more energy-efficient technologies and supplement those results by summarizing other related studies that confirm this study's basic conclusions.
Our analysis shows that substantial reductions in future greenhouse gas emissions can be realized through the use of more energy-efficient technologies that save society money (see box). In addition, these technologies often supply other benefits beyond energy, carbon, and dollar savings, including (1) improved indoor environment, comfort, health, and safety, (2) reduced noise, (3) improved process control, and (4) increased amenity or convenience. These indirect benefits, while difficult to quantify in economic terms, can be even more important than the energy cost savings, particularly when they improve the comfort of homeowners or the productivity of workers.

A summary of this work is forthcoming in the journal Energy Policy.
In a high-efficiency, low-carbon scenario, $23 \%$ of total U.S. baseline carbon emissions (all sectors) con be avoided, resulting in a return to 1990 levels. In this scenario, buildings sector electricity use drops $16 \%$ below baseline levels, as is shown here.

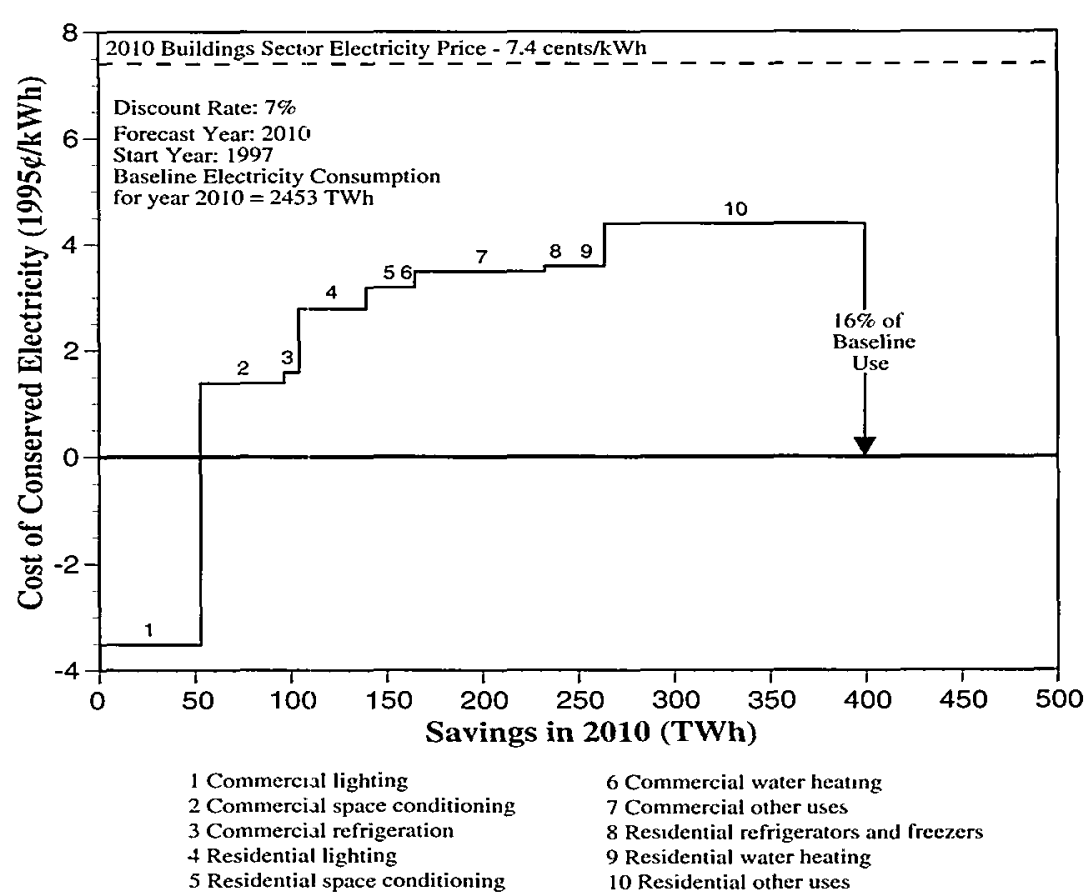

Efficiency potential is calculated assuming $65 \%$ of technoeconomic potential is captured in the high-efficiency/low-carbon case. Savings from reflective roofing are contained in the residential and commercial space conditioning end-use categories. 


\section{The Evolution of Carbon Dioxide Emissions From Energy Use in Industrialized Countries}

\section{Schipper, M. Ting, M. Khrushch, W. Golove}

Over the 1970s and 1980s, emissions of carbon dioxide from energy use fell in per capita, per unit GDP, and in some cases absolute terms in ten industrialized countries we analyzed in this study (see below). These countries account for nearly $80 \%$ of commercial primary energy use in industrialized countries and over $35 \%$ of worldwide energy use. The declines experienced in these countries were driven principally by falling end-use energy intensities and the decreasing carbon content of energy. In many countries, emissions from consumer activities (households, personal transportation, and portions of the service sector) fell less than emissions from manufacturing and freight.

By the early 1990s, however, energy intensities were declining more slowly and the continued growth of GDP and energy services activity reversed the downward trends in absolute emissions. We conclude that carbon dioxide emissions will continue to rise in the future unless energy intensities or the carbon content of energy can be decreased at an accelerated rate via policy changes, technological innovation, or behavioral adaptation.

\section{Reference}

Schipper, L., M. Ting, M. Khrushch, and W. Golove. The Evolution of Carbon Dioxide Emissions from Energy Use in Industrialized Countries: An End-Use Analysis. Energy Policy, Special Issue on Cross-Country Comparisons of Indicators of Energy Use, Energy Efficiency, and $\mathrm{CO}_{2}$ Emissions. 25 (7-9) 651-672. 1997. Also available as Lawrence Berkeley National Laboratory Report No. LBL-38547.

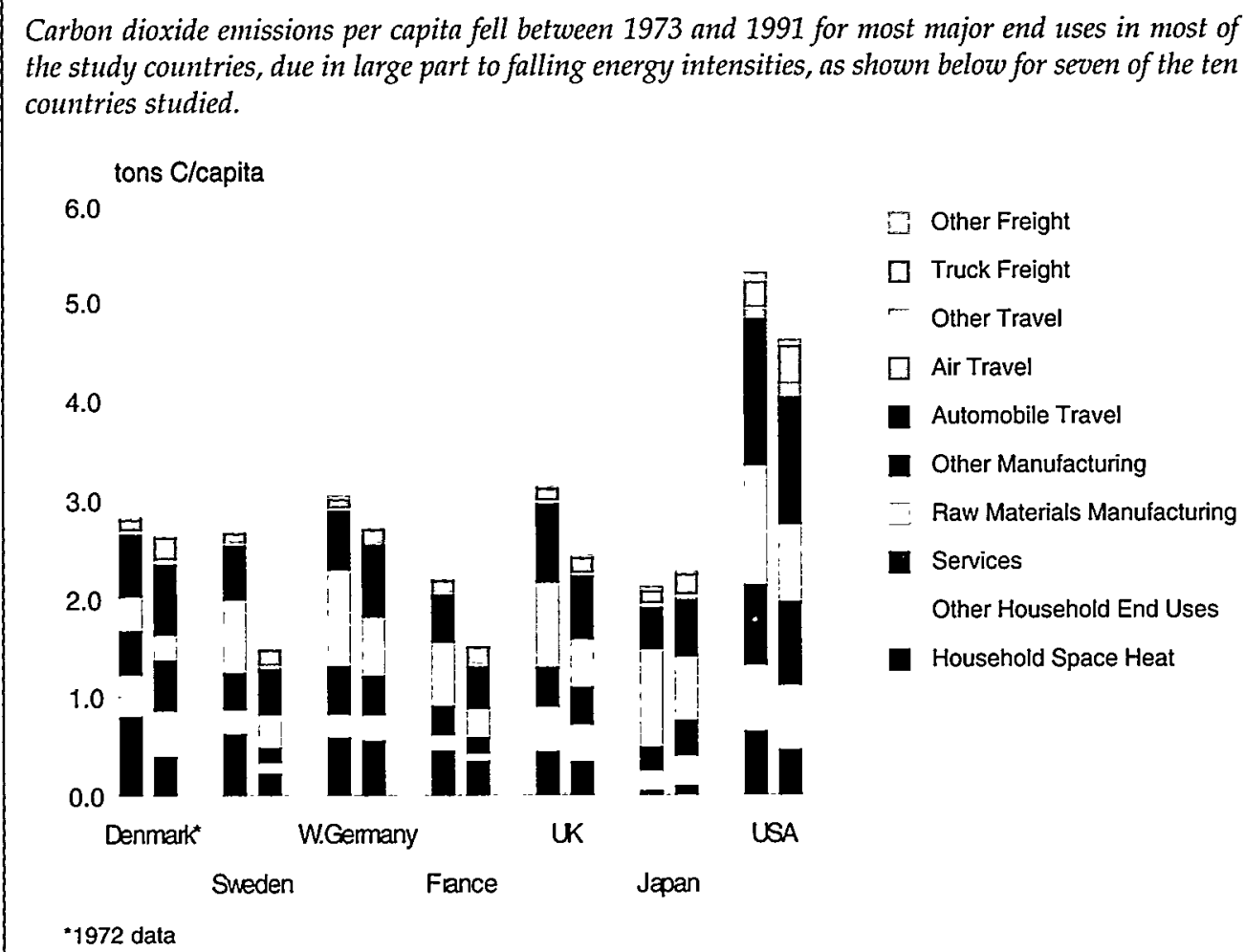




\title{
limate Change Mitigation
}

\begin{abstract}
Research into methods for assessing the potential for mitigating greenhouse gas emissions and develop-
\end{abstract} ing national action plans, and training for experts on the subject in over 40 developing countries.

\author{
Evaluating Technologies, Policies, and Measures \\ for Mitigating Climate Change
}

\section{M.D. Levine, L. Price, I. Sathaye, N. Martin, S. Wiel}

There is wealth of experience with technologies, policies, and measures for restraining and reducing greenhouse gas emissions in all economic sectors and throughout the world, but such voluminous amounts of information can be overwhelming for policymakers. In a technical paper prepared for the Intergovernmental Panel on Climate Change (IPCC), the lessons learned from past experience are distilled and presented by sector (residential, commercial, and institutional buildings; transportation; industry; energy and transformation industries; agriculture; forestry; and solid waste and wastewater disposal). Our contribution to this work focused on the forestry and buildings sectors and follows on previous analyses we conducted for the IPCC's Second Assessment Report in 1995.

Our forest sector analysis describes forest management practices that can restrain the rate of increase in atmospheric carbon dioxide. These practices include management for carbon conservation, management for carbon sequestration and storage, and management for carbon substitution. Estimates of the global potential to conserve and sequestor carbon show that the tropics have the largest potential $(80 \%)$, followed by the temperate $(17 \%)$ and boreal zones $(37 \%)$. Scenarios show that on a global scale, forests turn from a global source to a sink by about 2010, as tropical deforestation is offset by carbon conserved and sequestered in all zones.

Our buildings sector analysis indicates that $12 \%$ to $20 \%$ reductions in global greenhouse gas emissions in 2020 can be achieved from improving building and equipment energy efficiency, using both mandatory energy-efficiency standards, incentives, and market-based voluntary programs. We projected even larger savings by 2050 using the same policies: $20 \%$ to $50 \%$ of baseline building sector emissions in that year.

In a separate study, we calculated that under a "business-asusual" scenario, global emissions from the building sector would increase in 2020 by $90 \%$ over 1990 levels. A third analysis found that developing countries are experiencing growth rates of carbon dioxide emissions four times greater than those of the industrialized countries. This high growth rate is mainly due to population growth, increased urbanization, and increases in the amount of energy services demanded by energy customers. A combination of policy instruments such as the removal of energy price subsidies, aggressive use of energyefficiency policies, major programs to transfer knowledge, technology, and tools for transforming markets to developing countries, and continued investments in research and develop- ment of technologies and practices are needed to increase the pace of energy efficiency improvements in buildings.

\section{References}

Acosta-Moreno, R., R. Baron, P. Bohm, W. Chandler, V. Cole, O. Davidson, G. Dutt, E. Haites, H. Ishitani, D. Kruger, M.D. Levine, L. Zhong, L. Michaelis, W. Moomaw, J. Moreira, A. Mosier, R. Moss, N. Nakicenovic, L. Price, N. Ravindranath, H. Rogner, J. Sathaye, P. Shukla, and T. Williams. Technologies, Folicies, and Measures for Mitigating Climate Change. R.T. Watson, M.C. Zinyowera, R.H. Moss (Editors). Intergovernmental Panel on Climate Change, 1996.

Levine, M.D., L. Price, and N. Martin. Mitigation Options for Carbon Dioxide Emissions from Buildings: A Global Analysis, Energy Policy, 24 (10) 937-949. 1996. Also available as Lawrence Berkeley National Laboratory Report No. LBNL-39783.

Levine, M.D., L. Price, N. Martin, E. Worrell. Energy and Energy Efficiency in Buildings: A Global Analysis. In Proceedings of the ACEEE 1996 Summer Study on Energy Efficiency in Buildings, August 25-31, 1996. Washington, DC: American Council for an Energy-Efficient Economy. Vol. 9. pp. 9.141-9.157. Also available as Lawrence Berkeley National Laboratory Report No. LBNL-39785.

Wiel, S., N. Martin, M.D. Levine, L. Price, and J. Sathaye. The Role of Building Energy Efficiency in Managing Atmospheric Carbon Dioxide. In Proceedings of the ACEEE 1996 Summer Study on Energy Efficiency in Buildings, August 25-31, 1996. Washington, DC: American Council for an Energy-Efficient Economy. Vol. 9, pp. 9.1-12. Also available as Lawrence Berkeley National Laboratory Report No. LBNL-39875.

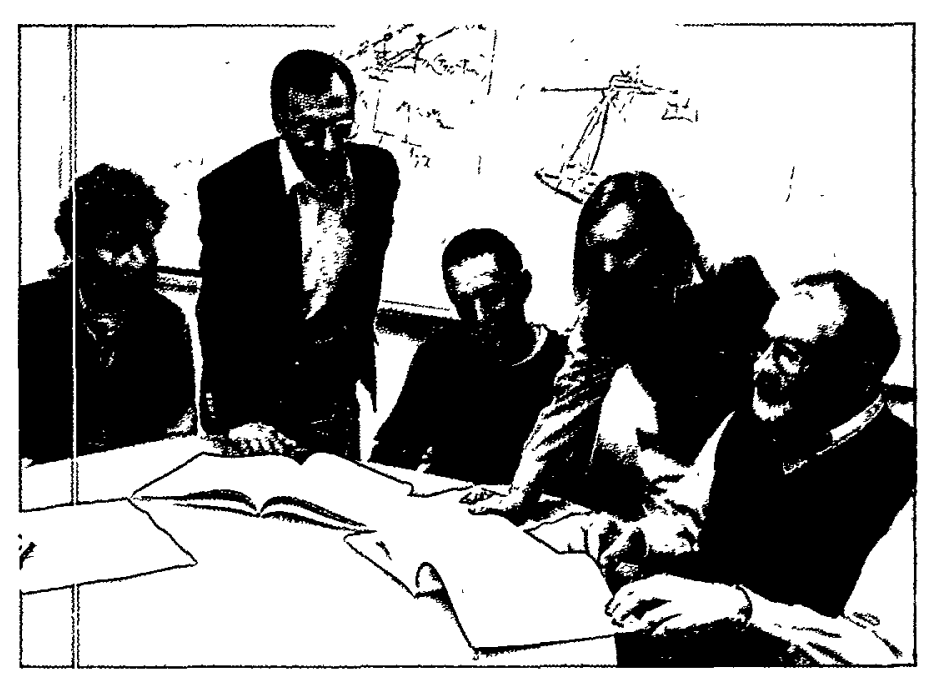


The Monitoring, Evaluation, Reporting, and Verification of Climate Change Mitigation Projects

\section{E. Vine, J. Sathaye}

Countries around the world are implementing climate change mitigation projects - either by themselves or in cooperation with other nations (i.e., joint implementation). These projects will reduce greenhouse gas (GHG) emissions or sequester carbon, and will also result in non-GHG impacts (i.e., environmental, economic, and social impacts). Monitoring, evaluating, reporting, and verifying (MERV) guidelines are needed for these projects to accurately determine their net GHG reductions and other benefits.

Having reviewed the issues involved in MERV activities and the protocols and guidelines that have been developed for MERV of GHG emissions in the energy and non-energy sectors by governments, nongovernmental organizations, and international agencies, we identified a number of topics that future protocols and guidelines need to address. They include (1) establishing a credible baseline; (2) accounting for impacts outside project boundaries; (3) measurement of net GHG reductions and other impacts; (4) precision of such measurement; (5) frequency of performing MERVs; (6) persistence (sustainability) of savings, emissions reduction, and carbon sequestration; (7) reporting by multiple project participants; (8) verification of GHG reduction credits; (9) uncertainty and risk; (10) institutional capacity in conducting MERV; and (11) the cost of MERV.

Some of the MERV issues are of a generic nature; their resolution would benefit all future MERV guidelines and protocols. These issues would be best addressed through an international consensus. The manner in which the topics addressed in this report are currently being dealt with in existing climate change mitigation projects needs to be analyzed and disseminated. The experience gained in these projects should be very helpful for formulating MERV guidelines for climate change mitigation projects.

\section{Reference}

Vine, E. and J. Sathaye. The Monitoring, Evaluation, Reporting, and Verification of Climate Change Mitigation Projects: Discussion of Issues and Methodologies and Review of Existing Protocols and Guidelines. Lawrence Berkeley National Laboratory Report No. LBNL40316, 1997.Downloadable; http://eetdlblgov/EA/ccm/ccmhtml
Proposals for JI projects are closely studied and reviewed by experts before receiving approval.

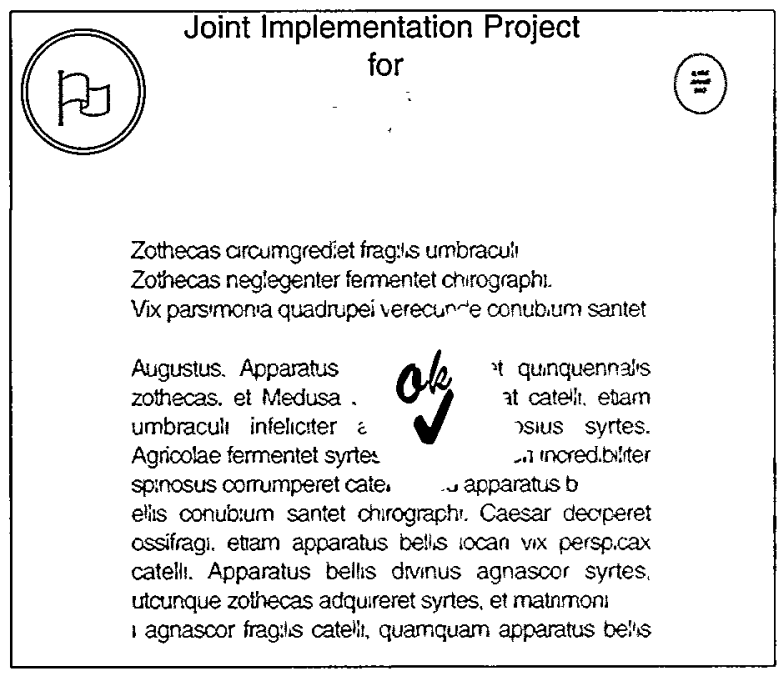

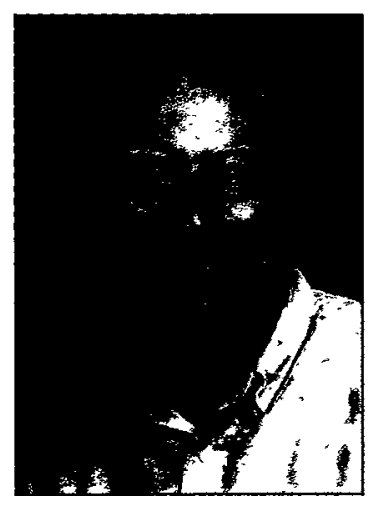


International Workshop on Greenhouse Gas

Mitigation Technologies and Measures

\section{J. Sathaye, S. Meyers, B. Goldberg}

In an effort to summarize several years of country studies of climate change mitigation assessments and to help support the technical discussions in preparation for the Third Conference of the Parties in Kyoto, we helped organize the International Workshop on Technologies and Measures held in Beijing, China, on November 12-15, 1996.

Policy measures to help implement the mitigation technologies were discussed in detail. There was a broad range of consensus that the role of governments in encouraging the application of those country-specific mitigation technologies should be to formulate effective policies, regulations, and laws. Participants proposed many useful recommendations, including innovative financing mechanisms, institutional restructuring, and setting up intermediaries-such as energy service companies-to provide capital, technical evaluation, energy auditing, market analysis, and operations and maintenance services. The importance of technology transfer and support for local production of climate-friendly technologies were emphasized in the workshop. The appropriate use of tax incentives and subsidy policies, as well as financing mechanisms, were recommended.

\section{Reference}

Meyers, S., J. Sathaye, B. Goldberg, W. Zongxin, and C. Bourdeaux (Guest Editors). Applied Energy, Special Issue on Greenhouse Gas Mitigation Technologies and Measure in Developing and Transition Countries. 56 (3/4) 203-223. 1997. See Lawrence Berkeley National Laboratory Report No. LBNL-39686 for the full Proceedings.

\section{International Workshop on Monitoring and Verification of Sustainable Forest Management}

J. Sathaye, W. Makundi, B. Goldberg, K. Andrasko (U.S. EPA), A. Sanchez (University of Costa Rica)

With the increased recognition of the potentially beneficial role of forests with regard to climate change, there is growing interest in ensuring that forestry mitigation activities lead to carbon sequestration or reduced emissions that are sustainable over the long term. Eighteen papers were presented at the International Workshop on Sustainable Forest Management: Monitoring and Verification of Greenhouse Gases, which was held in San Jose, Costa Rica, on July 29-31, 1996. They reflect two levels of assessment: (1) project-level methods, and (2) remote sensing of land cover change at national or regional scales.

There was consensus among the workshop participants that methods for monitoring forestry projects are well established, and techniques are known and extensively used, particularly in forest production. However, introducing climate change mitigation with its long-term perspective is often in conflict with the shorterterm perspective of most forestry projects and standard accounting principles. The resolution of these conflicts may require national and international agreements among the affected parties.

\section{Reference}

Sathaye, J., W. Makundi, B. Goldberg, K. Andrasko, and A. Sanchez (Guest Editors). Mitigation and Adaptation Strategies for Global Change, Special Issue, Sustainable Forest Management for Climate Change Mitigation: Monitoring and Verification of Greenhouse Gases. 2 (2-3) 87-339. 1997. Also available as Lawrence Berkeley National Laboratory Report No. L.BNL-40501.
Photo of two hillsides; one is natural forest, the other has been deforested. Management options include protection of the existing forest and reforestration of the degraded hillside.
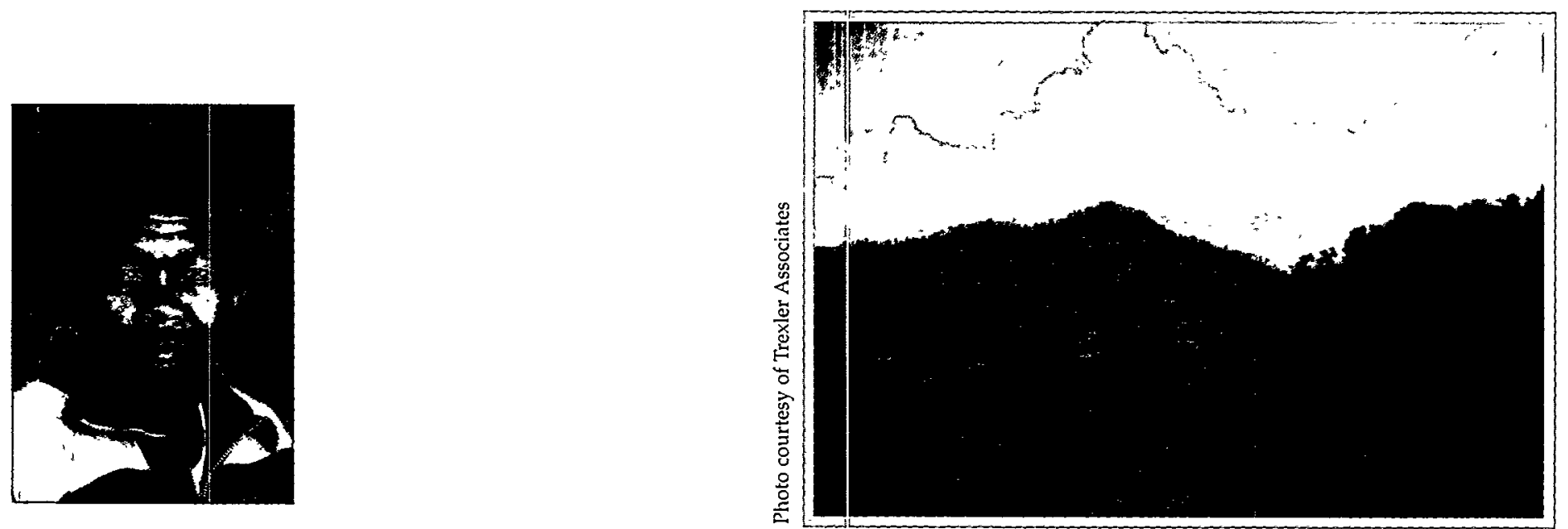
hina, India, and Other Partnerships

\begin{abstract}
Technical support to several developing countries for a variety of energy-efficiency projects, such as developing and implementing appliance standards and building codes, assessing the savings potential of new projects, and developing improved appliances.
\end{abstract}

\section{Overview of Developing Countries' Concerns About Joint Implementation: Case Studies from Brazil, India, Mexico, and South Africa}

\section{J. Sathaye, W. Makundi, K. Andrasko (U.S. EPA)}

The concepts of Joint Implementation (JI) and Activities Implemented Jointly (AIJ) owe their origins to carbon-offset projects, wherein greenhouse gas (GHG) emissions in developed (investor) countries are offset through projects implemented in other (recipient) countries where the reduction could be achieved at lower cost than in the investor country. Electric utility companies in the U.S., for example, offset their power plant emissions by planting trees in Guatemala, a developing country. These offset projects led to the inclusion of JI in Article 4.2 of the United Nations Framework Convention on Climate Change (FCCC). JI entails full or partial financial support from the party in the investor country, which receives credits for some of the GHG emissions reduced in the recipient country. These credits might be used toward the investor country's emissions-reduction commitment under the FCCC.

JI has been controversial since its inclusion in the FCCC. Concerns are particularly strong regarding investments by Annex I (industrialized) countries in projects in non-Annex I (developing) countries. Non-Annex I countries argue that industrialized investor countries should first reduce GHG emissions at home. In addition, JI projects are viewed as a kind of imperialism, which allows industrialized countries to maintain continued high standards of living at the expense of developing economies. NonAnnex I countries are also concerned that JI investors will implement low-cost emissions-reducing options abroad, forcing recipient countries to pursue expensive options on their own in the future when developing country GHG emissions may face restrictions.

Because of these reservations about JI, in 1995 the Conference of Parties to the FCCC (COP1) agreed to a pilot JI phase, known as Activities Implemented Jointly (AIJ). AIJ projects are designed so participants gain experience with implementation, as well as clarify conceptual and methodological issues and identify institutions to participate in future JI projects. No GHG emissions-reduction credits are awarded from AIJ projects unless the participating countries negotiate a specific agreement. AIJ pilot projects will be reviewed by the year 2000 .

At least $75 \mathrm{AIJ}$ projects have been planned or are under way. Two are in Africa, three in Asia, three in South America, and 20 are in Central America. The remaining are in Eastern Europe and Russia. The smaller number of projects in Africa, Asia, and South America, regions which will contribute the bulk of future increases in global carbon emissions, indicates the concern that these governments have about JI/AIJ.

A set of papers examined these concerns in the context of climate-change projects in Brazil, India, Mexico, and South Africa. Mexico's Ilumex project was not originally designed as an AIJ project but functions like one. (Ilumex substitutes efficient compact fluorescent for incandescent light bulbs.) India has an agro-forestry project that has been accepted by U.S. Initiative on Joint Implementation, and projects from South Africa have been submitted for consideration. Brazil has no AIJ projects or process in place, but several ongoing programs there, including the ethanol fuel program, could benefit from JI/AIJ support. The four papers analyze and examine these case study projects in reference to the concerns about JI/AIJ outlined above.

The four studies recognize jointly implemented climatechange projects as viable and cost-effective ways to reduce GHG emissions. The case studies illustrate that such projects can generate new technologies, investments, employment, and other ancillary socioeconomic and environmental benefits in developing countries. It will, however, be important to guard against inequitable distribution of the benefits from JI/AIJ projects.

\section{Reference}

Sathaye, J., W. Makundi, and K. Andrasko. Developing Countries' Concerns About Joint Implementation: Case Studies from Brazil, India, Mexico, and South Africa. Lawrence Berkeley National Laboratory Report No. LBNL-41403, 1997. 


\section{Financing Energy Efficiency in China}

\section{J. Sinton}

China is grappling with the challenge of maintaining high rates of investment in energy efficiency during the transition to a more market-oriented economy, in which the state has a shrinking role in direct support of projects. We participated in an Asian Development Bank project aimed at developing a mechanism for commercial financing of energy-efficiency investments in industry in southwestern China (see shaded areas of the map below), and assessing sample subprojects that would be financed through an ADB loan. China's banks have limited interest in lending for such investments, and many state-owned industrial enterprises have difficulty qualifying for commercial loans. Government and industry currently reject proposed funding mechanisms that do not include preferential terms, as in the past. Future large-scale financing for energy efficiency will require further development and demonstration of new organizations, like energy-service companies, and institutions, such as revolving funds dedicated to energy-efficiency projects.

Energy-efficiency projects in the auto parts industry in Shandong Province, the steel industry in Henan Province, and the heat exchange industry in Jiangsu Province have been identified as viable projects for potential U.S. private partnerships. The shaded provinces are areas where we have screened projects for implementing market-based channels for energy-efficiency funding.

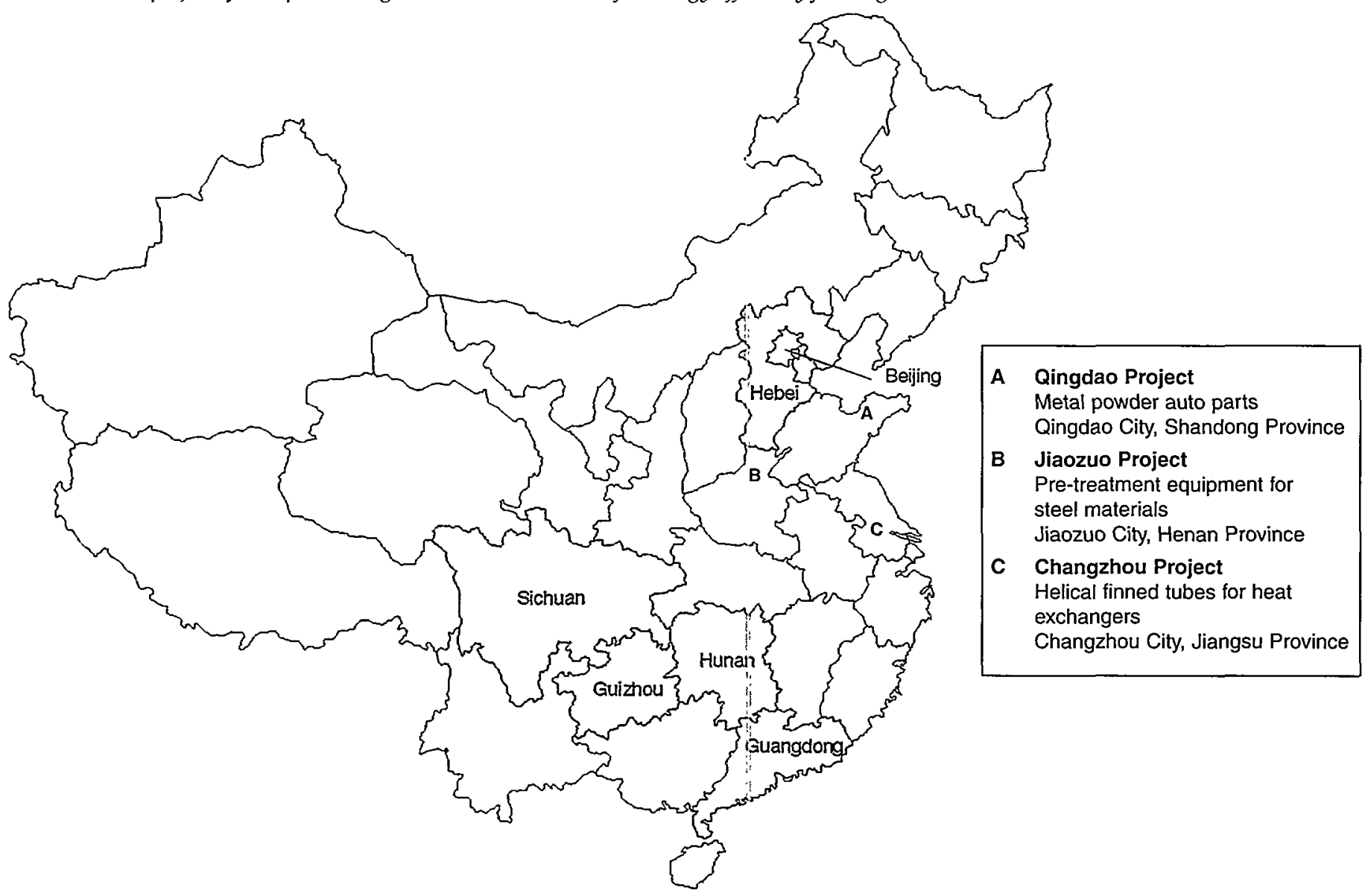




\section{Screening Commercial Energy-Efficiency Projects} in China

\section{F.Q. Yang, G. Zou (China Energy Conservation Investment Corporation, Beijing)}

Studies show a tremendous potential for improving energy efficiency in China through the introduction of new technologies into many of the energy-using sectors. However, finding commercial opportunities for transfer of these technologies - especially to small and medium-sized firms inside and outside China - is difficult. We are working with the China Energy Conservation Investment Corporation, a well-established, forprofit firm in Beijing, to identify specific industrial energy-efficiency projects. Researchers are preparing initial project evaluations to judge their suitability for participation by U.S. business firms. Proposals are initially screened to ensure they meet basic requirements for economic returns. These requirements usually stipulate improvements in productivity and product quality, and in addition they rank the endeavors by their environmental benefits. A brief description and location of three such qualifying projects are shown in the map on page 8 . The results of this study will help U.S. businesses develop energy-efficient commercial ventures in China.

\section{Reference}

Yang, F.Q. and G. Zou. Summary Descriptions of Three Prospective Energy-Efficiency Investment Projects in China. Lawrence Berkeley National Laboratory Report No. LBNL-41132, 1997.
Economic Reforms and Patterns of Industrial Energy Use in China

\section{J. Sinton}

Whether China continues its recent progress in improving industrial energy efficiency is of tremendous importance for local, regional, and global trade issues, energy security, and environmental problems. In pursuing its energy-conservation goals, should China emphasize direct promotion of energy efficiency, or should it focus on more general economic system reforms? Reforms have already caused energy prices to rise to market levels and made industrial end users more sensitive to costs, but case studies at cement plants representing a broad range of sizes, technologies, and forms of ownership show that decisions relating to technology choice have complex origins that are only partially influenced by energy costs. China will need to maintain a strong, sectorally focused program of energy-efficiency initiatives to meet its goals for energy efficiency.

\section{Reference}

Sinton, J. Energy Efficiency in Chinese Industry: Positive and Negative Influences of Economic System Reforms. Ph.D. thesis. Energy and Resources Group, University of California, Berkeley, CA, 1996.
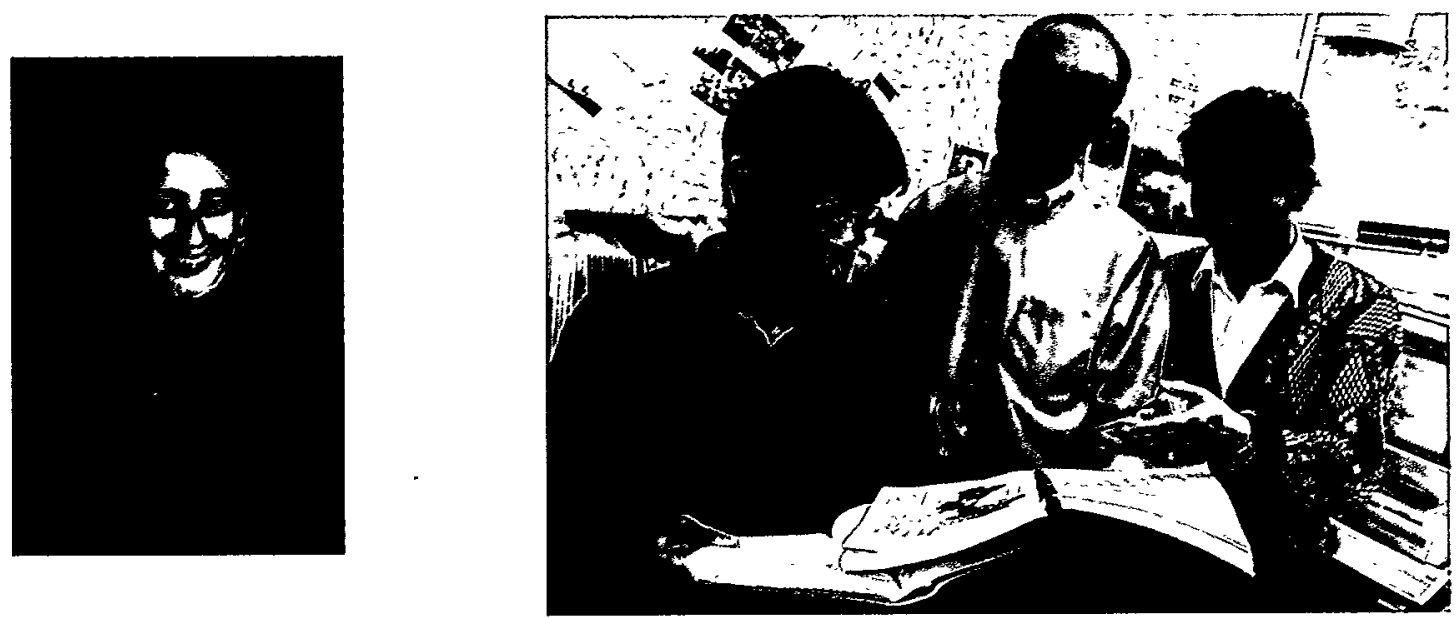


\section{Field Testing of Energy-Efficient Refrigerators in China}

\section{D.H. Fridley}

Household refrigerators in China currently account for approximately $40 \%$ of residential electricity use. In early 1995, 104 refrigerators of 220 -liter volume -85 energy-efficient prototype units and 19 baseline units (a popular model in the current Chinese market) - were installed in households in Beijing, Shanghai, and Guangzhou, replacing their existing units. Watthour meters were installed to monitor energy usage and the families were asked to respond to before and after questionnaires involving satisfaction with the new versus their old refrigerators, rating of the new refrigerator's characteristics, their ownership and use of other appliances, and other socioeconomic information. Statistical analysis of the energy consumption data showed that laboratory measurements demonstrating a 35\% energy savings for the energy-efficient prototype units closely matched actual field results in Shanghai. In the other cities, savings were lower, ranging from $22 \%$ in Beijing to $28 \%$ in Guangzhou. Data were insufficient to determine the direct cause of the differences. However, we found that variables exerting important influences on energy consumption included (1) unit type, (2) climate, (3) income level, (4) kitchen fans, and (5) air conditioning. Except for noise levels, the energy-efficient prototypes generally received high consumer satisfaction ratings.

\section{References}

Fridley, D., H.A. Fine, S. Nadel, R. Phillips, X. Leng, and J. Briskin. Field Testing of CFC-Free, Energy-Efficient Refrigerators in China. In Proceedings of the International Conference on Ozone Protection Technologies, Washington, DC, November 12 - 13, 1997, pp. 203-212.

Fine, H.A., D. Fridley, S. Nadel, R. Rademacher, I. Haider, X. Leng, R. Phillips, and J. Briskin. Sino-US CFC-Free Super Efficient Refrigerator Project Progress Report: Prototype Development and Testing, U.S. Environmental Protection Agency, Washington, DC, 1997.

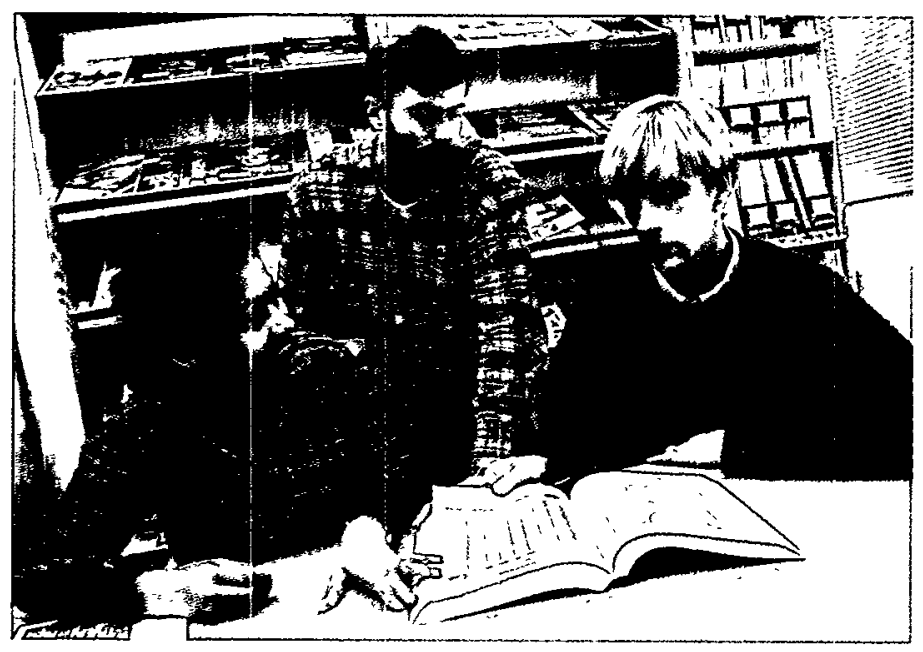

In the unheated apartments of Shanghai, where summers are hot and wet and winters are cool and dry, prototype refrigerators consume $35 \%$ less energy than conventional models.

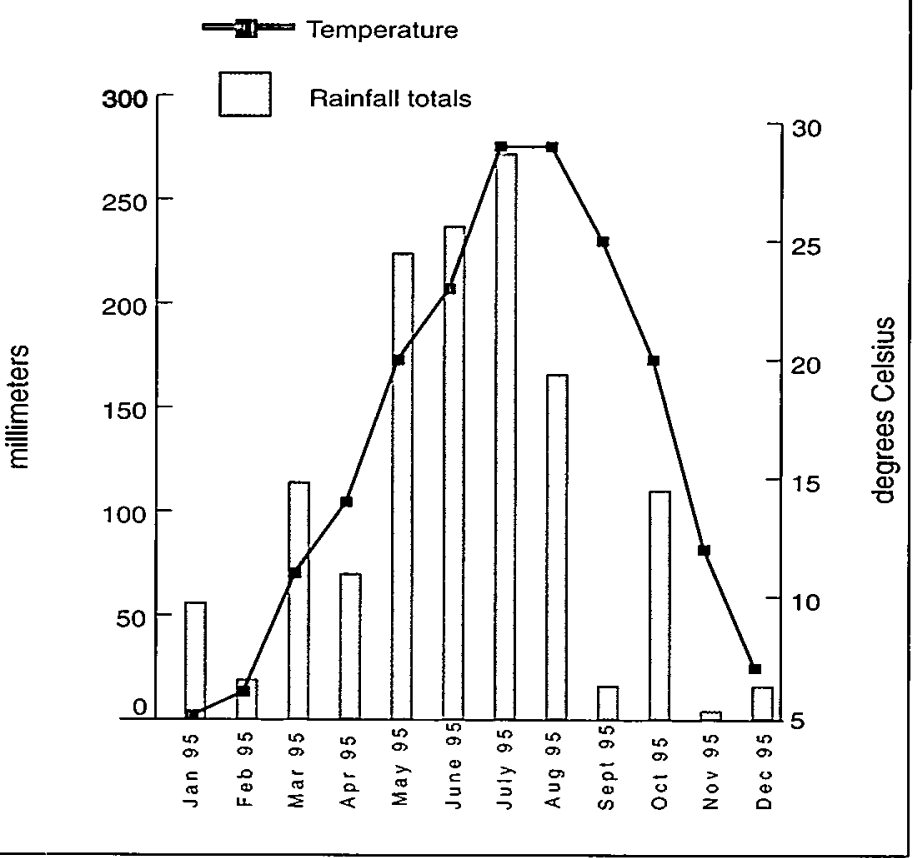

\section{Improving Industrial Energy Efficiency Through New Banking Practices in India}

\section{J. Sathaye, A. Gadgil (Indoor Environment Dept., EETD, LBNL)}

India's industrial sector constitutes a significant share of that country's total energy use. Energy intensity in Indian industry is high in comparison to world standards and serious efforts are being made within the sector to reduce its energy use. Recognizing these factors, the Asian Development Bank loaned $\$ 150$ million to the Industrial Development Bank of India (IDBI) so that it could in turn make loans for modernization and expansion to deserving industries that could show at least an $18 \%$ improvement in their energy intensity. Working through Energy Resources International and in collaboration with Dalal Consultants in India, we are assisting IDBI to evaluate these loans, determine benchmarks, and suggest improved institutional structure and practices for future lending.

Working with sector consultants from India, the project has completed studies on the paper, cement, steel, fertilizer, sugar cogeneration, and caustic soda industries. Except for the paper industry, all of them are procuring new plants that are close to world standards in their (lowered) intensity of energy use. We found that the ban on new mercury-process plants brought about by India's environmental regulations played a strong role in the setting up of new energy-efficient membrane-process plants in the caustic soda industry. 


\section{oluntary Government Programs}

Research on the effectiveness of programs such as government procurement, product labeling, and voluntary public/private partnerships in improving energy efficiency, preventing pollution, and reducing greenhouse gas emissions.

\section{Energy Efficiency in Government Purchasing}

\section{J. Harris, P. Coleman}

As the biggest customer in the world for most energy-using products, the federal government can play a significant role as a market leader in purchasing energy-efficient products. Each year, the federal government buys over $\$ 10$ billion in energy-related products and pays nearly $\$ 4$ billion for energy to operate its buildings and facilities. A 1994 Executive Order directs federal agencies to buy products that are among the most efficient $25 \%$ on the market and the President's recent climate-change initiatives feature proposals to further strengthen the role of the federal government as a buyer of energy-efficient technologies.

As part of the government-wide "Procurement Challenge," the Lab's Washington D.C. Project Office assists DOE's Federal Energy Management Program (FEMP) to develop criteria for energy-efficient federal purchasing and to use federal buying power to accelerate the introduction of new technologies. We also contribute to energy-efficient procurement by state and local governments through the EPA and DOE initiative for ENERGY STARß purchasing.

During the past year DOE published a total of 22 Product Energy Efficiency Recommendations for use by federal purchasers. Each Recommendation includes an efficiency level representing the top $25 \%$ of the market, information on cost-effectiveness, where to find efficient products, and other useful advice to buyers. Coverage includes residential-scale appliances and building equipment, lighting, office equipment, exit signs, large chillers, ice-cube machines, and water-saving plumbing fittings. Recommendations are being prepared for motors, commercial HVAC equipment, transformers, photovoltaics and other renewable energy measures, windows, and "cool" roofing products. Energy-efficient purchasing recommendations have been distributed to over 1500 federal buyers, and are also available on the Web (www.eren.doe.gov/femp/procurement). For products covered by the ENERGY STAR label, FEMP purchasing recommendations use the same criteria as ENERGY STAR does.

As a result of this project, both the General Services Administration (GSA) and Defense Logistics Agency (DLA) are adding a special symbol in their printed catalogs and new on-line "electronic commerce" systems to identify products that meet the FEMP efficiency criteria. The Army Corps of Engineers is incorporating FEMP efficiency criteria for lighting and HVAC equipment in its guide specifications and in bidding requirements for new construction. DOE has issued Department-wide guidance on purchasing energy-efficient products. Finally, the FEMP energyefficiency criteria are part of a DOE/GSA Basic Ordering Agreement designed to simplify and streamline the purchasing process for ozone-friendly chillers. Replacing older chillers in federal facilities has the potential to save $\$ 75$ million/year in energy costs, or a projected $\$ 1.4$ billion over the 23-year estimated life of the new chillers.

We have analyzed the annual energy and carbon-savings potential for one subset of federal purchases - efficient residential appliances and equipment (see box). These account for $15 \%$ of energy-related building equipment purchases and about $3 \%$ of all federal spending on energy-related equipment. We evaluated several scenarios, ranging from an initial limited compliance with the 1994 Executive Order (gradually increasing to $50 \%$ of all purchases by 2010 ) to the maximum technical potential ( $100 \%$ of new purchases consisting of the best available on the market). In a most likely scenario (Scenario III), annual energy cost savings for federal purchases of residential appliances and equipment alone would be $\$ 30$ million by 2010 .

\section{References}

McKane, A.T. and J. Harris. Changing Government Purchasing Practices: Promoting Energy Efficiency on a Budget. In Proceedings of the ACEEE 1996 Summer Study on Energy Efficiency in Buildings, August 25-31, 1996, Washington, DC: American Council for an Energy-Efficient Economy, 1996. Vol. 5, pp. 5.159-168.

Johnson, F.X., A.T. McKane, and J. Harris. Development of Federal Energy Efficiency Product Recommendations. In Proceedings of the ACEEE 1996 Summer Study on Energy Efficiency in Buildings, August 25-31, 1996, Washington, DC: American Council for an Energy-Efficient Economy, 1996. Vol. 2, pp. 2.107-117.

Purchasing energy-efficient residential products would save federal agencies at least $\$ 20$ million/year by 2010 under the most conservative assumptions, with a "most likely" savings of $\$ 30$ million/year (Scenario III). Higher compliance rates, and purchase of other efficient products, would increase savings several-fold.

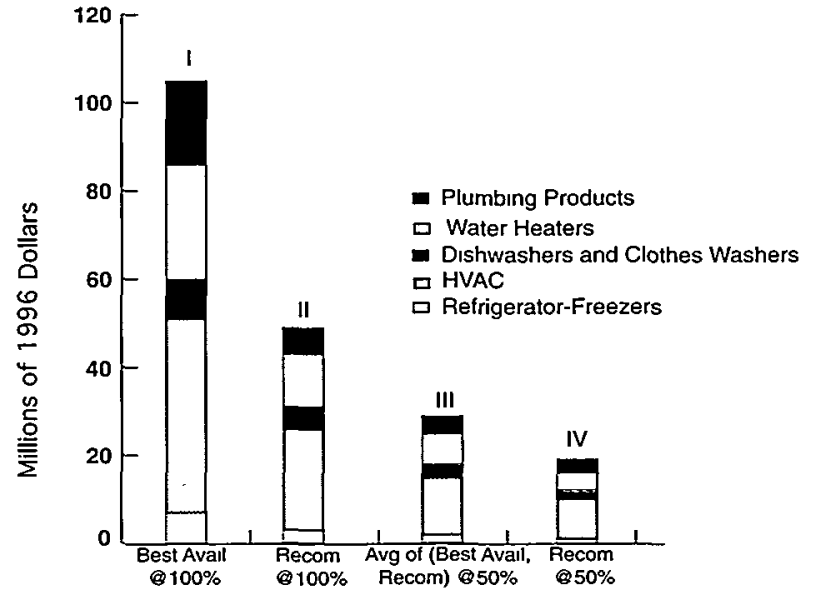

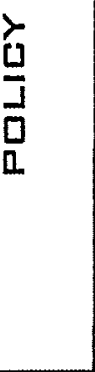

$\frac{7}{2}$ 
Saving Energy in the Government Sector: An International Review

J. Harris, N. Martin, E. Mills (Center for Building Science, EETD, LBNL), Alison ten Cate

In most countries government facilities are among the largest energy users and the most important customers for energy-using products and services. Potential energy savings in government facilities are often large, due to relatively old stock and a longer time for efficiency investments. In addition to direct energy savings and reduced operating costs, successful campaigns within the government sector itself can be key agents of market leadership toward energy efficiency, lower greenhouse gas emissions, and market transformation throughout the economy.

The Federal Energy Management Program (FEMP) offers a clear example of this strategy in the U.S. To ascertain if other countries are addressing energy-saving opportunities in their government facilities, we surveyed over 100 European, North American, Latin American, and Asian countries, focusing on facilities such as ministries, public housing, and government-owned corporations or utilities (but excluding public schools). Responses from 24 countries show that some have extensive energy-management programs, but finding comprehensive efforts on the scale of FEMP is rare. Many countries appear to have neglected these opportunities altogether. Some examples of broad-based programs are those in Canada, the Netherlands, and Switzerland; significant starts have been made in Japan, Germany, Mexico, Sweden, New Zealand, France, Indonesia, Korea, and Brazil. The survey identified several categories of existing programs and future opportunities:

- energy performance or savings targets

- energy-efficient criteria for equipment purchasing and leasing

- government procurement to accelerate the market entry of new technologies

- information, training, and energy audit programs

- demonstration projects

- efficiency standards for government buildings and equipment

- financing measures such as government-issued bonds, loans, shared-savings contracts, and the use of utility rebates

- budgeting reforms to emphasize life-cycle costing and to make it easier to combine capital and operating funds.

There are many reasons why energy management within the government sector has not been more widely practiced: lack of funding or in-house staff, inadequate data or lack of awareness of how energy is used or how much could be saved, the disruptive effects of deregulation and privatization movements, and a tendency of agencies to call first for actions by others.

At least one international collaborative effort is underway to help overcome these barriers. Nine countries including the U.S. (through the U.S. EPA) are currently participating in an international technology procurement project under the auspices of the International Energy Agency. Under this agreement, the countries will use technology procurement to stimulate demand, working with manufacturers and coordinating with buyers and sellers of highly energy-efficient products including clothes dryers, replacement incandescent light bulbs, vending machines, and photocopiers.

As an example of the energy savings possible from this program, let's look just at photocopiers. The majority of energy consurned by current copiers is used to power the machines when they are in standby (ready) mode, but not actively copying. We are assisting EPA to build U.S. demand for a next-generation office copier that uses almost no energy in the standby state. If manufacturers are able to produce machines to meet the specifications, the energy used to operate copiers could be reduced by about $60 \%$ below energy-efficiency levels established in existing voluntary labeling programs such as EPA's ENERGY STAR or the comparable standby levels of the Swiss Energy 2000 program (see box on next page). These energy reductions can be achieved while still offering advanced features such as enhanced duplex (twosided) copying and network connectivity for printing, scanning, and faxing.

For more information about the international technology procurement projects, see: http://eff.nutek.se/engelsk

\section{Reference}

Borg, N., E. Mills, J. Harris, and N. Martin. Energy Management in the Government Sector - An International Review. In The Energy Efficiency Challenge: Proceedings of the ECEEE 1997 Summer Study, Sustainable Energy Opportunities for a Greater Europe, June 9-14, 1997, Spindleruv Mlyn, Czech Republic: European Council for an Energy-Efficient Economy, 1997.

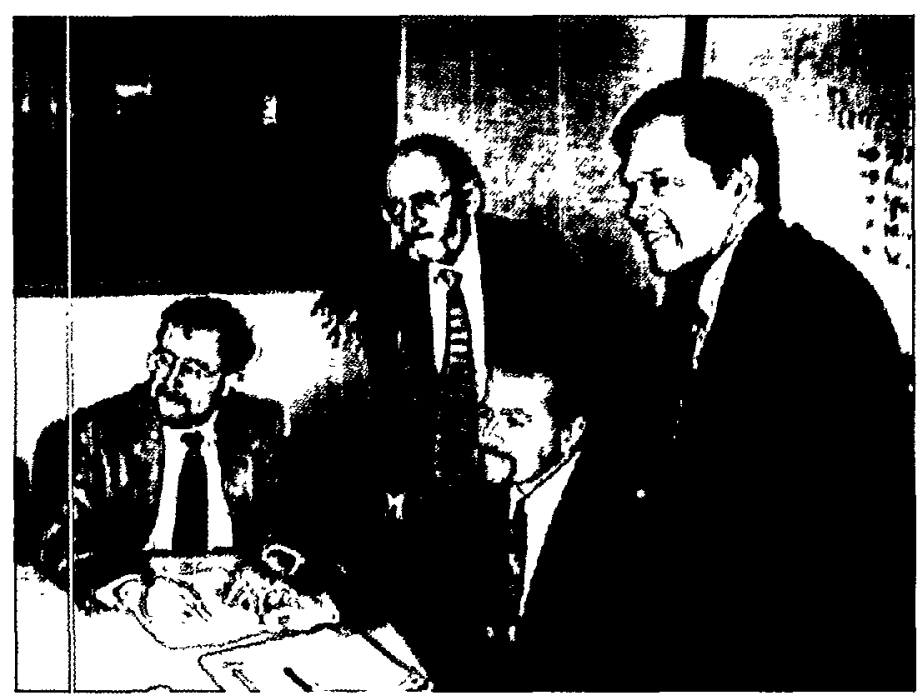


The copier procurement project targets very low standby mode energy consumption, a significant reduction from current voluntary energy-efficiency label requirements such as ENERGY STAR or Energy 2000 (Switzerland).

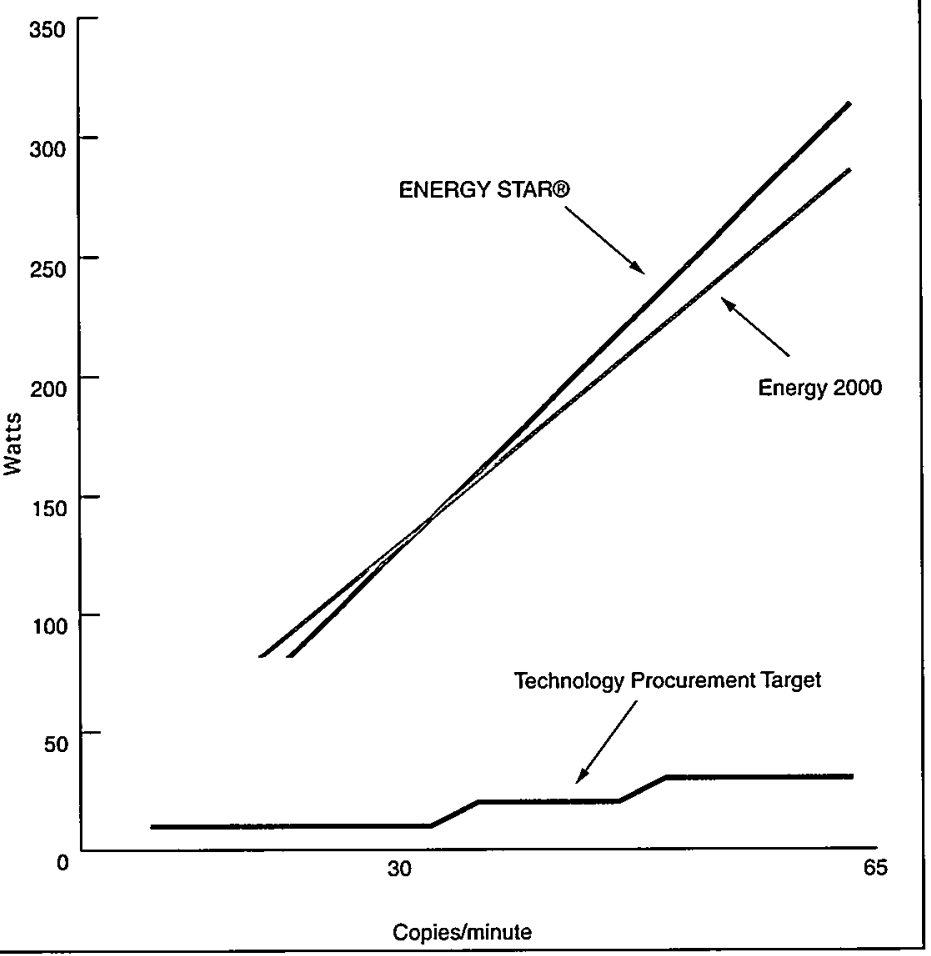




\section{Measuring and Verifying Energy Savings}

\section{S. Kumar}

Investments in energy and water efficiency in commercial and public buildings offer the largest and most cost-effective opportunity for both industrialized and developing nations to limit the enormous financial, health, and environmental costs associated with burning fossil fuels. On a global scale, opportunities for costeffective investments in energy and water efficiency in commercial and public buildings amount to an estimated tens of billions of dollars per year. However, the actual investment level is far less and covers only a small fraction of the existing, financially attractive opportunities for energy-savings investments.

One constraint on such investments has been the inability of project partners to agree on an accurate way to measure energy with our technical support, developed the North American Energy Measurement and Verification Protocol (NEMVP), which was published in March of 1996. The Protocol offers buyers, sellers, and financiers of energy and water projects a common, agreed-on method to quantify performance and savings of energy or water conservation measures. By reducing barriers to project financing, the Protocol also helps:

- increase reliability and level of savings,

- reduce transaction costs, and

- lower financing costs by standardizing the measurement of project savings, thereby allowing projects to be bundled for purposes of financing.

Energy service companies in North America have adopted the Protocol as an industry standard approach to measurement and verification $(\mathrm{M} \& \mathrm{~V})$. States ranging from Florida to New York now require its use in energy retrofits of state facilities. A growing number of utilities and energy service companies also now use the Protocol. DOE's Federal Energy Management Program (FEMP) relies on the Protocol for its accelerated program of thirdparty performance contracting, which is expected to provide up to several billion dollars of energy and water retrofits in U.S. federal buildings.

A review of several hundred million dollars worth of efficiency investments in U.S. buildings demonstrates that projects with strong $M \& V$ produce substantially more savings (20-30\% more) than projects with little or no M\&V (see box). A strong M\&V program, such as outlined in the Protocol, will typically add about $5 \%$ to energy retrofit project costs, but this added cost is paid back within a few months from substantially higher energy and water savings, as well as lower operations and maintenance (O\&M) costs.

Building on the success of the NEMVP, DOE has created an international version, the International Performance Measurement and Verification Protocol (IPMVP), with expanded coverage of energy-efficient new construction, efficient water use, and pollution trading systems. The IPMVP represents a remarkable collaborative effort between industry, federal, and state agencies, along with experts from several countries in North and South America, Europe, and Asia. Driven largely by industry itself, the new Protocol increasingly reflects a broad industry consensus. At least one international collaborative effort is underway to help overcome these barriers. Lending institutions such as the World Bank are using it as a requirement for about $\$ 500$ million of new energy-efficiency loans. The Protocol is being translated into
Bulgarian, Chinese, Czech, Hungarian, Japanese, Polish, Portuguese, Russian, Spanish, and Ukrainian, among other languages.

Visit the IPMVP web site at www.ipmvp.org

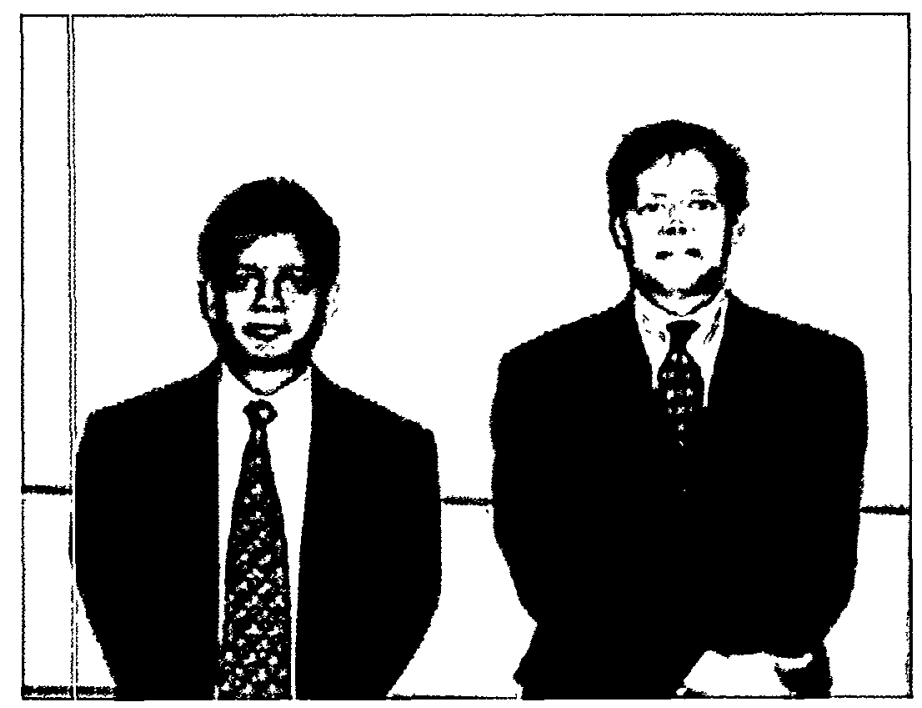

Efficiency projects undertaken without any measurement and verification (MEV) achieve less than the projected savings at the outset and experience substantial drops in efficiency savings over time. On the other hand, projects backed by good MEV practices often meet or even exceed projected savings and maintain the same level of savings over time. The right-hand scale is based on estimated cost savings, assuming a $20 \%$ real return on investment ( $R O I$ ). "Non-metered" retrofits with poor MEV average only about 15\% ROI whereas those with good MEV average about $23 \%$ ROI.

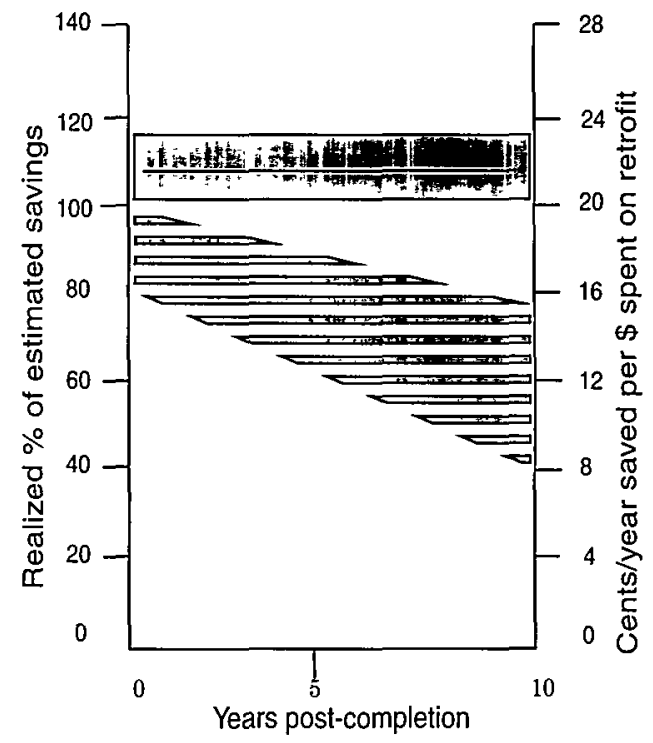

Good monitoring, diagnostics, and verification

Poor monitoring diagnostics, and verification 


\section{Energy Star Product Labeling}

R. Brown, C. Webber, A. ten Cate, S. Bretz, N. Raynolds, J. Koomey, A. Meier, M. Sanchez, W. Huber, M.A. Piette, B. Nordman

EPA and DOE are working together to promote the use of energyefficient equipment by awarding the ENERGY STAR label to products that save energy. The agencies set energy-efficiency criteria for specific consumer and commercial products. These criteria exceed the minimum national efficiency standards where such standards exist. Manufacturers and/or retailers volunteer to place the ENERGY STAR label on those models that meet or exceed the criteria set by EPA and DOE.

The ENERGY STAR label can help make purchasing decisions easier. These products not only save energy, they help prevent air pollution and save money, frequently with better performance. ENERGY STAR programs are currently in place for the following products:

\begin{tabular}{|lc|}
\hline \multicolumn{2}{|c|}{ ENERGY STAR labeled products } \\
Office equipment & Other products \\
Computers / Monitors & Exit signs \\
Copiers & \\
Printers & Residential lighting fixtures \\
Fax machines & Insulation \\
Photocopiers & \\
Scanners & \\
Multifunction devices & \\
Copiers & Consumer electronics \\
Appliances & TVs \\
Refrigerators & VCRs \\
Dishwashers & \\
Room air conditioners & \\
Clothes washers & \\
New homes & \\
Residential heating and cooling equipment \\
Programmable thermostats \\
Boilers \\
Furnaces \\
Heat pumps (air and ground source) \\
Central air conditioners
\end{tabular}

These programs are part of the U.S. commitment to reduce carbon dioxide emissions and avoid the possible consequences of global climate change. For this reason, the federal government is interested in tracking how much pollution is actually avoided by these programs, and projecting how much will be saved in the future. In fact, the government is legally obligated to report periodically to Congress and the United Nations on the pollution impacts of these programs. We have helped EPA track and forecast the impact of the ENERGY STAR programs for which EPA is directly responsible (all but appliances and windows), estimating carbon savings over time for each product. In addition, we have estimated the impacts of all the ENERGY STAR programs (including DOE programs), for use in marketing the ENERGY STAR label/logo. This effort included estimating the benefits an individual consumer would accrue by purchasing ENERGY STAR products.

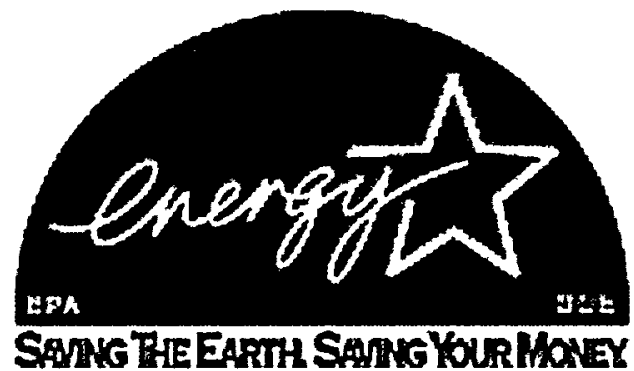

Recent activities have included:

(a) assessing potential energy, carbon, and dollar savings from the ENERGY STAR specifications for dedicated compact fluorescent lamps (CFL) fixtures, TVs, and VCRs, and conducting similar analyses for proposed ENERGY STAR specifications for other products;

(b) analyzing the effect of low power factor on energy savings from CFLs;

(c) estimating cost-effectiveness of ENERGY STAR exit signs;

(d) developing the ENERGY STAR programs for insulation and multifunction office equipment;

(e) measuring savings from ENERGY STAR office equipment in the field; and

(f) conducting detailed technical and market analysis for the proposed ENERGY STAR roofing program.

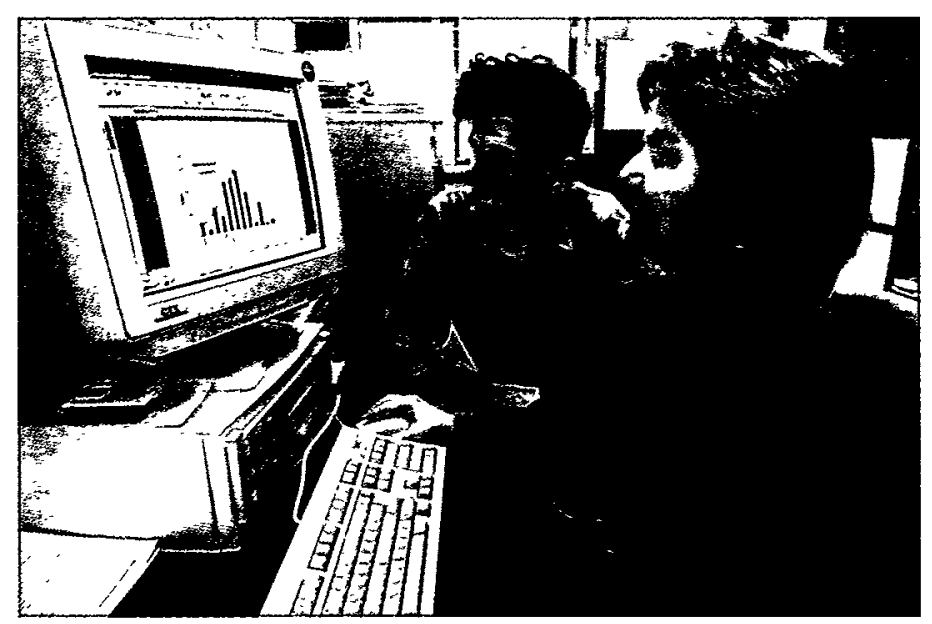




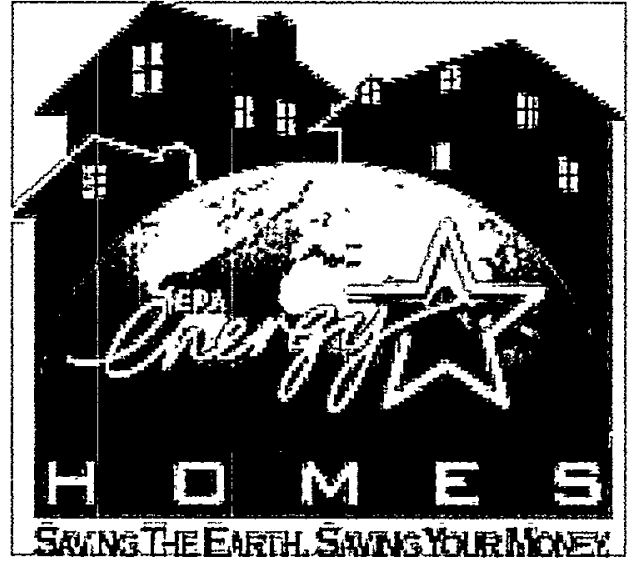

ENERgy STAR New Homes

R. Brown, J. Roberson, D. Mauritz, C. Atkinson, M. Moezzi, J. Warner, S. Bretz, M. Sanchez, J. Koomey, J. Kollar

The average household in the U.S. spends more than $\$ 1200$ per year for energy consumed in the home. In spite of this large expenditure, prospective home-buyers rarely have all the information they need to evaluate the energy efficiency of a home. In response to this lack of information, EPA designed the ENERGY STAR Homes program to overcome market barriers that can limit the energy efficiency of new homes, using technologies that dramatically reduce energy requirements for heating, cooling, and water heating.

The Homes program promotes the construction of new homes that consume at least 30\% less energy for heating, cooling, and water heating than the 1993 Model Energy Code specifications. The program operates by providing new-home builders a recognized logo to promote their energy-efficient homes, sales training and marketing materials, and technical assistance in designing and building them. We support EPA in this latter area - developing technical information to help builders more easily meet the guidelines of the ENERGY STAR program. We have provided the following energy-use analysis and program (technical) support:

(a) developing packages of energy-efficiency measures to help production home builders meet the ENERGY STAR guidelines in 14 U.S. metropolitan areas;

(b) recommending mechanical ventilation strategies in four climates, based on an analysis of costs and performance of nine such strategies in each climate;

(c) identifying cost-effective regions for central air conditioner heat recovery units (desuperheaters);

(d) providing general information on energy-efficiency upgrades such as sealed ducts, solar-reflective roofs, and desuperheaters;

(e) sampling contract specifications for energy-efficient heating and cooling ducts;

(f) evaluating the energy savings actually achieved by the ENERGY STAR homes program;

(g) preparing Consumer Fact Sheets on energy-efficient improvements to ENERGY STAR homes;

(h) providing customer service support to program partners and allies in Connecticut, Maine, Massachusetts, New Hampshire, New Jersey, New York, Rhode Island, and Vermont.
We also examined the ENERGY STAR Homes program in its pilot stage, in which 60 builder-partners have committed to constructing more than 14,000 homes that meet the ENERGY STAR criteria for energy efficiency. We conclude that the improved efficiency of these homes, when built and occupied, will prevent annual emissions of 6400 metric tons of carbon as carbon dioxide, 130 metric tons of sulfur dioxide, and 50 metric tons of nitrogen oxides. In terms of carbon, the emissions avoided as a result of the pilot program are equivalent to removing almost 5000 cars from the road for one year. Collectively, residents of the homes will save an estimated $\$ 5$ million per year on their energy bills.

\section{Reference}

Bretz, S., L. Bloomfield, T. Rooney, and J. Kollar. Marketing Energy-Efficient Residential Construction Nationwide: EPA's ENERGY STAR Homes Program. In Proceedings of the ACEEE 1996 Summer Study on Energy-Efficiency in Buildings, August 25-31, 1996. Washington, DC: American Council for an EnergyEfficient Economy, 1996. Vol. 2, pp. 2.13-2.24. Also available as Lawrence Berkeley National Laboratory Report No. LBNL39266.



\section{The Home Energy Saver / Virtual House}

E. Mills (Center for Building Science, EETD, LBNL), R. Brown,

S. Webster (Center for Building Science, EETD, LBNL),

M. Pinckard, J. Warner, J.D. Lutz, E. Page (Building Technologies

Dept., EETD, LBNL), M. Moezzi, Y.J. Huang, S. Offutt (U.S. EPA),

W. Read, J. Koomey

The Home Energy Saver is the first Internet-based tool to help homeowners reduce energy use in their homes. This World Wide Web site serves as a "do-it-yourself" home energy audit, helping homeowners identify the best energy upgrades and providing the information and resource contacts to help implement these upgrades. The site is being developed as part of EPA's ENERGY STAR program for reducing carbon dioxide emissions from energy use in homes.

The Home Energy Saver quickly computes a home's energy use on-line. By simply changing one or more features of the home, users can estimate potential energy savings of energy-efficiency improvements. Separate modules are provided for heating/cooling, domestic hot water, lighting, appliances and miscellaneous uses. Energy consumption is estimated using state-of-the-art models and data developed at LBNL, most notably the DOE-2 building simulation model for the heating/cooling module. We developed a coordinated system of software and hardware to make the tool easy to use - involving an interactive database accessed through common gateway interface (CGI) applications. In addition to calculating energy use on-line, the tool connects users to an expanding array of hundreds of other web sites providing information on energy-efficient products, residential utility programs, home builders, practical newsletters, energy software, and other useful topics.

The Home Energy Saver is designed for the lay-person, but is also useful to energy analysts, utilities, residential builders, and equipment/service vendors. This Web-based approach has several advantages over the traditional process of designing and deploying energy tools, such as a dynamic information network, and low-cost, immediate software distribution.

To try the HES yourself, visit the web site: http://eetd.lbl.gov/hes/

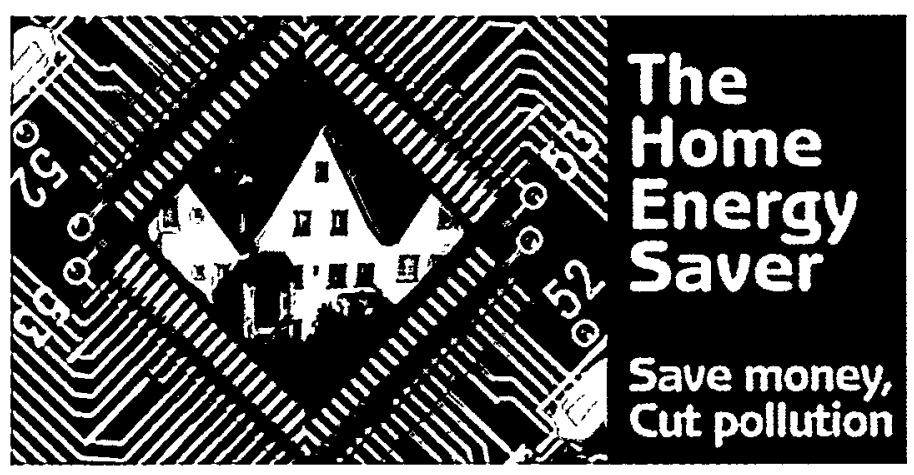




\title{
$\overline{\mathrm{C}}_{\text {nergy Efficiency Standards }}$
}

\begin{abstract}
Research into the impacts and savings potential of energy-efficiency performance standards on a wide range of energy-consuming products, incuding home appliances and equipment, office equipment, plumbing products, electric motors, and commercial, industrial, and residential lighting.
\end{abstract}

\section{Comparing Energy Efficiencies of Lamp Ballasts}

I. Turiel, B. Atkinson, A Denver, D. Fisher, S. Hakim, J. Lin, X. Lin, C. Marnay, J. McMalon

The Energy Policy and Conservation Act, as amended by subsequent laws including the Energy Policy Act of 1992, authorizes the U.S. Secretary of Energy to issue new or amended energy-efficiency standards for several products, including fluorescent lamp ballasts, air conditioners, ovens and ranges, dishwashers, clothes washers, dryers, refrigerators, and freezers.

To assist the U.S. DOE in this process, we conducted an analysis of lamp ballasts that compares energy-efficient magnetic, cathode cutout, and electronic ballasts in their operation of several fluorescent lamp types. The analysis included life-cycle cost (LCC), payback period, national energy consumption and savings, net present value of energy cost savings, and impacts on utilities and the environment. In addition to calculating LCC for average values of electricity price, ballast lifetime, and operating hours, sensitivity analyses were carried out with high and low values of these parameters and with distributions representing the proba- bility of occurrence of specific values. The results of the sensitivity analysis for twelve types of lamp/ballast systems showed that in most cases electronic ballasts have the lowest LCC, indicating that most end users will save money if they choose an electronic ballast.

We also calculated the potential energy savings for the nation as a whole under a program of energy-efficiency standards: the savings from a potential electronic ballast standard imposed in the year 2001 ranged from about 2 to 5 exajoules of primary energy over the period 2001-2030. An important question that remains is what would happen in the marketplace in the absence of standards for lamp ballasts. The chart below shows that the market share of electronic ballasts appears to be leveling off.

\section{Reference}

Turiel, I., B. Atkinson, A. Denver, D. Fisher, S. Hakim, J. Lin, X. Liu, C. Marnay, and J. McMahon. Draft Report on Potential lmpact of Alternative Efficiency Levels for Fluorescent Lamp Ballasts, Lawrence Berkeley National Laboratory, LBNL-40801, 1997.
The rapid rise in market share of clectronic ballasts appears to be leveling off, as indicated by this chart and partial 1997 data (not shown here).
Natıonal Electrical

Manufacturers Association

U.S. Bureau of the Census

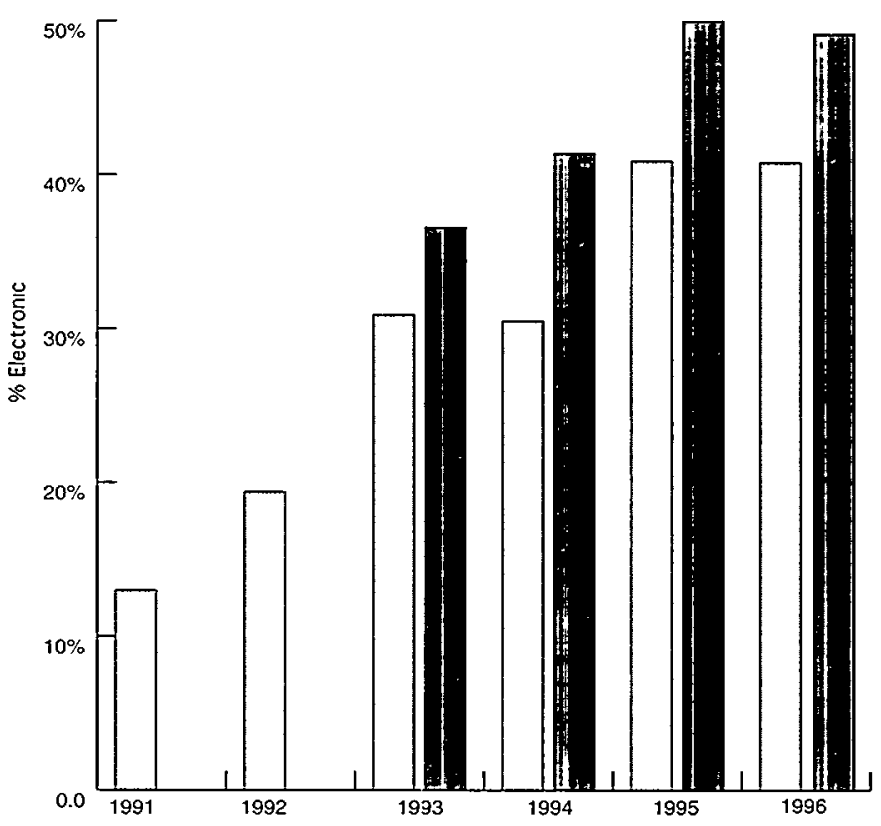




\section{Energy and Water-Saving Potential of Dishwashers and Clothes Washers}

\section{P.J. Biermayer, P. Chan, G. Rosenquist, J. McMahon}

DOE is required to review periodically the minimum energy-efficiency standards in effect for residential appliances, including dishwashers and clothes washers. Although large gains in energy efficiency for dishwashers and clothes washers have been made in the past, further gains are still possible. Currently, dishwashers use approximately $1.4 \%$ of total residential energy and clothes washers and dryers (together) approximately $5.6 \%$. The diagram shows where almost half of laundry energy is used: the dryer.

We analyzed the energy savings due to the implementation of new design options in dishwashers and clothes washers along with the cost to implement them. We determined that the best combination of design options could reduce dishwasher energy consumption by $10 \%$ and the combined clothes washer and dryer consumption by up to $60 \%$ and still have payback periods shorter than the life of the appliance.

\section{Reference}

Biermayer, P.J. Energy and Water-Saving Potential of Dishwashers and Clothes Washers: An Update. In Proceedings of the ACEEE 1996 Summer Study on Energy-Efficiency in Buildings, August 2531, 1996. Washington, DC: American Council for an EnergyEfficient Economy, 1996. Vol. 2, pp. 2.1-11. Also available as Lwrence Berkeley National Laboratory Report No. LBNL39698.

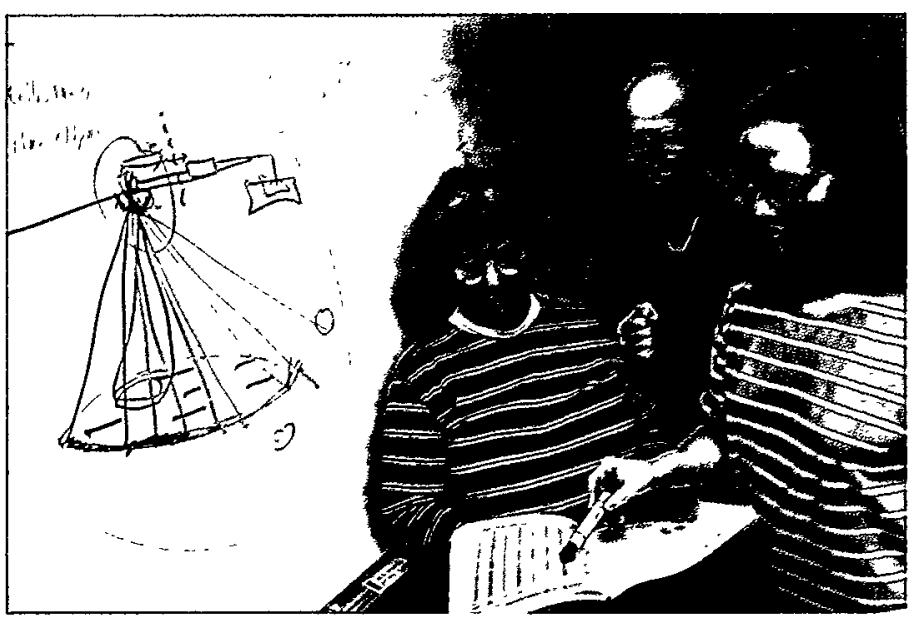

Energy is used in typical washer/dryers almost equally for heating wash and rinse water and for drying the washed clothes.

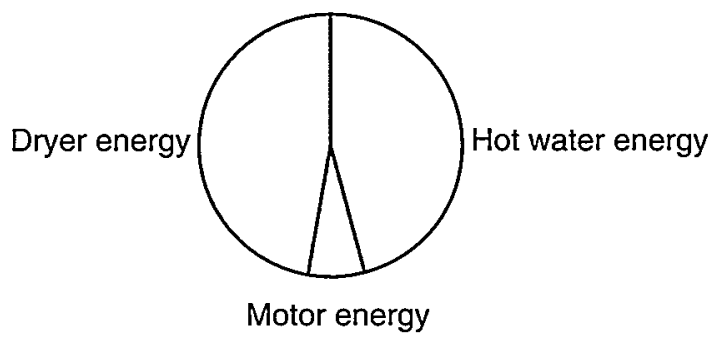

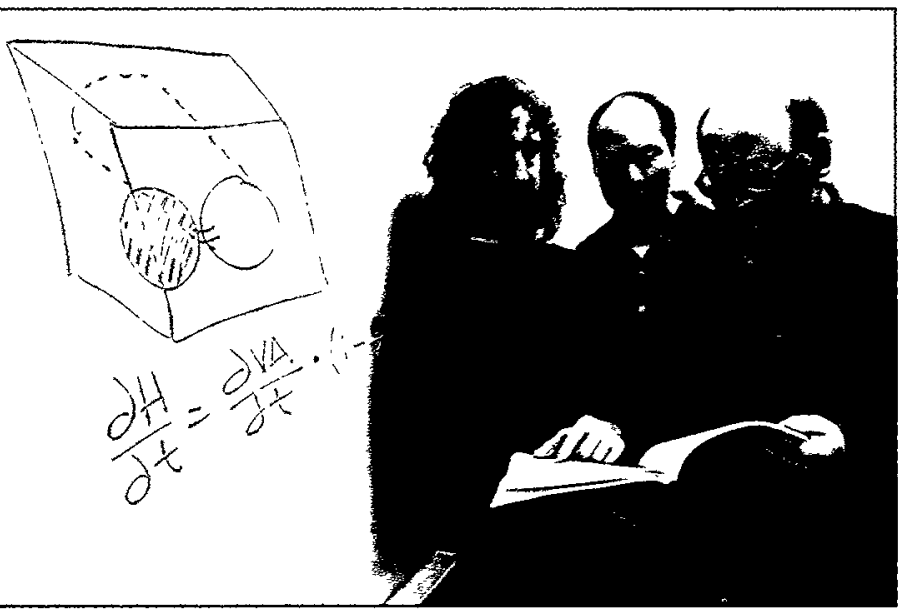




\section{Alternative Efficiency Levels for Residential Cooking Products}

G. Rosenquist, A. DeVuono, P. Chan, J. Lutz, C. Marnay, J. McMahon, T. Chan, S. Pickle, I. Turiel

Residential cooking products include electric and gas cooktops, ovens, and ranges as well as microwave ovens. Most of these products are relatively inefficient. Typical electric and gas cooktops have efficiencies of approximately $75 \%$ and $40 \%$, respectively, while electric and gas ovens exhibit extremely low efficiencies of approximately $12 \%$ and $6 \%$. Microwave ovens typically have efficiencies of about $55 \%$. Boosting these low equipment efficiencies appears, therefore, to offer a significant opportunity for reducing the country's overall residential energy consumption and accompanying air-borne nitrogen oxides and carbon dioxide

We have reviewed several technologies for each of these types of cooking products and found that few new technologies can costeffectively improve energy efficiency. Many technologies, such as halogen or radiant burners for electric cooktops, forced convection for electric and gas ovens, and more efficient magnetrons for microwave ovens, are simply too costly. In addition, the energy consumed by residential cooking equipment has decreased significantly over the past 15 years, putting severe limits on the additional energy savings that can be achieved by increased cooking efficiency. The graph below demonstrates how the annual energy useful cooking output (the energy used to cook food) has decreased significantly since DOE first established a test procedure for cooking products in the late 1970s.

One relatively simple technology that is cost-effective, however, is pilotless ignition for gas cooking products. In both gas cooktops and ovens, the consumer payback periods of pilotless ignition devices are less than half the lifetime of the products. Corresponding life-cycle costs are less than for similar products with standing pilots. Pilotless ignition devices, moreover, have no significant impacts on manufacturer profitability or electric utility revenues. If pilotless ignition were to be implemented as a minimum efficiency standard for all gas cooking products, the societal benefits would include cumulative energy savings between the years 1999 and 2030 of 0.5 EJ, with corresponding ntirogen oxide and carbon dioxide emission reductions of $30 \mathrm{kt}$ and $22 \mathrm{Mt}$, respectively.

\section{Reference}

DeVuono, A., P. Chan, J. Lutz, C. Marnay, G. Rosenquist, J. McMahon, T. Chan, S. Pickle, and I. Turiel. Draft Report on Potential Impact of Alternative Efficiency Levels for Residential Cooking Products. Lawrence Berkeley National Laboratory Report No. LBNL-40799, 1997.
Recent field data collected between 1988 through 1994 dentonstrate (1) the significant decrease in energy used by conventional cooktops and ovens since the inception of DOE's test procedure in the late 1970s, and (2) the dramatic difference in energy used by cooktops relative to ovens.
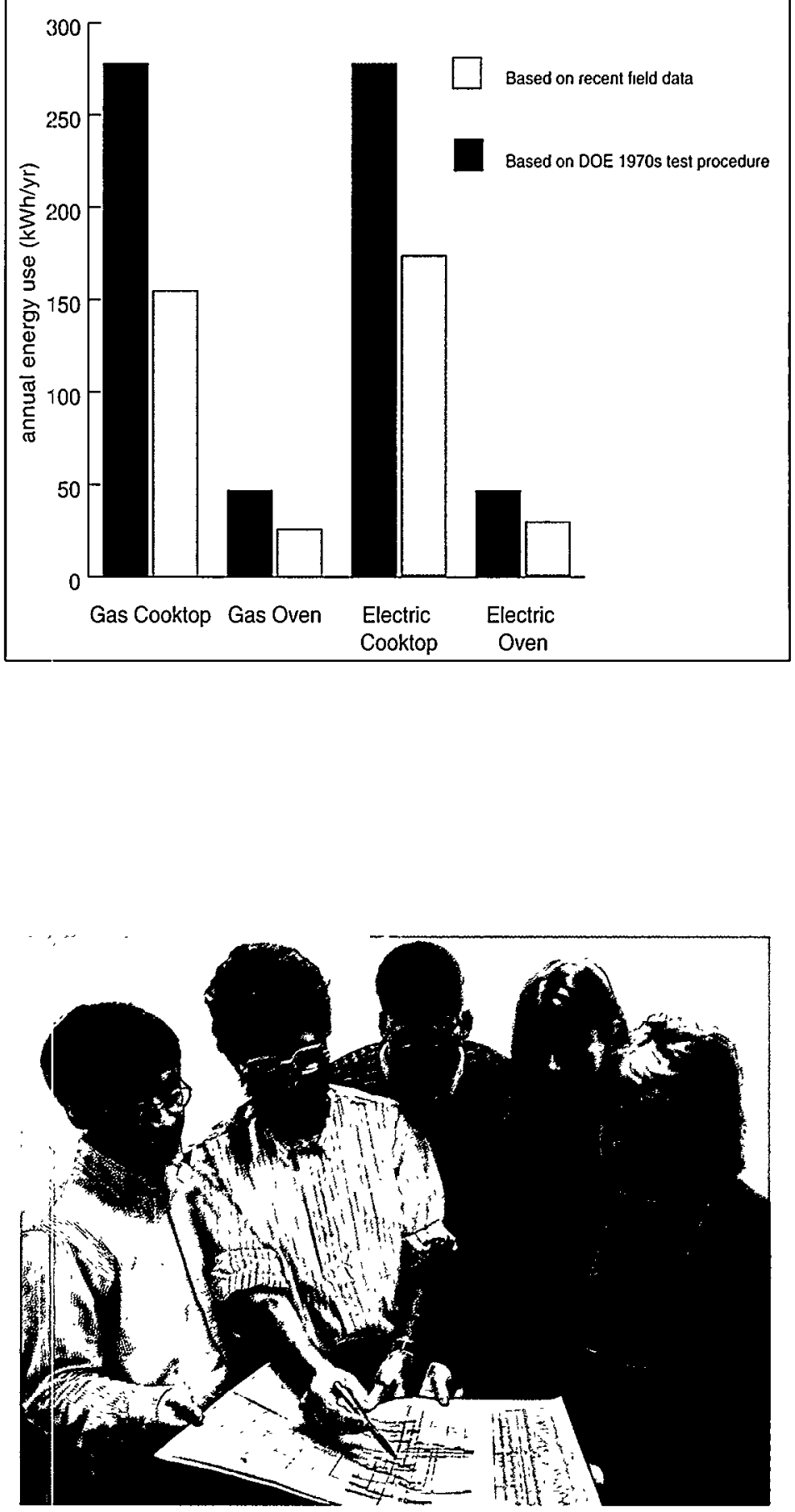


\section{New Energy-Saving Design Features for Room Air Conditioners}

G. Rosenquist, P. Chan, T. Chan, C. Marnay, J. McMahon, S. Pickle, I. Turiel

The energy use of residential household appliances comprises a significant portion of U.S. overall energy consumption. Windowtype room air conditioners constitute approximately $2 \%$ of the energy consumed by household appliances in the U.S. Although the room air conditioner industry has gradually introduced more energy-efficient products during the past 20 years, opportunities still exist for improving product efficiency beyond its yearly average rate of increase.

We have found that for the most popular classes of room air conditioners, energy efficiency ratios (EER) of approximately $3 \mathrm{~W} / \mathrm{W}$ $(10.0 \mathrm{Btu} / \mathrm{hr} / \mathrm{W})$ can be achieved by incorporating commonly used technologies such as high-efficiency rotary compressors, grooved refrigerant tubing, slit-type fins, subcoolers, and permanent split capacitor fan motors. When compared to current minimum efficiency designs, these new designs have a lower life-cycle cost (e.g., see figure below) and a payback period that is no greater than half the lifetime of the appliance. These new design levels also demonstrate no significant impact on manufacturer profitability or electric utility revenues. When included with costeffective designs for all other classes of room air conditioners, implementation of these new design levels as national minimum efficiency standards would result in cumulative energy savings of 0.7 EJ (for the period 1999-2030) and accompanying carbon dioxide emission reductions of $60 \mathrm{Mt}$.

\section{References}

Rosenquist, G., P. Chan, T. Chan, C. Marnay, J. McMahon, S. Pickle, and I. Turiel. Draft Report on Potential Impact of Alternative Efficiency Levels for Room Air Conditioners. Lawrence Berkeley National Report No. LBNL-40800, 1997.

Rosenquist, G. Opportunities for Improving the EnergyEfficiency of Window-Type Room Air Conditioners. In Proceedings of the ACEEE Summer Study on Energy-Efficiency in Buildings, August 25-31, 1996. Washington, DC: American Council for an Energy-Efficient Economy, 1996. Vol. 1, pp. 1.205-1.216. Also available as Lawrence Berkeley Nationa Report No. LBNL-39699.
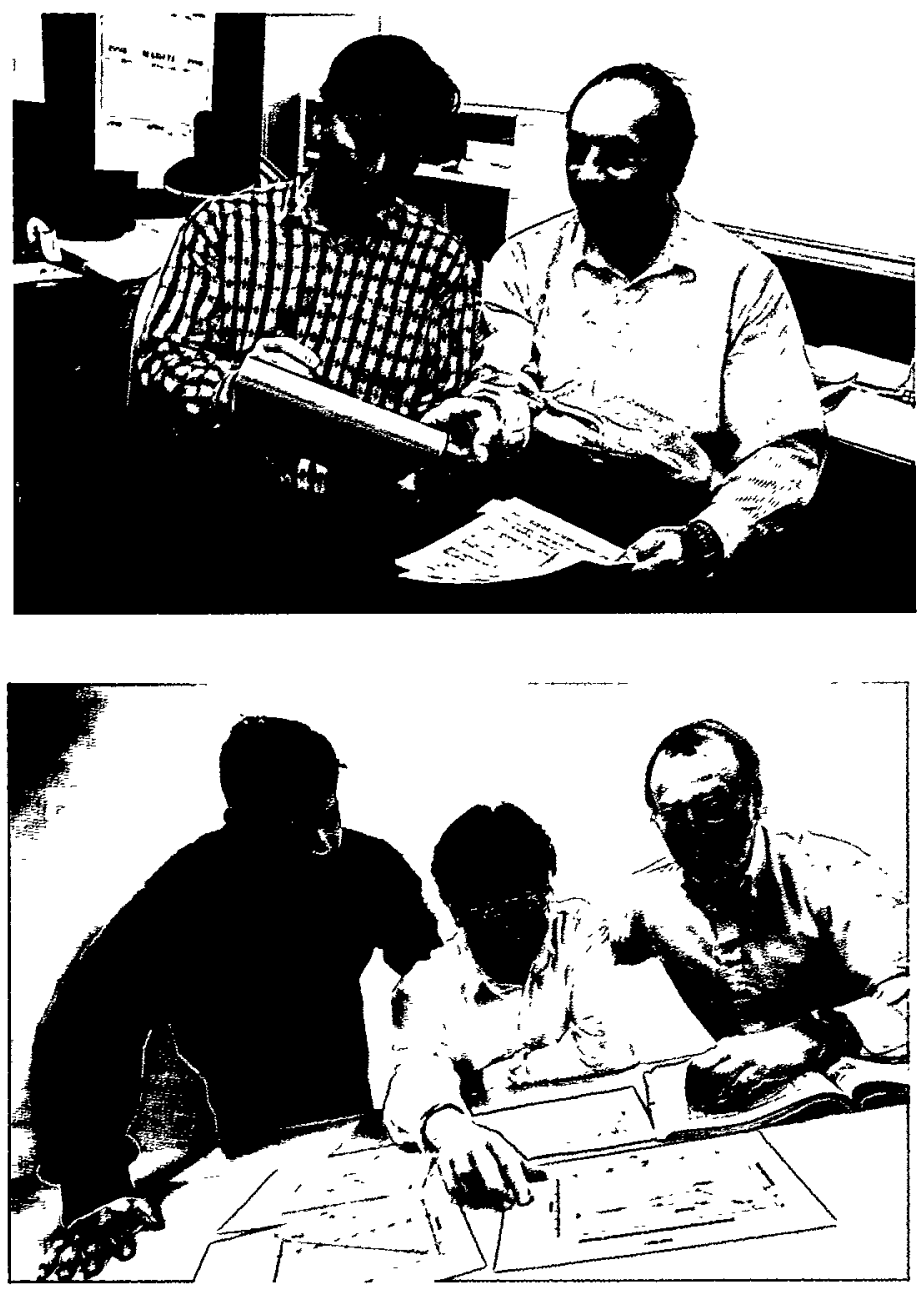

This figure, depicting the relationship between life-cycle cost (LCC) and energy efficiency for room air conditioners with cooling capacities between 2350 and 4100 watts, shows that a combination of commonly used technologies can be utilized to raise the EER to 2.96 $W / W$ while lowering the LCC relative to baseline (i.e., minimum efficiency) designs. Although less commonly used technologies such as increased heat exchanger areas, electronically commutated fan motors (ECM), and variable speed compressors improve energy efficiency, they excessively raise LCC and, thus, are not cost-effective.

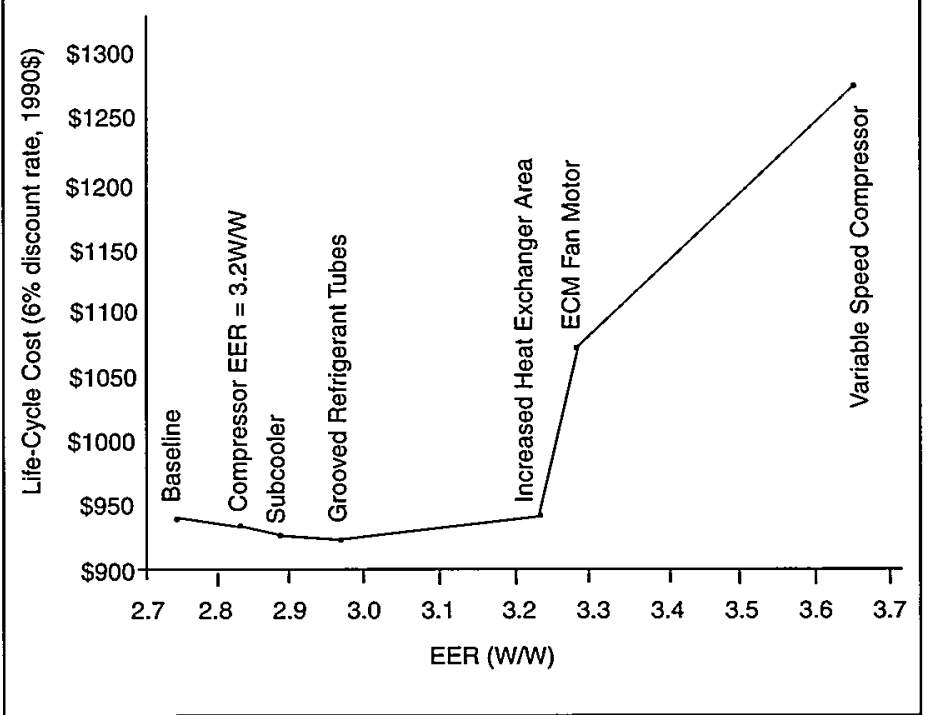


Effects of Appliance Standards on Product Price and Attributes: A Hedonic Pricing Model

\section{L.A. Greening, A.H. Sanstad, J.E. McMahon}

We have examined the tradeoffs between the energy efficiency gains and product attributes that result from the implementation of federal energy performance standards. Under a statutory mandate to DOE, this is an issue that must be addressed during the implementation process.

We used hedonic pricing relationships to estimate changes in standardized marginal attribute prices for freezer compartment volumes, fresh food volumes, and annual energy consumption for refrigerators and refrigerator/freezers.

This was the first retrospective analysis of energy performance standards ever undertaken. The analysis indicated that from 1987/88 to 1993 , energy performance standards significantly reduced energy consumption and at the same time, a historical decline in "quality-adjusted" real prices continued without disruption and consumers appeared to experience a welfare gain as a result of improving levels of energy efficiency.

Reference

Greening, L., A. Sanstad, and J. McMahon. Effects of Appliance Standards on Product Price and Attributes: An Hedonic Pricing Model. Joumal of Regulatory Economics 11 (2) 181-194. 1996. Also available as Lawrence Berkeley National Laboratory Report No. LBNL-39739.

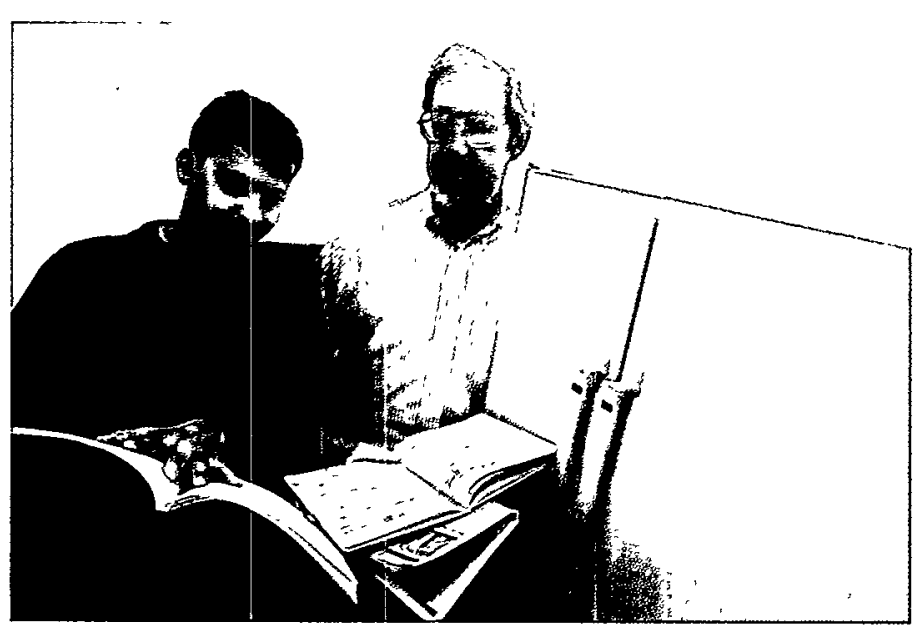

\section{Observed Savings from Appliance Efficiency Standards}

\section{A. Meicr}

Estumates of energy savings due to efficiency standards are based on laboratory tests rather than on direct field measurements. Laboratory measurements are both cheaper and faster than field measurements, but they still require calibration to measurements made in the field. There are both methodological and practical obstacles to directly observing savings in the field, including defining baseline energy use and isolating the impact of the technical improvements in efficiency from other changes in usage patterns. Field measurements of energy savings from more efficient appliances - often prompted by efficiency standards - have been made in the U.S., Canada, Sweden, Japan, and elsewhere.

Energy savings due to refrigerator efficiency improvements have been the most closely examined. Savings in both the U.S. and Europe have frequently exceeded $50 \%$. The savings have been observed through laboratory comparisons, field measurements, and utility bill analysis. Actual reductions correspond closely to those predicted in laboratory tests. Reductions in energy use due to improvements in HVAC equipment efficiencies have also been observed for both heating and cooling equipment. One study in Kansas found that replacement of old room air conditioners with ones meeting the new standard cut energy use by roughtly $30 \%$. The relative savings generally correspond to those projected from the laboratory measurements, but it is impossible to accurately translate laboratory measurements into absolute energy savings. Energy savings due to efficiency improvements have also been observed for freezers, water heaters, and showerheads.

The most convincing demonstrations of savings due to appliance efficiency standards occur in homes where an old model is replaced by a new nodel meeting the standards and the two appliances are monitored both before and after. A Swedish study shows the observed drop in energy use when new refrigerators replaced older units. Similar studies in the U.S. often reveal more than $50 \%$ reductions in energy use.

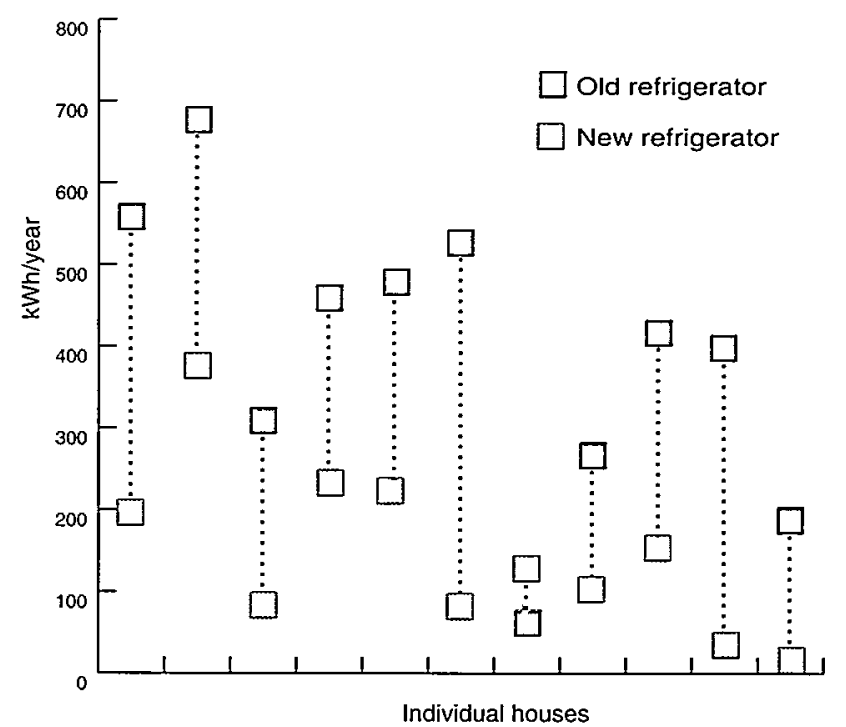




\section{Energy Test Procedures for Appliances: The Next Generation}

\section{A. Meier and J. Hill (National Institute of Standards and Technology)}

An energy test procedure is the technical foundation for all energy efficiency standards. It also provides manufacturers, regulatory authorities, and consumers a way of consistently evaluating energy use. The ideal test procedure reflects actual usage conditions without compromising reliability and ease of testing. These goals are contradictory, so every test procedure is a compromise.

Many countries have their own unique test procedures. Conversion formulas from one test to another cannot be constructed due to differences in definitions of appliance categories, features, and measurement criteria. The test procedures will face unprecedented pressures in the next decade to accommodate to the complexities of international economic integration and technical innovations.

Three trends will help force these changes. First, the appliance industry is becoming increasingly international. As international trade in appliances rises, firms will seek to reduce trade barriers, including the use of local test procedures. Second, "ownership" of test procedures is shifting from test-setting organizations to government agencies in charge of efficiency regulations and labels. Finally, the introduction of microprocessors to control appliance operation is causing an increasing discrepancy between energy test procedures and actual operation. Current test procedures test mechanical efficiency of appliances but ignore the "software" features of modern models. Most energy test procedures will need to be revised soon or become hopelessly obsolete.

Energy test procedures are the technical foundation for many energy-efficiency programs.

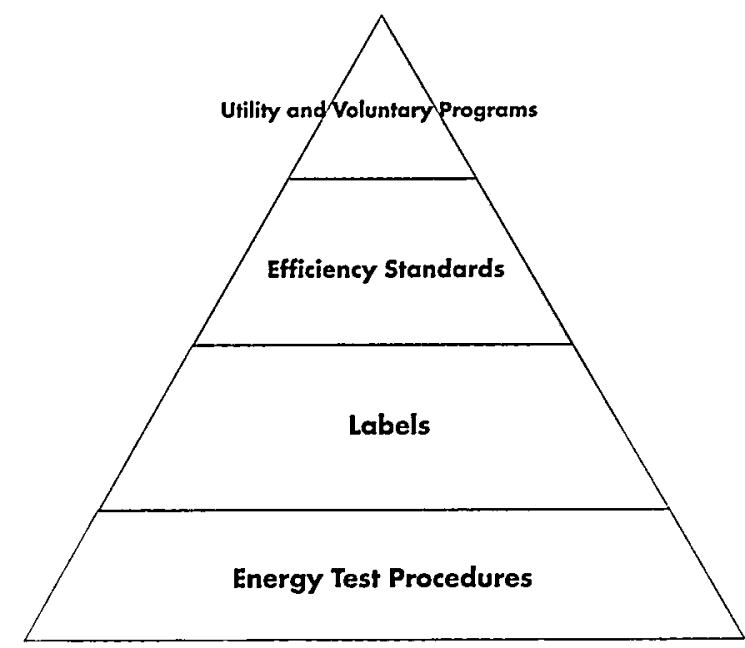




\section{Electricity Markets and Policy}

Research on public policy issues, from transmission pricing and market power to the role of renewables and energy efficiency, as the utility industry undergoes restructuring.

\section{Utility Restructuring}

Restructuring of the power sector is creating dramatic changes in the organization and operation of this essential element of a nation's infrastructure (see box on following page). In the U.S., retail choice, or the ability of consumers to choose their electricity supplier, is a central element of these activities. Our recent research focuses on the public interest policy issues that are raised by restructuring. These issues include energy-efficiency policies for a restructured utility industry, private-sector energy-efficiency activities, renewable energy policy, market power and transmission, and electricity industry restructuring in unique cultural/geographic contexts.

\section{Energy-Efficiency Policies for a Restructured Electricity Industry}

\section{J. Eto, C. Goldman, W. Golove, S. Kito, E. Vine}

Regulated utilities in the U.S. have, in the past, been responsible for "public purpose" programs - for example, promoting energy efficiency and demand-side management (DSM) - that contribute to the general social good. As utilities restructure and competition enters the energy market, there are questions about the future of these public purpose activities and the role and goals of government in providing them.

Several of our recent studies address the future of energy-efficiency programs in a restructured electricity industry. Market Barriers to Energy Efficiency: A Critical Reappraisal of the Rationale for Public Policies to Pronote Energy Efficiency provides a background to these discussions by reviewing the decade-long academic debate among economists, technologists, and other social scientists regarding the rationale for promoting energy efficiency. The review concludes that there remain important rationales for government intervention to improve the functioning of electricity markets. It recommends that future public policies supporting energy efficiency be grounded in a sound understanding of the market problems that the policies seek to correct; this understanding can only emerge from detailed investigations of the current operation of particular markets.

The Past, Present, and Future of U.S. Utility Demand-Side Management Programs offers a historic overview of utility DSM programs. DSM programs are utility-sponsored activities to promote customer adoption of energy-efficient technologies and practices. The study takes the general findings from the previous report and applies them to the specific circumstances created by electricity restructuring. It concludes that the basic rationales for public policies to promote energy efficiency remain valid in a restructured electricity industry.
Ratepayer-Funded Energy-Efficiency Programs in a Restructured Utility Industry: Issues, Options, and Unanswered Questions reviews the restructuring process in several states and offers guidelines for future regulation of energy-efficiency programs. We suggest that regulators: carefully define the goals and objectives of energy-efficiency programs in a restructured industry; carefully balance public and private interests; keep programs under the purview of utilities only if they have been well-run in the past and regulators can mitigate the disincentives and conflicts of interest the utility may face in running programs in the future; and pay special attention to new program accountability and governance issues if they choose not to rely on utilities to deliver programs in the future.

Energy-efficiency market transformation is emerging as a new organizing principle for ratepayer-funded energy-efficiency programs in a restructured electricity industry. In A Scoping Study on Energy-Efficiency Market Transformation by California Utility Demand-Side Management Programs, we propose a definition of market transformation that has since become the standard for the inclustry. The definition is consistent with a view that the role of ratepayer-funded energy-efficiency programs is to improve the furctioning of markets to the point where customers and other market participants find it in their own self-interest to pursue cost-effective energy-efficiency opportunities and, therefore, future programs are no longer needed. We also review recent utility DSM programs to find good reasons to believe-yet little concrete evidence to support-that limited market transformation may have taken place through these programs. Finally, we review California's DSM policies and find that a new policy framework, which consciously promotes market transformation and aims to overcome the disincentives of current DSM policies, would more effectively transform the energy-efficiency market.

Many utilities are requesting that data they submit to state utility regulatory commissions remain confidential (particularly data collected from energy-efficiency programs). In Confidential Data in a Competitive Utility Environment: A Regulatory Perspective, we conclude that utility withholding of ratepayer-funded information they have collected is likely to have serious negative impacts on the design, implementation and evaluation of future energy-efficiency programs, plans, and policies; consumer education activities; the creation of a fair market for competitive energy services; regional and national assessments of energy-savings opportunities; and research and development. We recommend that regulatory utility commissions carefully examine their regulatory needs for information in a restructured electricity industry, assess the adequacy of information currently provided, and determine what information should be required in the future. 


\section{References}

Golove, W. and J. Eto. Market Barriers to Energy Efficiency: A Critical Reappraisal of the Rationale for Public Policies to Promote Energy Efficiency. Lawrence Berkeley National Laboratory Report No. LBL-38059. 1996. Downloadable. See also Golove, W. and J. Eto. Energy Efficiency, the Free Market and Rationales for Government Intervention. In Proceedings of the International Association for Energy Economics: (De)Regulation of Energy: Intersecting Business, Economics and Policy, October 27-30, 1996, Boston, MA. pp. 135-144.

Eto, J. The Past, Present, and Future of U.S. Utility Demand-Side Manngement Programs. Lawrence Berkeley National Laboratory Report No. LBNL-39931. 1996. Downloadable. See also Eto, J. The Past, Present, and Future of U.S. Utility Demand Side Management Programs. Revue de l'Energie , \#483, 626-638, 1996.

Eto, J., C. Goldman, and S. Kito. Ratepayer-Funded EnergyEfficiency Programs in a Restructured Electricity Industry:
Issues, Options, and Unanswered Questions. In Proceedings of the ACEEE 1996 Summer Study on Energy Efficiency in Buildings, August 25 - 31, 1996. Washington, DC: American Council for an Energy-Efficient Economy. 1996. Vol. 9. pp. 9.55-64. LBNL40026. Downloadable.

Eto, J., R. Prahl, and J. Schlegel. A Scoping Study on EnergyEfficiency Market Transformation by California Utility DSM Programs. Lawrence Berkeley National Laboratory Report No. LBNL-39058. 1996. Downloadable.

Vine, E. Confidential Data in a Competitive Utility Environment: A Regulatory Perspective. Lawrence Berkeley National Laboratory Report No. LBL-38622. 1996. See also Vine, E. Confidential Data in a Competitive Environment: Setting a Regulatory Agenda. Electricity Journal 10 (3) 62-69, 1997.

In a restructured electricity industry, transmission and distribution companies will become regulated common carriers of an electricity commodity. Independent system operators will coordinate operation of the transmission grid. Generators and aggregators of generation will be free to contract directly with customers or retail energy service companies. Customers will be able to purchase both electricity and other value added services, such as energy efficiency, from retail energy service providers. Energy-efficiency service companies will also offer energy-efficiency services on a stand-alone basis.

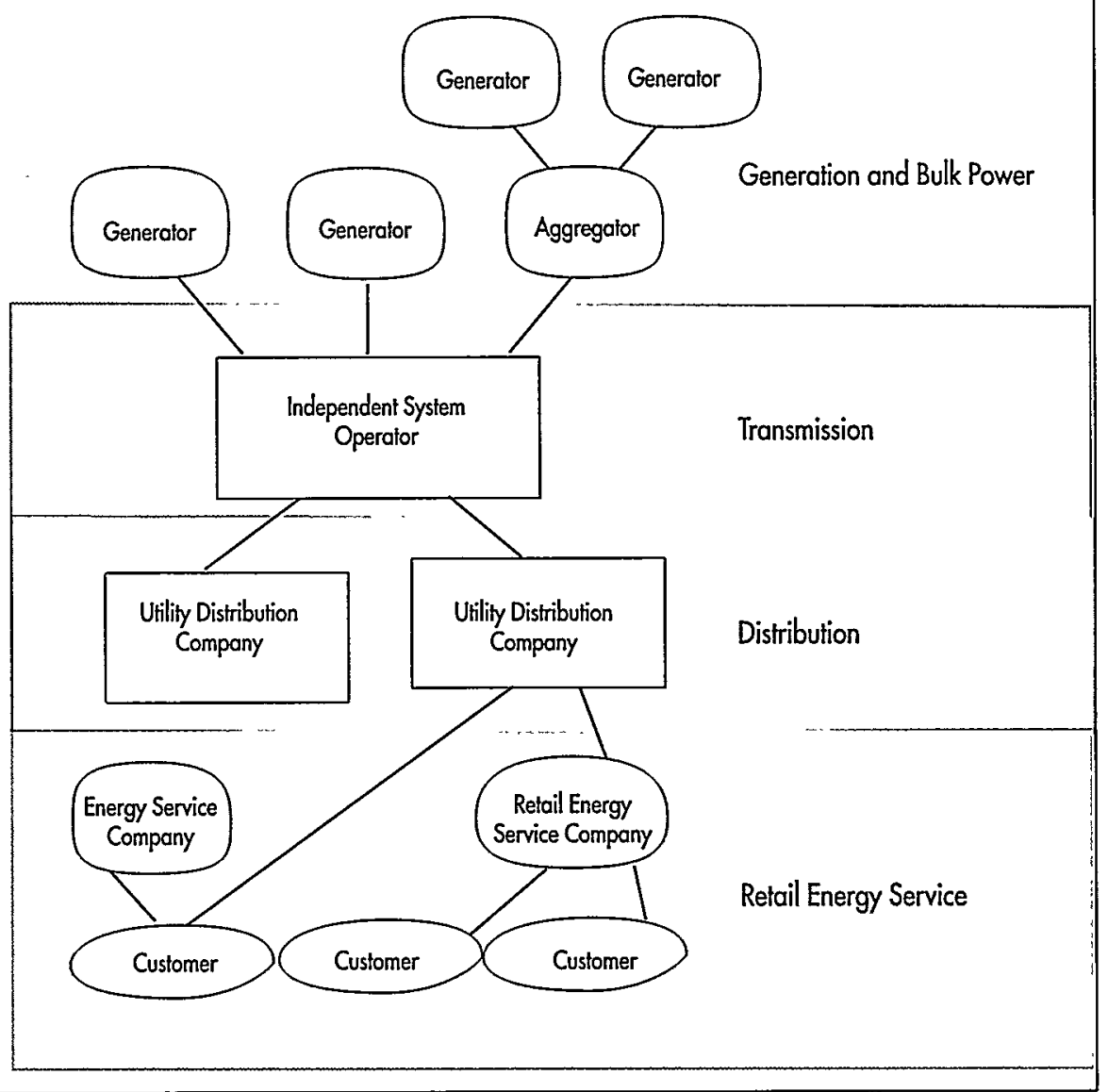




\section{Renewable Energy Policy}

R. Wiser, S. Pickle, C. Goldnan, C. Marnay, J. Eto, E. Jones, C. Richey, S. Bretz, R. Markel

Policies to promote renewable energy, like those for energy efficiency, address an important public purpose activity that is threatened by restructuring. Our research has been directed toward understanding emerging trends, analyzing recent policies, and creating analytical tools to understand the likely effects of future policies.

Electricity industry restructuring creates new opportunities for marketing "green" power to consumers and highlights a potential role for public policies that might stimulate the more rapid devel-

opment of this market. Green Marketing, Renewables, and Free

$\Gamma$ Riders: Increasing Customer Demand for a Public Good looks at recent $\overline{7}$ green market activities by utilities. We reviewed the literature on $\prec$ free riders (i.e., participants in utility-sponsored energy-efficiency programs who would have purchased the technology even in the absence of the program). Based on this review, we made four broad recommendations to firms marketing green power. Providers should take advantage of community and social pressures for the public good, assure customers that their decision to purchase green power will make a difference, emphasize customer retention, and bundle green power products with features that also offer private value.

The study California Renewable Energy Policy and Implementation Issues: An Overviezv of Recent Regulatory and Legislative Action assesses the aggressive approach California has undertaken to promote renewable energy in the context of electricity industry restructuring. In it, we examine the two types of policies that were proposed to support renewable energy in California - a surcharge-funded production support system and a minimum renewable energy purchase requirement - and then analyze the reasons for the failure of the latter.

A critical element to the success of any renewable energy policy is the ability to meet the considerable financing requirements associated with renewable technologies. Our report Financing Investments in Renewable Energy: The Role of Policy Design and Restructuring finds one key reason that renewable energy technology policies have not been more effective in the past is that project development and financing processes were frequently ignored or misunderstood. We describe the process of power plant financing and offer insights for policymakers on the interaction between financing and renewable energy policy design. A related report, Financing End-Use Solar Technologies in a Restructured Electricity Industry: Comparing the Cost of Public Policies looks in greater detail at the relationships between these issues (e.g., different types of ownership/financing, subsidies, or policies, and the role of indirect costs) and policies to promote end-use solar technologies.

Estimating the Environmental and Economic Effects of Widespread PV Adoption Using GIS and NEMS employs two computer models to provide a comprehensive analysis of the regional and national effectiveness of various policies to stimulate adoption of another renewable technology, rooftop photovoltaic systems.

\section{References}

Wiser, R. and S. Pickle. Green Marketing, Renewables, and Free Riders: Increasing Customer Demand for a Public Good. Lawrence Berkeley National Laboratory Report No. LBNL-40632. 1997. Downloadable. See also Pickle, S. and R. Wiser. Green Power
Marketing: Boosting Demand for Renewables. Public Utilities Fortnightly 135 (22) 30-35, 1997, and Wiser, R, and S. Pickle. Green Marketing and Renewables: What Role for Public Policy in a Restructured Electric Industry? In Proceedings of the International Association for Energy Economics: International Energy Markets, Competition and Policy Conference, September 7 10, 1997, San Francisco, CA, pp. 563-572.

Wiser, R., S. Pickle, and C. Goldman. California Renewable Energy Policy and Implementation Issues-An Overview of Recent Regulatory and Legislative Action. Lawrence Berkeley National Laboratory Report No. LBNL-39247. 1996. Downloadable. See also Wiser, R., S. Pickle, and C. Goldman. Designing Renewable Energy Policies Within California's Electricity Restructuring Process. In Proceedings of the 1997 American Solar Energy Society Annual Conference, April 25 - 30, 1997, Washington, DC, pp. $185-$ 190.

The Green-e Renewable Branding Project is a voluntary program through which customers can easily identify certified "green" electricity products. Certified products have a higher proportion of renewables (at least 50\%) and lower air pollution emissions per kilowatt-hour. Displaying the logo is one way green power marketers are trying to distinguish themselves in the market and increase customer demand for renewable energy.

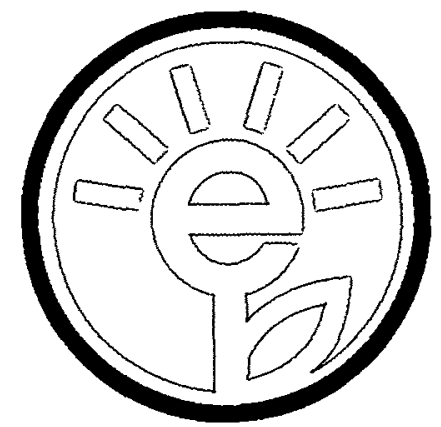

Wiser, R. and S. Pickle. Financing Investments in Renewuable Energy: The Role of Policy Design and Restructuring. Lawrence Berkeley National Laboratory Report No. LBNL-39826. 1997. Downloadable. See also Wiser, R. and S. Pickle. The Impact of Financing on Renewable Energy Costs: Implications for Renewables Policy. In Proceedings of the 1997 American Solar Energy Society Annual Conference, April 25 - 30, 1997, Washington, DC, pp. 197- 205, and Wiser, R., S. Pickle and C. Goldman. Renewable Energy and Restructuring: Policy Solutions to the Financing Dilemma. The Electricity Journal 10 (10) $65-75,1997$.

Jones E. and J. Eto. Financing End-Use Solar Technologies in a Restructured Electricity Industry: Comparing the Cost of Public Policies. Lawrence Berkeley National Laboratory Report No. LBNL-40218. 1997. Downloadable.

Marney, C., R.C. Richey, S. Mahler, S. Bretz, and R. Markel. Estimating the Environmental and Economic Effects of Widesprend Residential PV Adoption Using GIS and NEMS. Lawrence Berkeley National Laboratory Report No. LBNL-41030. See also Marnay, C., C. Richey, S. Mahler, and R. Markel. Estimating Environmental and Economic Effects of Widespread Residential PV Adoption Using GIS and NEMS. In Proceedings of the 1997 American Solar Energy Society Annual Conference, April 25 - 30, 1997, Washington, DC, pp. 335-340. 


\section{Private-Sector Energy-Efficiency Activities}

\section{Goldnan, C. Marnay, S. Pickle, F. Olken (Information and} Computing Sciences Division, LBNL)

Electricity industry restructuring is creating new business opportunities for private-sector firms to promote energy efficiency, for example, by linking energy and telecommunications services or offering contracts to save energy for customers. EA's recent work has emphasized tracking developments in these areas in order to gain insight into emerging trends.

In the study, Impact of Information and Communications Teclinologies on Residential Customer Energy Services, we analyzed 21 utility projects under way in areas such as utilizing communications technologies for automated meter reading, time-differentiated pricing, and customer-controlled load management (see box). Other services also being offered by utilities include home security alarms and long-distance telephone and cable access. We found that considerable barriers exist to large-scale deployment of these communication services but that they are almost certain to become part of future residential energy services.

Information Systems Requirements for a Deregulated Electric Power Industry reports on an LBNL-organized workshop premised on the idea that information technologies - computing, communications, instrumentation, data storage, and networking - are key components in the development and operation of the new, competitive electric power industry. The workshop addressed two main questions: what are the information technology requirements of the industry and what, if any, are the public policy concerns that might motivate involvement of the U.S. DOE in research or in development of standards?

Our study titled Future Prospects for ESCOs in a Restructured Electricity Industry explores future prospects for energy service companies (ESCOs) to deliver energy efficiency and other services in a restructured electricity industry. We found that ESCOs offering three services - addressing multiple customer demands related to energy and facility problems, identifying energy-efficiency opportunities and proposing viable means of taking advantage of them, and verifying future savings from efficiency improvements - will have the best competitive position in the new retail energy market.

\section{References}

Goldman, C., W. Kempton, A. Eide, M. Iyer, M. Farber, and R. Scheer. Impact of Information and Communications Technologies on Residential Customer Energy Services. Lawrence Berkeley National Laboratory Report No. LBNL-39015. 1996. Downloadable. See also Goldman, C., M. Farber, and R. Scheer. Impact of Information and Communication Technologies on Residential Customer Energy Services. Utilities Policy 6 (2) 151161, 1997.

Pickle, S., C. Marnay, and F. Olken. Information Systems Requirements for a Deregulated Electric Power Industry: Assessment and Perspectives from the 1996 Informatics Workshop. Utilities Policy. 6 (2) 163-176. 1997. See also Lawrence Berkeley National Laboratory Report No. LBNL38666 for the Workshop Summary and Proceedings.

Goldman, C. and D.S. Dayton. Future Prospects for ESCOs in a Restructured Electricity Industry. In Proceedings of the ACEEE 1996 Summer Study on Energy Efficiency in Buildings, August 25 31, 1996. Washington, DC: American Council for an EnergyEfficient Economy. 1996. Vol. 10, pp. 10.59-69.
Recently developed communication technologies will likely be used for automated meter-reading, time-differential pricing, and customer-controlled load management in ways which will profoundly change how people use electricity.
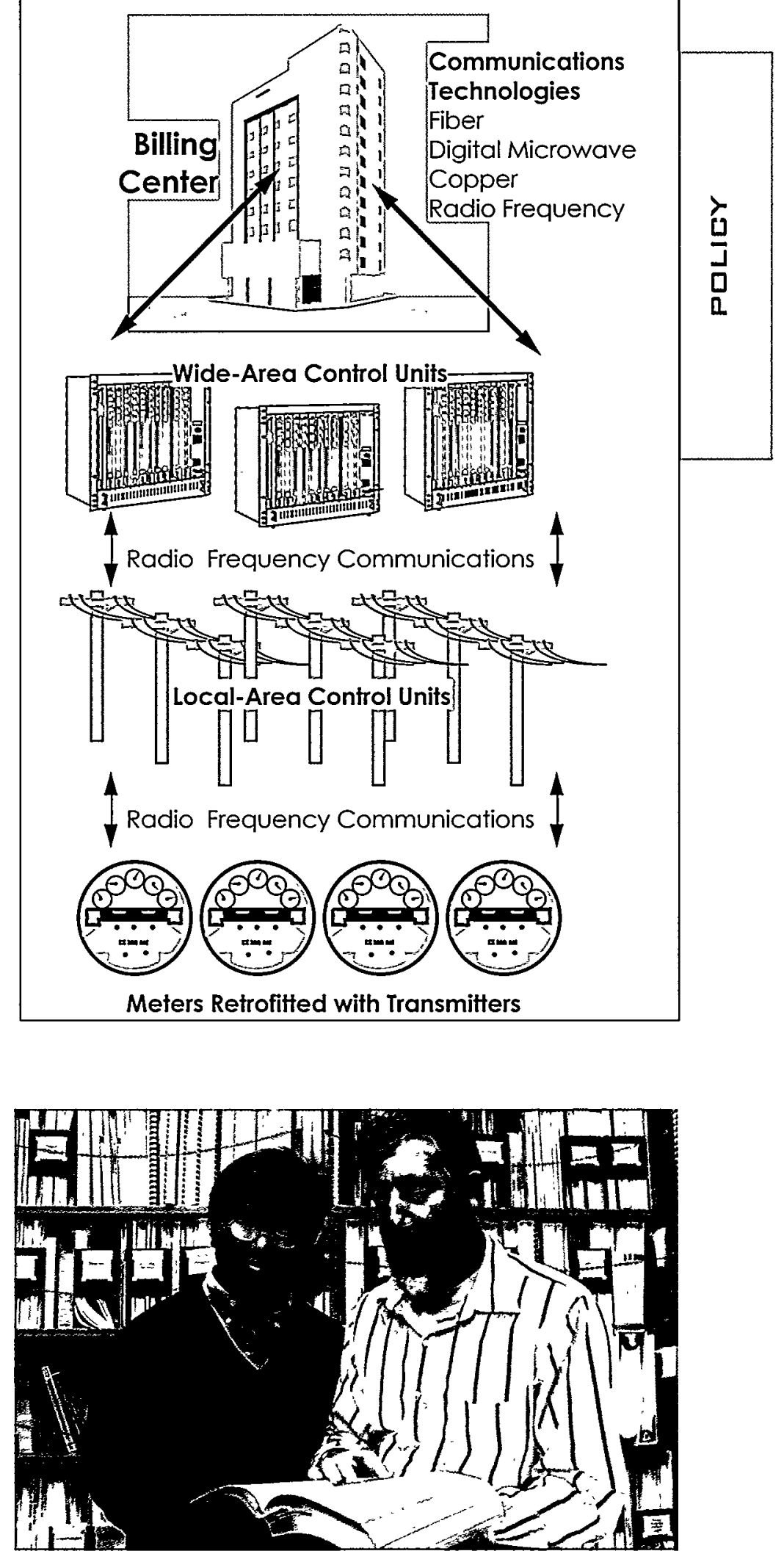


\section{Market Power and Transmission}

\section{S. Stoft, C. Webber, R. Wiser}

In a restructured electricity industry, the planning and operation of the transmission system will be integral to ensuring equitable and fair distribution of the benefits of a competitive market. We have studied a number of important technical issues associated with the way market power may be exercised through the operation of the transmission grid and, in particular, the role played by transmission pricing.

Transmission Pricing and Renewables: Issues, Options, and Recommendations reviews current transmission pricing policies and examines the effects of different pricing schemes on different work access based on energy rather than capacity As part of ry method of pricing transmission services. However, congestionbased pricing is insufficient to cover all costs of planning and operating the transmission system. This report shows that energy-based rather than peak-based charges are economically efficient, in combination with congestion charges, to recover the costs of the transmission system.

In 1996, California's three major investor-owned utilities filed an application (the "WEPEX" application) with the Federal Energy Regulatory Commission (FERC) to create an independent system operator (ISO) and power exchange (PX). Our Analysis of the California 'WEPEX' Applications to FERC demonstrates the important problems that would arise from adoption of the WEPEX recommendation to include a restrictive rule to prevent the proposed ISO from "clearing the market," i.e., ensuring that all profitable energy trades would be made. Based in part on our work, FERC's final order requires the ISO to use all the information it receives to develop a least-cost schedule, which would insure that all profitable trades are made.

In The Effect of the Transmission Grid on Market Pozver, we analyze the effect of transmission grid congestion on the physical extent of energy markets and thus on the degree of generators' market power. We find that, in an unregulated market, it will be socially beneficial to build a grid that has greater capacity than what has been optimal up to now in a regulated market. Finally, in the work titled How Financial Transmission Rights Curb Market Power, we demonstrate that, contrary to some prior claims, financial transmission rights can dramatically reduce the market power of generators when several generators face a congested transmission path and there is no local demand for electricity. These findings provide market designers and policymakers with a new and potentially powerful market-based tool for constraining the market power of generators.

\section{References}

Stoft, S., C. Webber, and R. Wiser. Transmission Pricing and Renewables: Issues, Options, and Recommendations. Lawrence Berkeley National Laboratory Report No. LBNL-39845. 1997. Downloadable.

Stoft, S. Analysis of the California WEPEX Applications to FERC. Lawrence Berkeley National Laboratory Report No. LBNL39445. 1996. Downloadable. See also Stoft, S. California's ISO: Why Not Clear the Market? The Electricity Journal 9 (10) 38-43, 1997, and Stoft, S. Transmission Pricing Zones: Simple or Complex? The Electricity Journal 10 (1) 24-31, 1997.

Stoft, S. The Effect of the Transmission Grid on Market Power. l_awrence Berkeley National Laboratory Report No. LBNL40479. 1997. Downloadable.

Stoft, S. How Financial Transmission Rights Curb Market Power. Lawrence Berkeley National Laboratory Report No. LBNL40568. 1997. Downloadable.
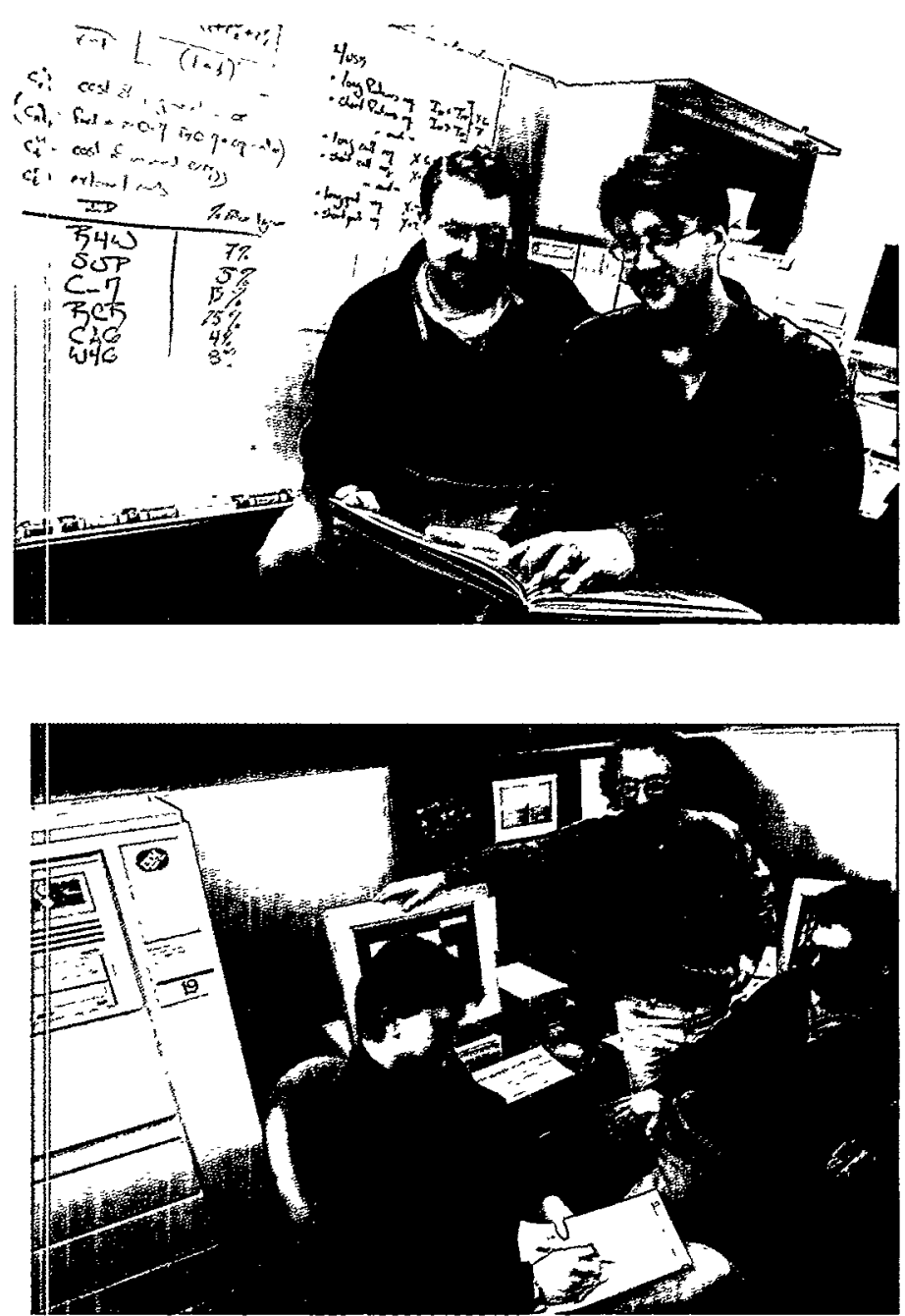


\section{Electricity/Industry Restructuring in Unique Cultural/Geographical Contexts}

\section{Marnay, S. Pickle, E. Vine, J. Busch}

Our recent work has also included studies of the effects of electricity industry restructuring in specific geographical and cultural contexts: power supply expansion in Poland, opportunities for ESCOs in Japan, and issues specific to native American tribes.

Power Supply Expansion and the Nuclear Option in Poland presents an analysis of electricity capacity expansion in that country. We conclude that natural gas is a highly desirable fuel for power generation in Poland but primarily for use as a peak resource. Nuclear power cannot be ruled out in Poland on economic grounds alone. Another report, International ESCO Business Opportunities and Challenges: A Japanese Case Study finds that current barriers to ESCOs in Japan might be overcome through the development of funding sources, education and training, demonstration projects, and a certification process. The study, American Indian Tribes and Electric Industry Restructuring: Issues and Opportunities, sponsored by the Native American Renewable Energy Education Project (NAREEP), concludes that although wholesale competition in the U.S. electricity industry is unlikely to harm most American Indian tribal interests and may benefit some tribes, retail competition is likely to be harmful. The report describes several options for tribes, including creating a tribal utility, aggregating tribal customers, regulating electricity industry service providers, becoming electricity suppliers, and developing grid-independent community or home energy systems.
This logo for the Native American Renewable Energy Education Project (NAREEP) symbolizes a commitment to research, education, and information exchange that assists American Indian and Alaskan and Hawniian Native communities in pursuing sustainable energy strategies.

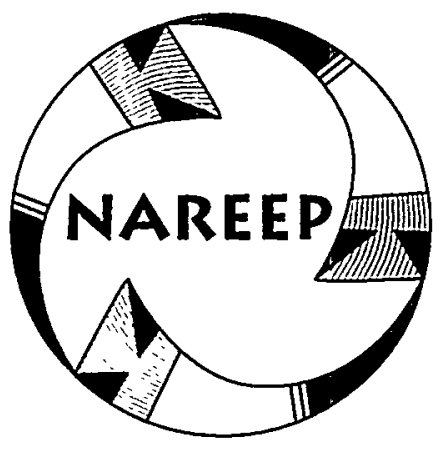

\section{References}

Marnay, C. and S. Pickle. Power Supply Expansion and the Nuclear Option in Poland. Lawrence Berkeley National Laboratory Report No. LBNL-40391. 1997. Downloadable.

Vine, E. and C. Murakoshi. International ESCO Business Opportunities and Challenges: A Japanese Case Study. In 1997 Conference and Annual Meeting of the Association of Energy Services Professionals, Dec. 8-10, 1997, Boca Raton, FL. Also available as Lawrence Berkeley National Laboratory Report No. LBNL-40809.

Howarth, D., J. Busch, and T. Starrs. American Indian Tribes and Electric Industry Restructuring: Issues and Opportunities. Lawrence Berkeley National Laboratory Report No. LBNL39804. 1997.

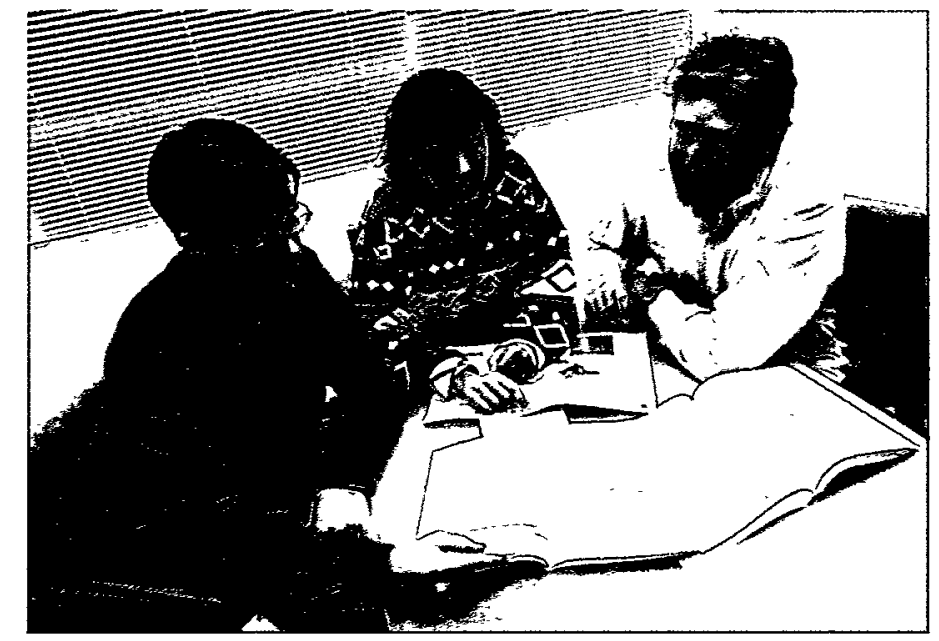

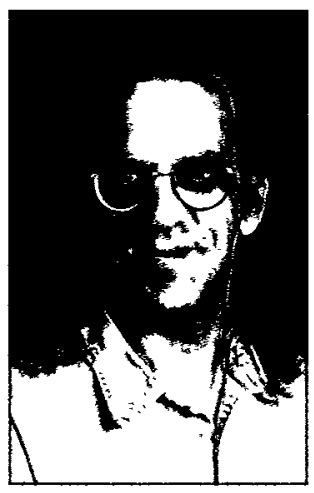




\section{Collaborative Restructuring Decision-Making}

\section{S. Wiel, S. Chaitkin}

The National Council on Competition and the Electric Industry (National Council) was formed in 1994 as a joint venture of the National Association of Regulatory Utility Commissioners and the National Conference of State Legislatures to facilitate dialogue and information exchange between the members of these two organizations. The Federal Energy Regulatory Commission is also an active participant in the National Council. Thus, the National Council provides a forum for the primary decision-makers who are restructuring the electricity industry in the U.S. In 1997, the

7 National Council turned to Berkeley Lab to provide an Executive

- Director and related support services. With DOE funding,

I. Stephen Wiel was appointed to serve as the Council's Executive

5 Director. Working with the Council's Steering Committee, we

$\prec$ have helped facilitate the organization's national workshops, assisted in the preparation of research reports and briefing papers, published the National Council's newsletter, and developed its web site. Our work focuses on restructuring issues relating to tax implications, market power, energy efficiency, renewable energy, public-interest $R \& D$, and customer information disclosure.

Visit the site at http://eetd.lbl.gov/NationalCouncil/

\section{Reference}

Blumstein, C., R. Scheer, and S. Wiel. Public Interest Research and Development in the Electric and Gas Utility Industries. National Council on Competition and the Electric Industry, 1998 (forthcoming).

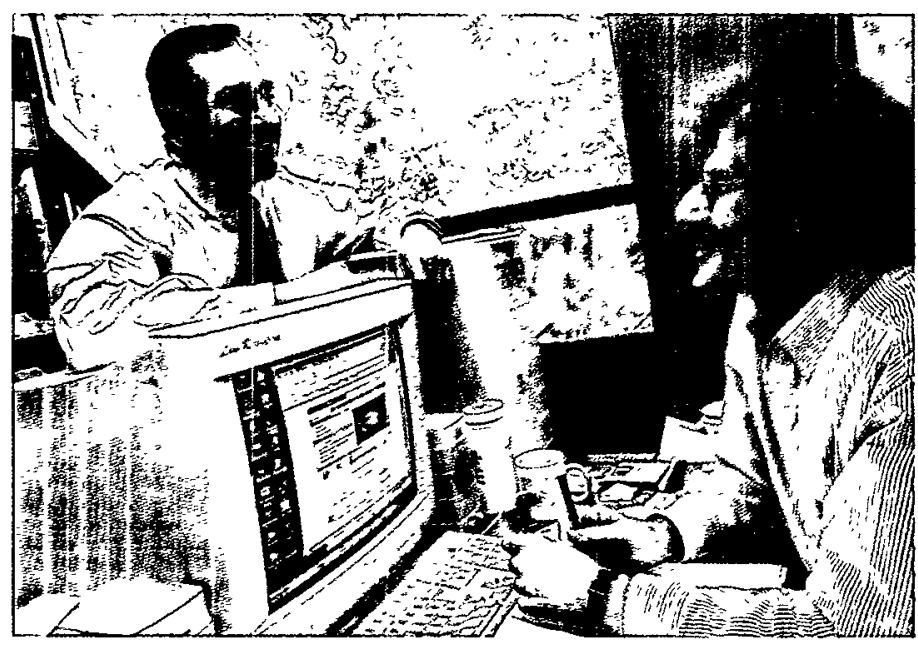


Mitigation of Heat Islands

Research on solutions to smog and energy waste caused by human-induced warming occurring in urban areas, with special emphasis on the development of more reflective surfaces for roadways and building surfaces.

Heat islands occur in cities where heat-absorbing buildings and dark pavements have replaced shade trees and shrubs, causing summer temperatures to rise up to 6 degrees $C$ higher than the surrounding countryside.

\section{Mesoscale Meteorological and Air Quality Impacts of Increased Urban Albedo and Vegetation}

\section{H. Taha}

Increasing the albedo (solar reflectance) of building materials and shading buildings with trees can directly save significant amounts of cooling energy at the building scale. By lowering the ambient temperature, these measures can also indirectly affect the air-conditioning energy use in buildings and improve ozone air quality in major U.S. airsheds.

We have made a first attempt at quantifying the potential air quality impacts of large-scale surface modifications in the Los Angeles Basin, using state-of-the-science mesoscale meteorologi$\mathrm{cal}$ and photochemical simulation models.

We found that large-scale implementation of reflective materials and urban forests has a net beneficial impact on ozone air quality. During our simulation of a typical summer day in August, population-weighted exposure to ozone above the California Air Quality Standard was decreased by up to $12-14 \%$ during peak hours and by up to $17-22 \%$ with respect to the national standard. These findings suggest that the net effects of increasing albedo and planting shade trees are comparable to those obtained from strict control of mobile-source emissions.

\section{Reference}

Taha, H. Mesoscale Meteorological and Air Quality Impacts of Increased Urban Albedo and Vegetation. Lawrence Berkeley National Laboratory Report No. LBNL-36887, 1997.

\section{Cooling Energy Savings Potential of Light-Colored Roofs}

\section{S. Konopacki, H. Akbari, M. Pomerantz, L. Gartland}

Light-colored roofs reflect more sunlight than dark roofs, and thus keep buildings cooler in summer and reduce air-conditioning demand. Typical roofs in the United States, however, are dark, which creates a potential for saving energy and money by changing to reflective roofs.

We have made quantitative estimates of the impact of using high-reflectance roofs on buildings' heating and cooling energy use for several prototypical buildings in 11 U.S. metropolitan areas. The results show:

- a total annual electricity savings of 2.6 terawatt hours (TWh),

- a net energy savings of \$194 million, and

- peak electricity demand savings of 1.7 gigawatt (GW).

Extrapolating the savings to the entire U.S., we estimate annual electricity savings of about 10 TWh and a net savings of about $\$ 750$ million in annual energy payments. Peak electricity power reduction is estimated to be about $7 \mathrm{GW}$.

\section{Reference}

Konopacki, S., H. Akbari, M. Pomerantz, K. Gabersec, and L. Gartland. Cooling Energy Savings Potential of Light-Colored Roofs. Lawrence Berkeley National Report No. LBNL-39433, 1997.
An infrared photo of a section of a roof taken at noon on a sumny summer day shows that the top white-coated portion of the roof is $16^{\circ} \mathrm{C}$ $\left(60^{\circ} \mathrm{F}\right)$ cooler than the lower, uncoated portion. Dark roof seams in the uncoated area show up as hot lines on the roof.

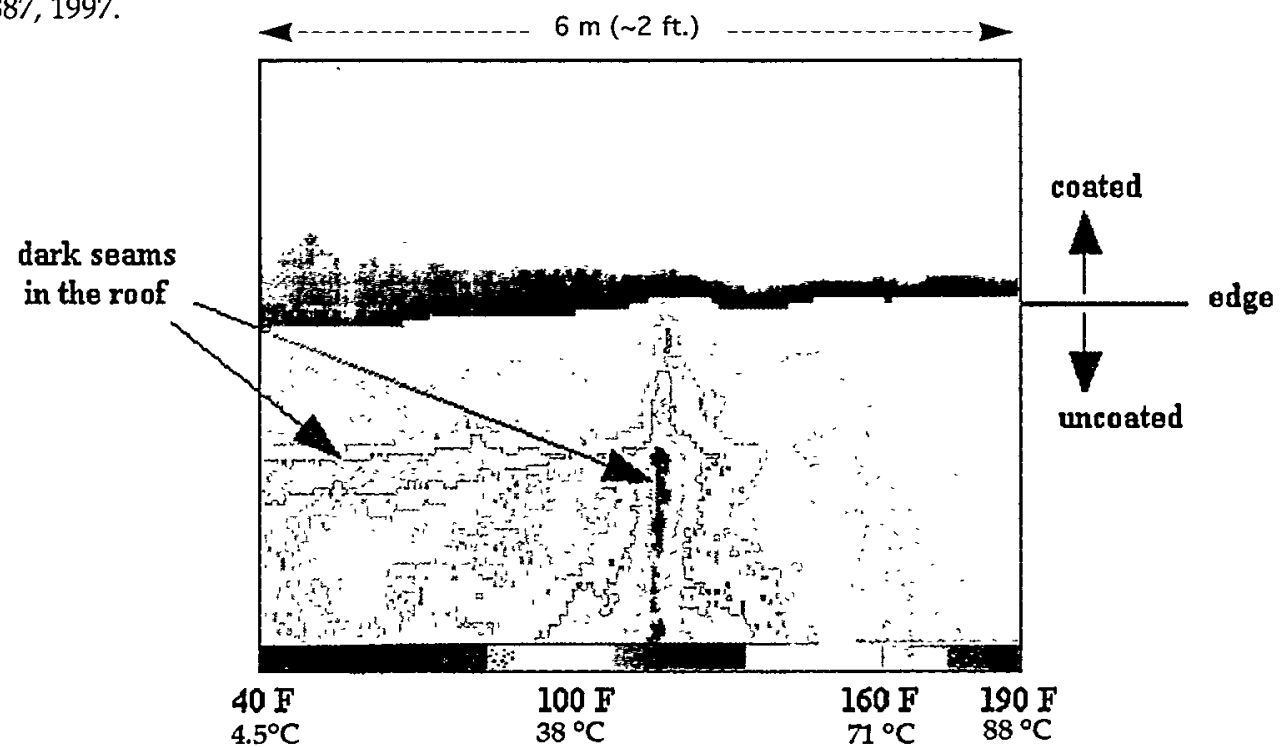




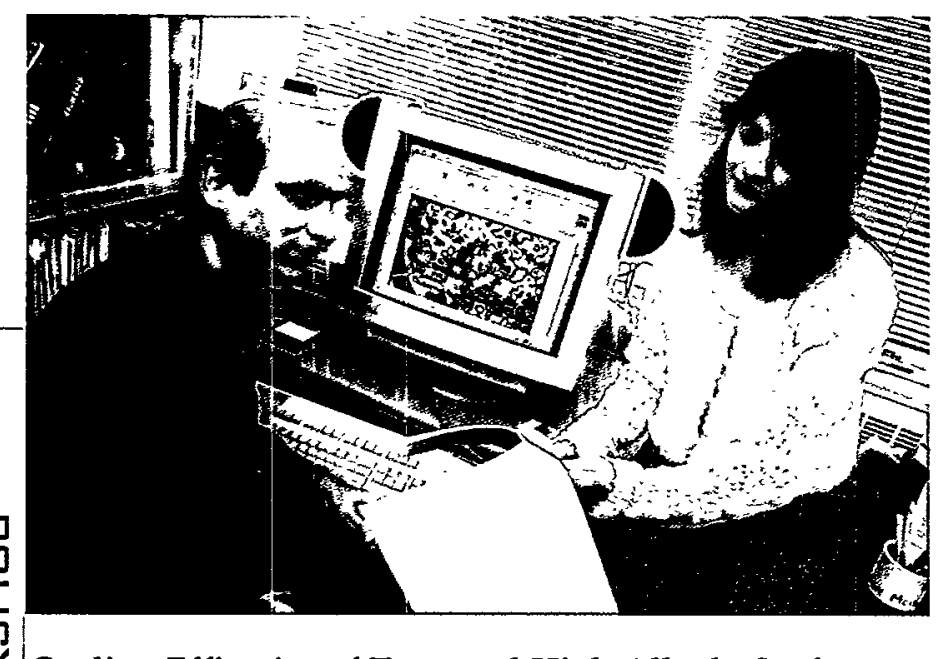

Cooling Efficacies of Trees and High-Albedo Surfaces

R. Leiinson

Daytime summer urban heat islands arise when the prevalence of dark-colored surfaces and lack of vegetation make a city warmer than the surrounding countryside. Two frequently proposed mitigation schemes are to plant trees and to raise the albedo (solar reflectivity) of ground surfaces.

We found that increasing the albedo of a ground surface lowers the surface temperature of an object near the ground - e.g., people, vehicles, and buildings - only if the object's albedo exceeds a critical value that depends on wind speed, object geometry, and the height of the atmospheric thermal boundary layer. The tem- perature of the air in contact with a reflective surface, however, is always lowered. Planting a tree was found to yield either a small decrease or a small increase in solar heating of ground-level air, depending on (a) the extent to which the solar heating of the tree's canopy is dissipated by evaporation, and (b) the fraction of air heated by the canopy that flows downward and mixes with the ground-level air.

\section{Reference}

Levinson, R. Near-Ground Cooling Efficacies of Trees and High-Albedo Surfaces. Ph.D Thesis, Energy and Resources Group, University of California, Berkeley. Lawrence Berkeley National Laboratory Report No. LBNL-40334, 1996.

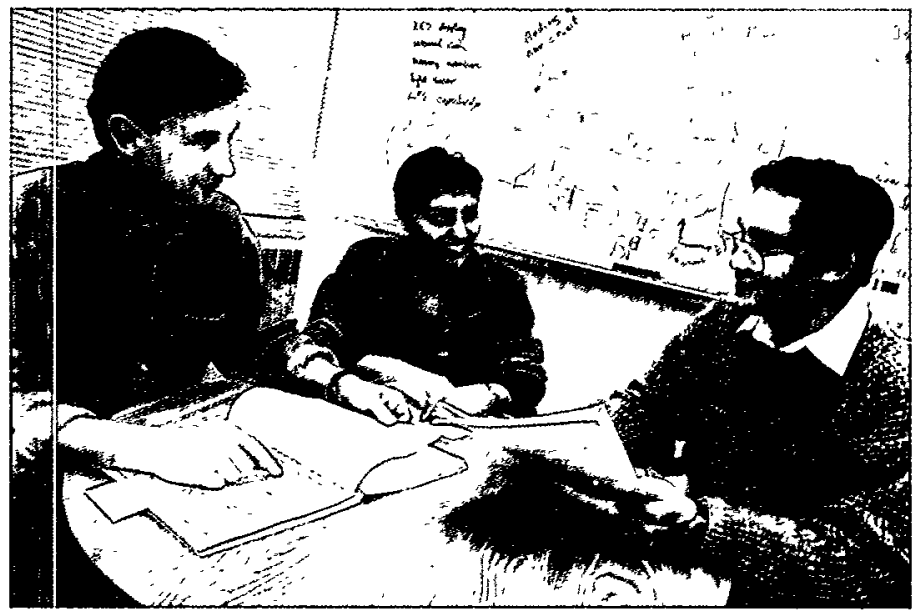

A load cell beneath the tree sitting on a roof at LBNL senses changes in the tree's mass, while nearby instruments measure air temperature, humidity, wind speed, and other ambient environmental conditions.

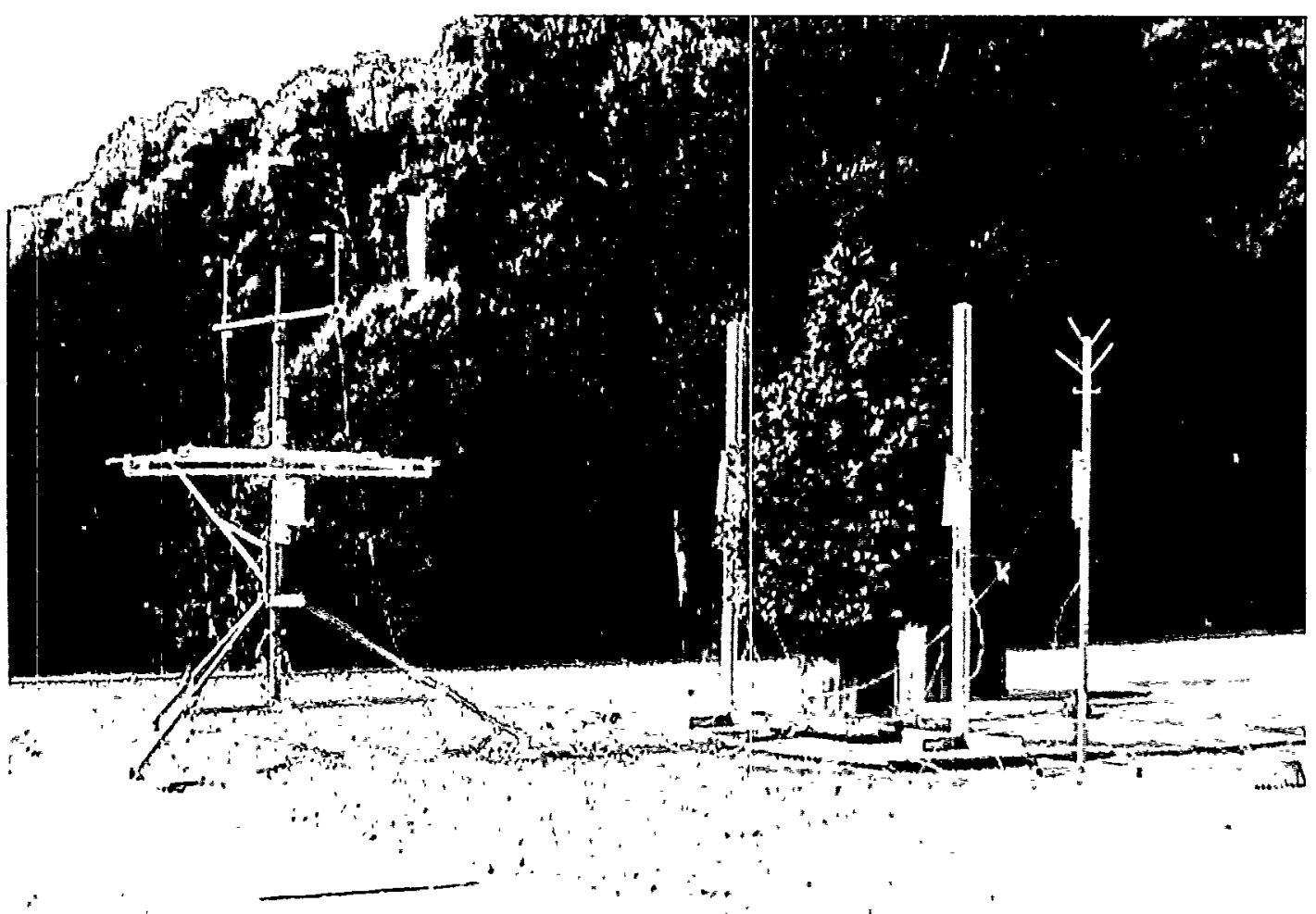



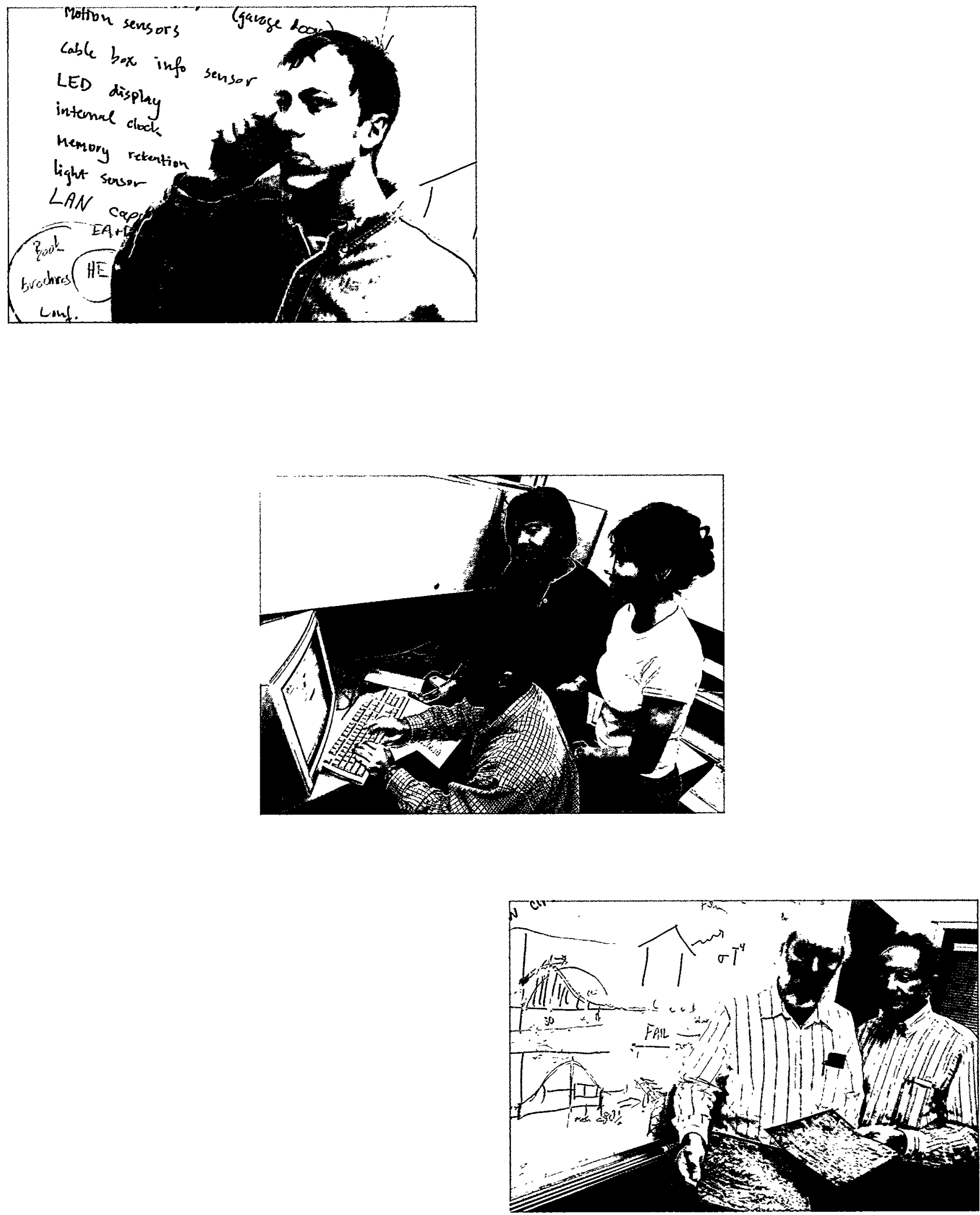


\section{Building Energy End-Use Forecasting}

Research to deliver to policymakers the latest information on current and expected future characteristics of markets for efficient products in the building sector.

\section{Energy Data Sourcebook for the U.S. Residential Sector}

\section{T. Wenzel, J. Koomey, G. Rosenquist, M. Sanchez}

Analysts assessing policies and programs to improve energy efficiency in the residential sector require diverse input data from a variety of sources. This sourcebook, which updates a previous report, is a compilation of these input data presented in one document. The data provided include information on end-use unit energy consumption (UEC) values of appliances and equipment, historical and current appliance and equipment market shares, appliance and equipment efficiency and sales trends (see, for example, sales of cooling equipment shown below), appliance and equipment efficiency standards, cost vs. efficiency data for

a appliances and equipment, product lifetime estimates, thermal 다이 characteristics of buildings, heating and cooling loads, shell $\Gamma$ measure cost data for new and retrofit buildings, baseline housing stocks, forecasts of housing starts, and forecasts of energy $\mathbf{Z}$ prices and other economic drivers. This report is the essential I. sourcebook for policy analysts interested in residential sector in energy use.

\section{Reference}

Wenzel, T., J. Koomey, G. Rosenquist, M. Sanchez, and J. Hanford. Energy Data Sourcebook for the U.S. Residential Sector. Lawrence Berkeley National Laboratory Report No. LBNL-40297, 1997. Downloadable; http://enduse.lbl.gov/projects/RED.htmI

\section{Lighting Market Sourcebook for the U.S.}

D. Vorsatz (Central European University, Budapest, Hungary), L. Shown, J. Koomey, M. Moezzi, A. Denver, B. Atkinson

Throughout the United States, in every sector and building type, lighting is a significant electrical end use. There are potentially large, cost-effective, energy savings to be achieved in this end use but because consumers most often do not adopt cost-effective lighting technologies on their own, programs and policies are needed to promote their adoption.

We have prepared a sourcebook for policymakers that identifies patterns of lighting energy use and provides data characterizing the marketplace in which lighting technologies are distributed, promoted, and sold. We examine residential and commercial

U.S. sales of central air conditioners and heat pumps reflect the national cycles in new housing starts.

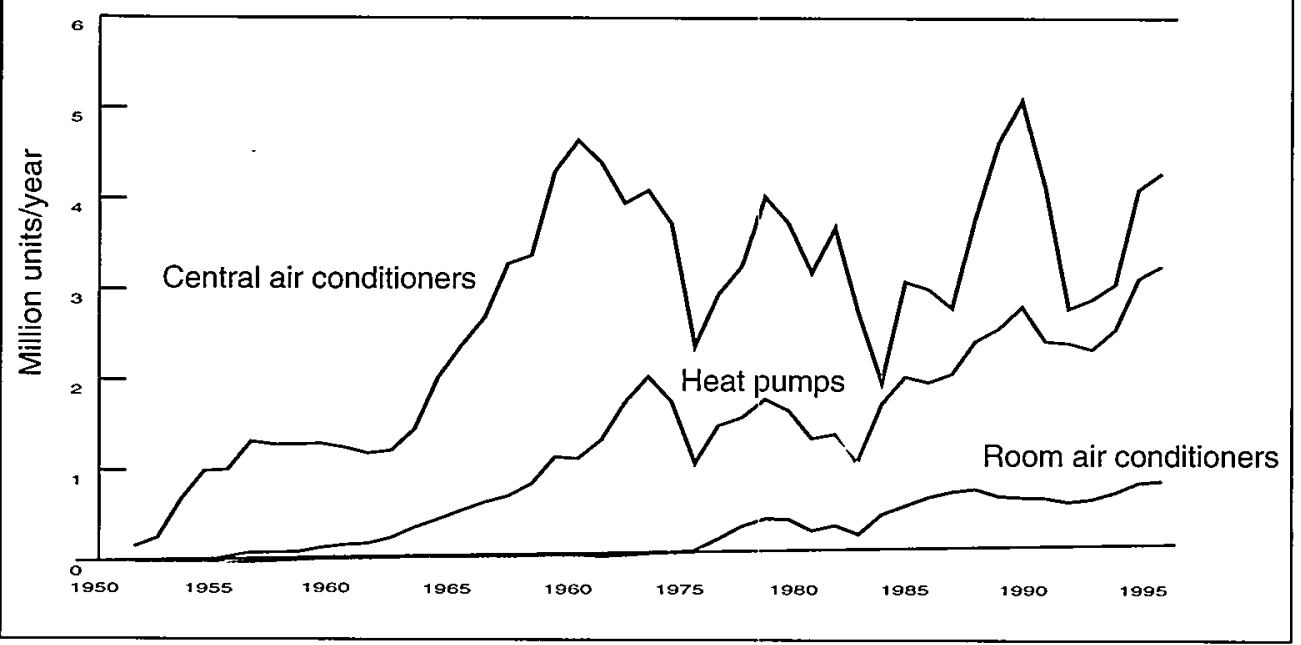


Annunl lighting energy consumption and installed lamp wattage in households by room type. One can see that kitchens, for example, accounted for nearly $19 \%$ of lighting energy consumption although only $11 \%$ of installed wattage, making them one of the best targets for replacing incandescent lamp with fluorescents. Almost $18 \%$ of installed lighting wattage is in bedrooms, more than for any other room type, but bedroom lamps are used relatively little despite their preponderance, and thus comprise only the fourth most important room type in terms of total lighting energy consumption.

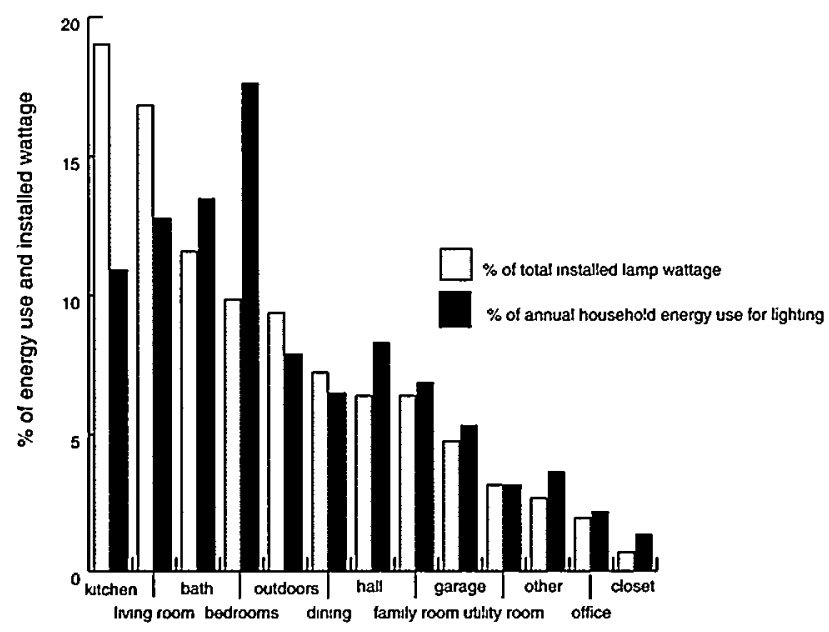

lamps, ballasts, fixtures, and lighting controls.

This sourcebook will help policymakers answer important market-related questions such as:

- Who uses which lighting technologies and how much do they use them?

- What market shares do various technologies represent and how have these market shares changed over time?

- Who are the key participants in the lighting marketplace?

- Which distribution channels do these key participants use?

In addition, we discuss the policy implications of lighting energy use and current market conditions. We also address technical characteristics of lighting products, including lamps, ballasts, fixtures, and lighting controls.

\section{Reference}

Vorsatz, D., L. Shown, J. Koomey, M. Moezzi, A. Denver, and B. Atkinson. Lighting Market Sourcebook for the U.S. Lawrence Berkeley Laboratory Report No. LBNL-39102, 1997. Downloadable; http://enduse.lbl.gov/projects/LMS.html

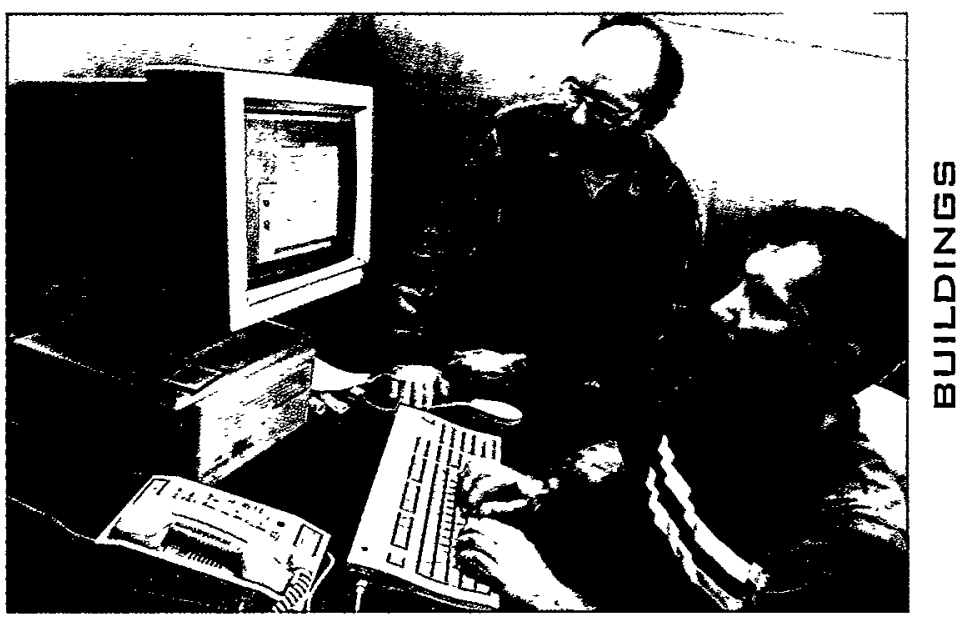

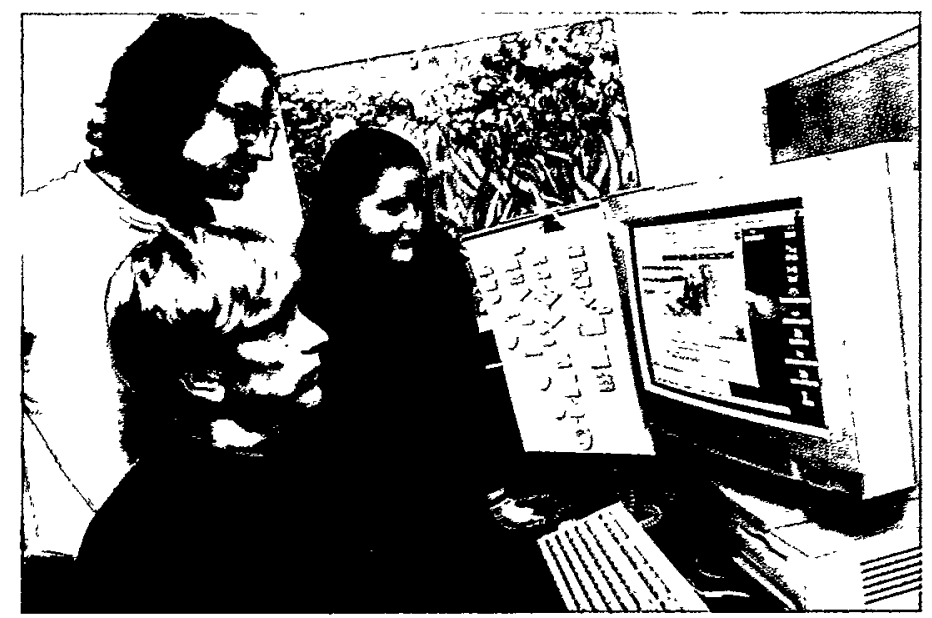




\section{Miscellaneous Electricity in the U.S. Residential Sector}

\section{Sanchez, J. Koomey, M. Moezzi, A. Meier, W. Huber, C. Webber}

Historically, U.S. residential energy and carbon emissions-saving efforts have targeted conventional end uses such as water heating, lighting, and refrigeration. The emergence of new household appliances has transformed energy use from a few large and easily identifiable end uses into a broad array of "miscellaneous" energy services. This group of so-called miscellaneous appliances has been a major contributor to growth in electricity demand in the past two decades.

Based on shipments, lifetimes, and wattage data from 1976 to 1995 for over 90 individual products, we constructed a bottom-up end-use model. The model was then used to produce historical and forecasted growth trends and to identify the most energyconsuming individual products within the miscellaneous category. We also used the end-use model to identify and analyze policy priorities. From 1995 to 2010, the miscellaneous end use is expected to be one of the fastest growing residential electricity end uses.

We found that roughly $40 \%$ of the projected miscellaneous growth is due to consumer electronics products - TVs, VCRs, audio systems, home office equipment, microwave ovens, etc. making this component of miscellaneous electricity a particularly fertile area for efficiency programs. One method of reducing electricity consumption in electronic products is to focus on reducing standby losses. Nearly one-half of the energy use in household electronics is consumed while in standby (ready) mode. The potential savings from reducing standby losses equal 30 TWh/year, roughly $\$ 2-3$ billion dollars annually.

\section{Reference}

Sanchez, M.C. Miscellaneous Electricity Use in U.S. Residences. M.S. Thesis, University of California, Berkeley, 1997. Lawrence Berkeley National Laboratory Report No. LBNL-40295.

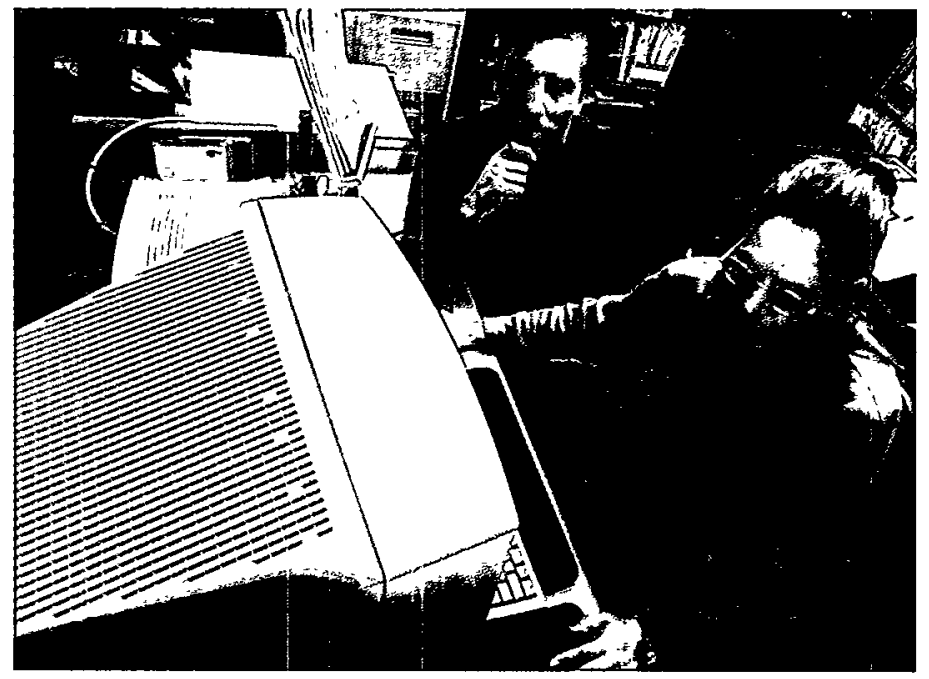

Disaggregation of residential miscellaneous energy use by major end-use category.

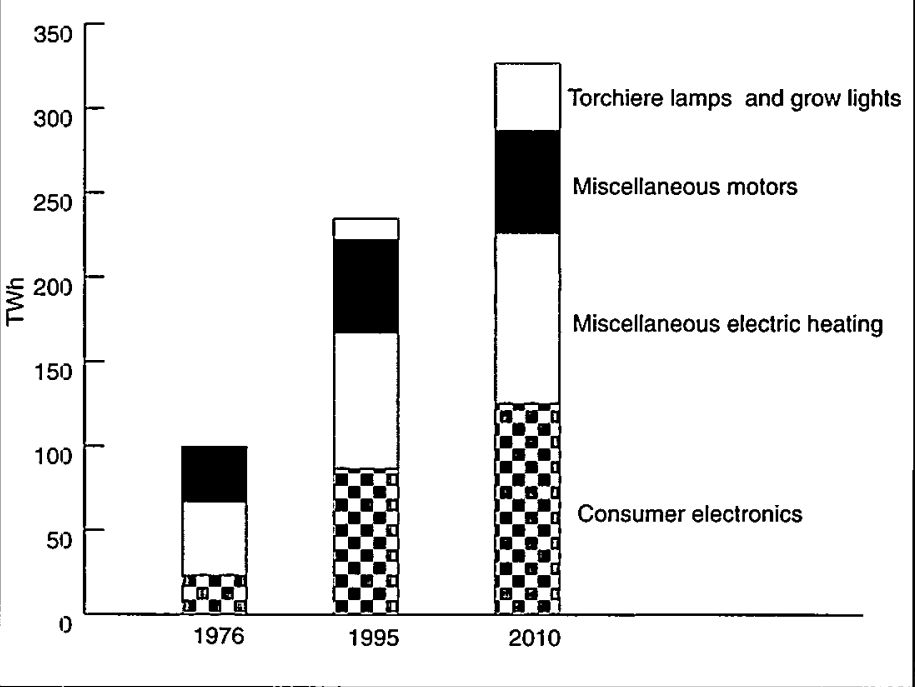


B uilding Energy Measurement and Performance Analysis

\author{
Research into energy use testing, field measurement, monitoring, and verification of energy-consuming \\ equipment and energy-saving projects in the building sector.
}

\section{Integrated Information Technologies for Commercial Building Performance Assurance}

M.A. Piette, A.O. Sezgen, S. Selkowitz and R. Hitchcock (Building Teclmologies Dept., EETD, LBNL), F. Olken and C. McParland, (Information and Computing Sciences Division, LBNL), B. Smith (Indoor Environment Dept., EETD, LBNL), D. Sartor (Center for Building Science, EETD, LBNL)

Buildings consume one-third of all energy used in the U.S. at a cost of over $\$ 200$ billion annually - as much as half of which is wasted compared to what is cost-effectively achievable. Assuring total building performance, which includes health, comfort, and productivity in addition to operating expense such as energy costs, is a priority in an increasingly competitive world. Achieving this goal requires a careful examination of the process by which buildings are designed, built, and operated.

Architects, engineers, building owners, and operators currently use a variety of software and information management tools to improve the energy efficiency of new and existing buildings, primarily in the design phase of new construction or retrofitting. Each tool may be sophisticated in terms of its ability to simulate some aspects of the energy performance of buildings, but each requires users to re-enter building-related data they may already have entered in another program - such as a computer-aided design (CAD) package. Much of the valuable information collected earlier in the life cycle is not in the format needed by the new tools. Furthermore, once the building is operational, real performance data becomes available but is rarely integrated into the simulation tools, in part because of the technical difficulties of adding a new data stream to the existing building descriptions. Too often there is no feedback at all between operations and design. Plus, every time new data are entered or translated from one program to another, there is the strong possibility of the introduction of errors into the data. Another reason buildings do not perform in an optimal, energy-efficient manner is that critical information needed to improve designs and ensure optimal operation is often not accessible, lost, or poorly documented. This loss of information is endemic in the highly complex, fragmented, and often adversarial nature of the building industry.

A multi-division group at LBNL has created the Integrated Information Technology Initiative to address these myriad problems. One goal of this activity is to initiate the development and standardization of integrated, interoperable information technologies to address the problems of fragmented information transfer in the building life cycle. The box below outlines some problems in today's buildings, and the features offered by "tomorrow's" integrated information technologies. The tools we are developing are individually optimized to respond to the specific needs of each phase of the building's life, and are linked by a shared information infrastructure, a Building Life-cycle Information SyStem (BLISS). The BLISS project has had three major elements: a distributed software architecture, a life-cycle database, and a mechanism to capture "intent." The distributed systems architecture describes how various building software components communicate and the schema specifies the structure and semantics of the database.

A related problem is that buildings and their various subsystems often do not perform as well as intended in the design stage. Building energy performance suffers from insufficient documentation of design intent, inadequate building commissioning, and a lack of robust methods for short-term and continuous performance tracking. Several case studies have shown whole-building energy savings of $20 \%$ or more through changes in operation and maintenance $(O \& M)$ practices based on evaluations of detailed energy performance monitoring. Three demonstration projects

Todny's problems and solutions offered by integrated information technologies.

Life-Cycle Phase

Design

Commissioning

Operations
Today

No reference to energy performance. Performance continuously assessed using simulation tools coupled No archive of key assumptions and intent.

No energy performance testing.

No monitoring of energy use or feedback to design.
Tomorrow

to design data base. Interoperable data base records equipment, system, and whole-building design intent and operational sequences.

Systematic performance testing before acceptance by owner. Tests results linked to original design intent, with changes noted and impacts evaluated.

Energy monitored continuously and compared with on-line simulation derived from commissioning results. Diagnostic procedures initiated by significant discrepancies. Feedback results to design. 
have been underway to explore techniques and methods to address these problems. These demonstrations are described below.

A multi-departmental group within the Environmental Energy Technologies Division developed a performance-tracking tool based on a calibrated chiller model and demonstrated how such tools can be used. The following Figure shows the results of various design and operating changes. This project is part of a larger effort to develop building life-cycle information systems, which with widespread use could greatly reduce the performance problems related to poor information transfer and lead to large energy savings.

Performance of a chiller in a university building under different scenarios.

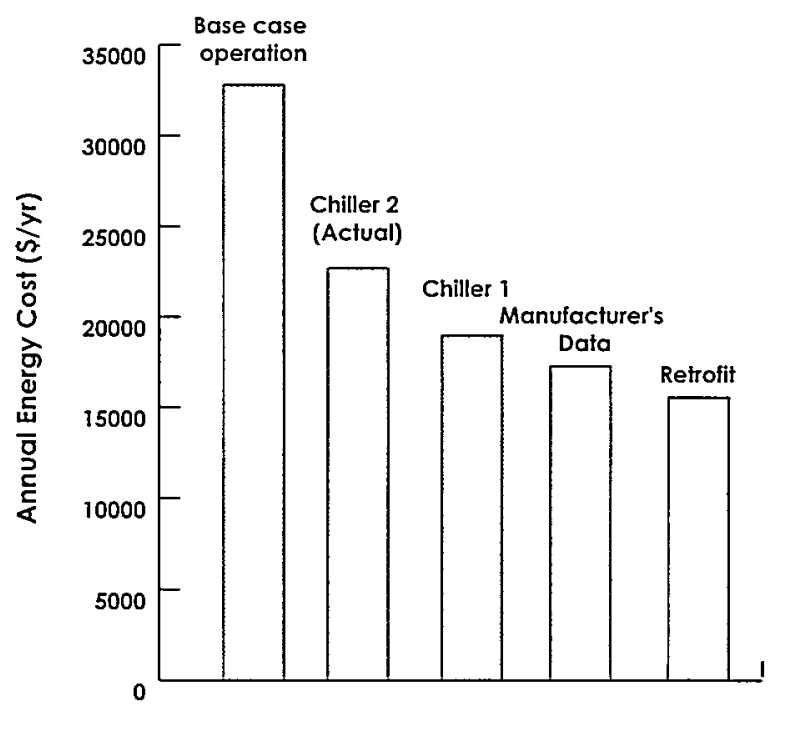

In a second project, a multi-institutional team has developed a prototypical Information Monitoring and Diagnostics System (IMDS) to address common O\&M problems and pinpoint the facts needed by office building owners and property managers in order to address these problems. The purpose of the IMDS is to present a set of standard diagnostics plots to evaluate key performance metrics and curves and identify opportunities for energy improvements. An example plot is presented in the Figure in the next column. This project is part of a multi-year effort that includes testing the prototypical system in an actual building.

Thirdly, we have developed a prototype system to permit remote monitoring and control of multiple buildings across the Internet from a single control center. Such a system is of interest to operators concerned with multiple buildings, such as building management firms, school districts, and large retailers. An electronic gateway between the energy management and control system and the Internet was built using a common interface. Data are stored in a relational database which is linked to a standard set of graphics to allow for the evaluation of key performance data. This project is part of a multi-year effort that includes testing the prototypical system in several buildings.

For more information, see http://eetd.lbl.gov/CBS/BPA/BPA.html

\section{References}

Olken, F., C. McParland, M.A. Piette, D. Sartor, and S. Selkowitz. Remote Building Monitoring and Control. In Proceedings of the ACEEE 1996 Summer Study on Energy Efficiency in Buildings, August 25-30, 1996. Washington, DC: American Council for an Energy-Efficient Economy, 1996. Vol. 4, pp. 4.285-295. Also available as Lawrence Berkeley National Laboratory Report No. LBNL-38827, 1997.

Piette, M.A., G. Carter, S. Meyers, O. Sezgen, and S. Selkowitz. Model-Based Chiller Energy Tracking for Performance Assurance at a University Building. Lawrence Berkeley National Laboratory Report No. LBNL-40781, 1997.

Sebald, A. and M.A. Piette. Dingnostics for Building Commissioning and Operations. Lawrence Berkeley National Laboratory Report No. LBNL-40512, 1997.

An analysis of a chiller efficiency reveals three problem areas.
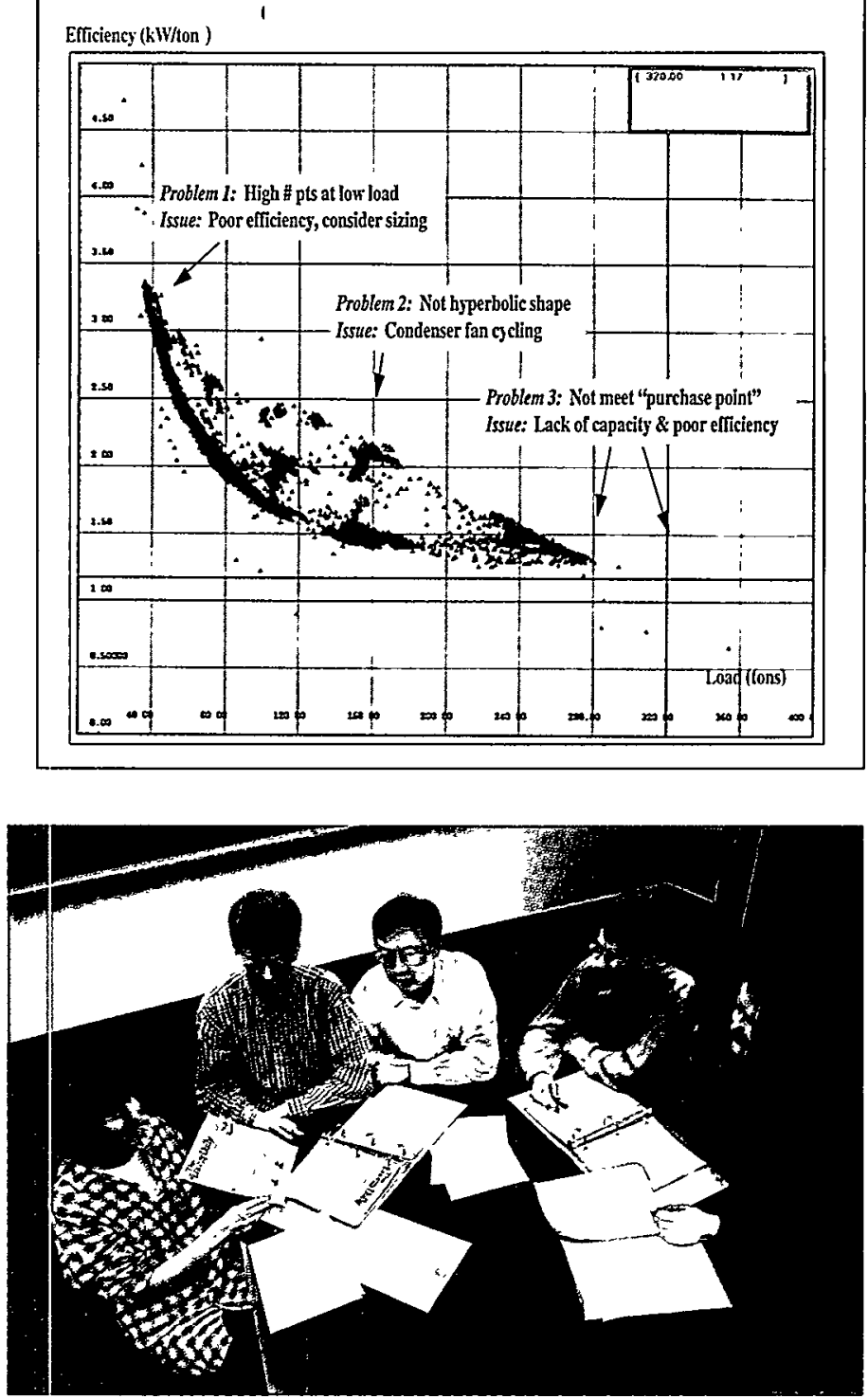


\section{Mandatory and Voluntary Approaches for Promoting Energy Efficiency in Residential Construction}

\section{E. Vine, A. Meier, J. Stein}

Two projects focused on promoting energy efficiency in residential construction: an analysis of residential building code compliance, and an evaluation of home energy rating systems.

Knowing how well builders comply with (or exceed) energyrelated building codes is critical for completing a sound evaluation of utility residential new construction (RNC) programs and for determining the actual cost-effectiveness of these programs. Obtaining credit from utility regulators for additional energy savings from code compliance in participant houses is one of the key options available for utilities for improving the cost-effectiveness of these programs. We examined residential building energy code compliance and specific code violations in three states (California, Oregon, and Washington). We compared residential building energy code compliance for program participants and nonparticipants as well as estimates of the energy-savings impacts from noncompliance. We found that homes may fall below code and also that homes participating in utility RNC programs may have higher frequency and levels of building compliance compared to nonparticipating homes. For example, in the evaluation of the Pacific Gas and Electric Company's (PG\&E) 1992 RNC program, nonparticipating homes in PG\&E's service territory were, on average, built about $6 \%$ below (i.e., did not meet) state building energy codes (based on calculated energy usage) across all measures and equipment. In contrast, PG\&E's program required participating builders to participate in the program's Plan Check process to comply with the codes when they might not have otherwise done so (i.e., $100 \%$ compliance). Accordingly, PG\&E claimed additional energy savings from its program through its role in enforcing compliance with the energy codes. We expect the differences in compliance to be greater in those states with less experience and expertise in building energy codes and energy code compliance. Accordingly, we believe utility RNC programs in other states could be more cost-effective if utility regulators recognize the role of RNC programs in increasing compliance with codes.

In the evaluation of home energy rating systems (HERS), we found that HERS can, on average, accurately predict annual energy cost for the 500 houses in four states that were used in our study. However, on an individual house basis, the agreement between predicted energy cost and actual energy cost was often poor, especially for older houses. Individual variation is to be expected because actual occupant behavior differs from the behavior assumed by the HERS estimation tools; however, this has important implications for the true cost effectiveness of HERS-recommended improvements. Contrary to expectation, there was no clear relationship between rating score and actual energy cost. HERS providers need to give consumers more information about accuracy and how to interpret ratings.

\section{Reference}

Vine, E. Residential Building Code Compliance: Implications for Evaluating the Performance of Utility Residential New Construction Programs. Energy-The International Journal 21 (12) 1051-1058, 1996. Also available as Lawrence Berkeley Laboratory Report No. LBL-38382.

Stein, J. Home Energy Rating Systems: Actual Usage May Vary. Hone Energy 14 (5) 21-27, 1997.
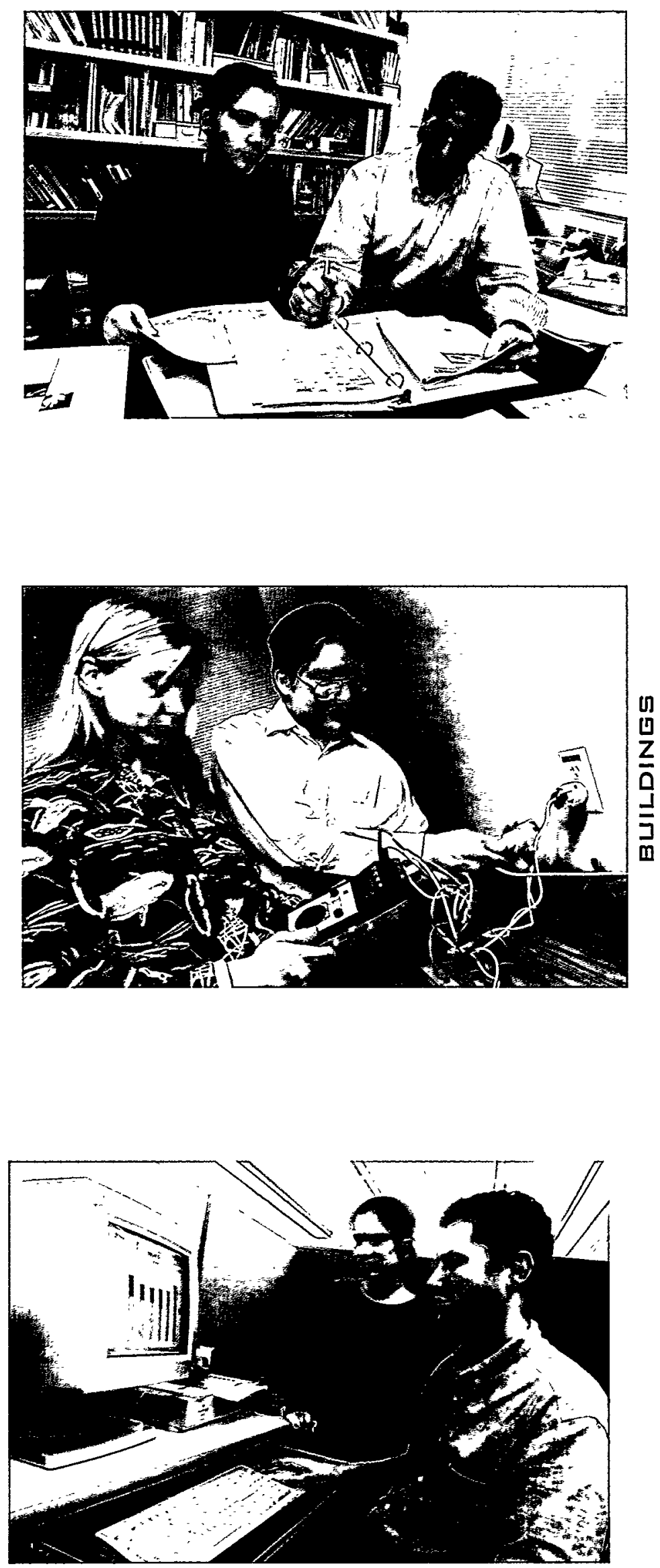


\section{Monitored Energy Use of Homes with Geothermal Heat Pumps: A Compilation and Analysis of Performance}

\section{J. Stein, A. Meier}

Geothermal (or ground source) heat pumps are an effective means of heating and cooling residences. In order to better understand the economics of such systems, it is essential to evaluate the energy savings from geothermal heat pumps compared to other systems. A total of 87 geothermal heat pump (GHP) houses in 10 states were compared to appropriate control houses that were either the GHP houses themselves before being retrofitted with GHPs or houses of similar size, location, and construction. In order to make the comparisons as accurate as possible, we normalized for differences between the GHP and control houses in terms of heating degree days during the monitoring period and floor area or total insulation value, as appropriate. The data, which were primarily supplied by utilities, were not necessarily a representative sample. In some cases, we also knew very little about the circumstances of data collection or the appropriateness of some of the controls.

The predicted savings were consistently slightly below the expected savings but still within the range of performance commonly cited by the GHP industry. The average rated coefficient of performance (COP) equalled 3.4: average measured COP equalled 3.1. Based on measured COPs, the GHP houses were predicted on average to save $66 \%$ of HVAC energy compared to W electric resistance homes and $42 \%$ compared to air-source heat ․ pump (ASHP) houses.

The actual savings, however, were inconsistent and sometimes $\underline{Z}$ significantly below the predicted savings. Based on COP mea$Z$ surements, $15 \mathrm{GHP}$ homes in Virginia were predicted to save $37 \%$ G] of HVAC energy compared to a set of ASHP homes but actually

in saved only $27 \%$. HVAC savings ranged from $-20 \%$ to $68 \%$ and whole house savings ranged from $4 \%$ to $36 \%$. On average, the GHP homes saved as much energy as predicted compared to ASHP homes but less than predicted compared to electric resistance homes.

\section{Reference}

Stein, J.R. and A. Meier. Monitored Energy Use of Homes with Geothermal Heat Pumps: A Compilation and Analysis of Performance. Lawrence Berkeley National Laboratory Report No. LBNL-40189, 1997.

\section{A geothermal system circulates water or antifreeze through a closed- loop network of plastic pipe that is buried in the ground.}

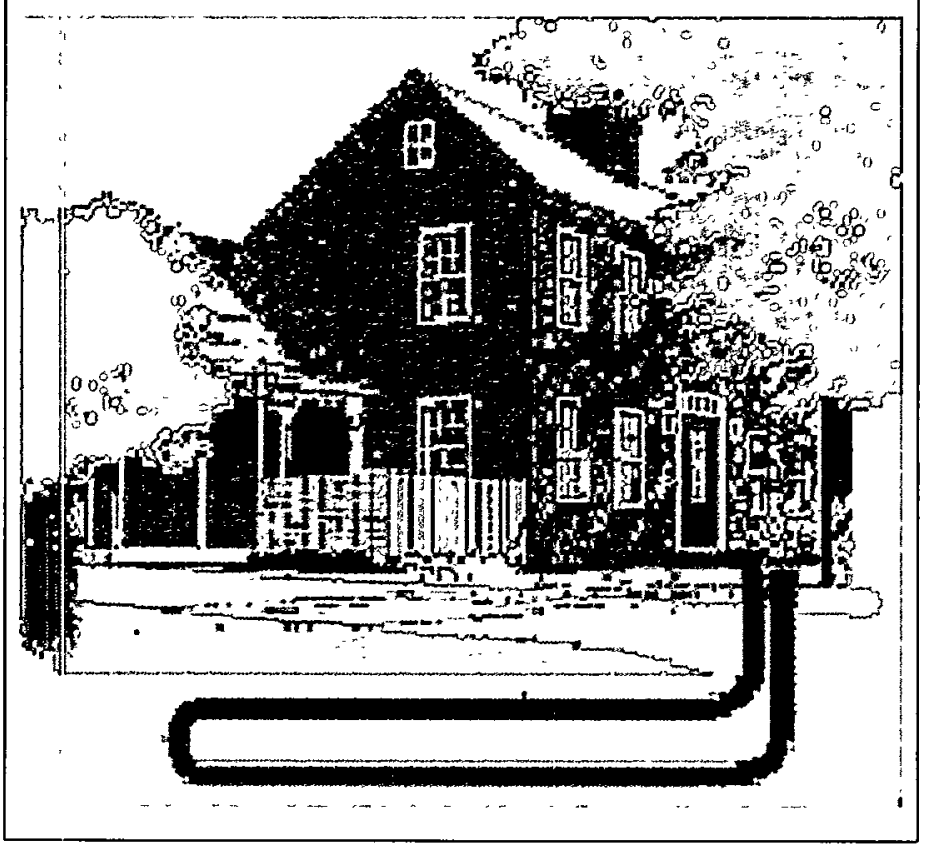




\section{Office Equipment: Energy Efficiency Research and Information}

\section{B. Nordman, M.A. Piette, A. ten Cate, C. Webber, K. Kinney}

Office equipment energy use has been rising steadily in the U.S. over the last decade, with PCs and monitors alone accounting for about 14 billion $\mathrm{kWh} /$ year of electricity. As a response to this increase, power-management technologies have been developed and deployed which reduce power use during times when the device is idle. We have conducted research to help design, evaluate, and improve energy savings in office equipment.

Office copiers use energy both in direct use of electricity and that embodied in the paper they use. To identify and realize energy savings, it is necessary to have accurate and valid test procedures for copiers. We compared the standard test results with actual monitored electricity use for three copiers. We found that they agreed closely enough to be useful for evaluating the energyefficiency of the copier, except for the amount of time in the lowpower state. The test results were then used to design the criteria for the ENERGY STAR copier program.

We evaluated PC power management systems and concluded that most are not properly enabled. Problems arise from lack of awareness about the presence of power management, incompatibility with networks, and user dissatisfaction with delays or interference with software. Most power management savings are currently from monitors, amounting to about $200 \mathrm{kWh} /$ year per monitor; power management has the potential to cut PC and monitor energy use in half. Newer systems tend to be more successful than the first generation of power-management technologies, so that more savings may accrue in the future. However, the rapid pace of change complicates our ability to predict how information technology and related energy-savings features will evolve.

In response to finding power management disabled in many PCs and monitors, we prepared a guide to help computer support professionals understand how power management works, how to enable it, and how to diagnose and fix many common problems. The schematic opposite illustrates suggested steps for reducing monitor energy use. If the information is widely distributed and utilized, millions of PCs and monitors that do not presently power manage could be made to successfully do so.

Energy-saving features in copiers include power management as well as duplexing options, which offer consumers energy and cost savings on paper purchase and use. However, these features are often disabled before the equipment is put into use. To reach the thousands of copier sales and service representatives responsible for the installation and maintenance of copier equipment, we developed a "Copier Tool Kit" intended for use in training efforts. The kit provides sales tips describing the environmental and economic benefits of using the features, training information for dealers, answers to frequently asked questions, and many sample materials for education and advertising. Working with manufacturers indicates that the information is greatly needed and use of the materials will increase the enabling rate of power management features.

See http://enduse.lbl.gov/esoe/CTKintro.htm for an on-line version of the Copier Tool Kit.

\section{References}

Nordman, B., M.A. Piette, K. Kinney, and C. Webber. User Guide to Power Management for PCs and Monitors. Lawrence Berkeley National Laboratory Report No. LBL-39466, 1997.

Dandridge, C.D., L.K. Norford, and B. Nordman. Monitoring Energy Use of Copiers to Determine Program Design and Potential Savings for the ENERGY STAR Copier Program. In Proceedings of the ACEEE 1996 Summer Study on Energy Efficiency in Buildings, August 25-31, 1996. Washington, DC: American Council for an Energy-Efficient Economy, 1996. Vol. 4, pp. 4-7786. Also available as Lawrence Berkeley National Laboratory Report No. LBNL-39552.

Nordman, B., M.A. Piette, and K. Kinney. Measured Energy Savings and Performance of Power-Managed Personal Computers and Monitors. In Proceedings of the ACEEE 1996 Summer Study on Energy Efficiency in Buildings. August 25-31, 1996. Washington, DC: American Council for an EnergyEfficient Economy, 1996. Vol 4. pp. 4-267-278. Also available as Lawrence Berkeley National Laboratory Report No. LBNL38057.

How to optimize PC monitor energy savings.

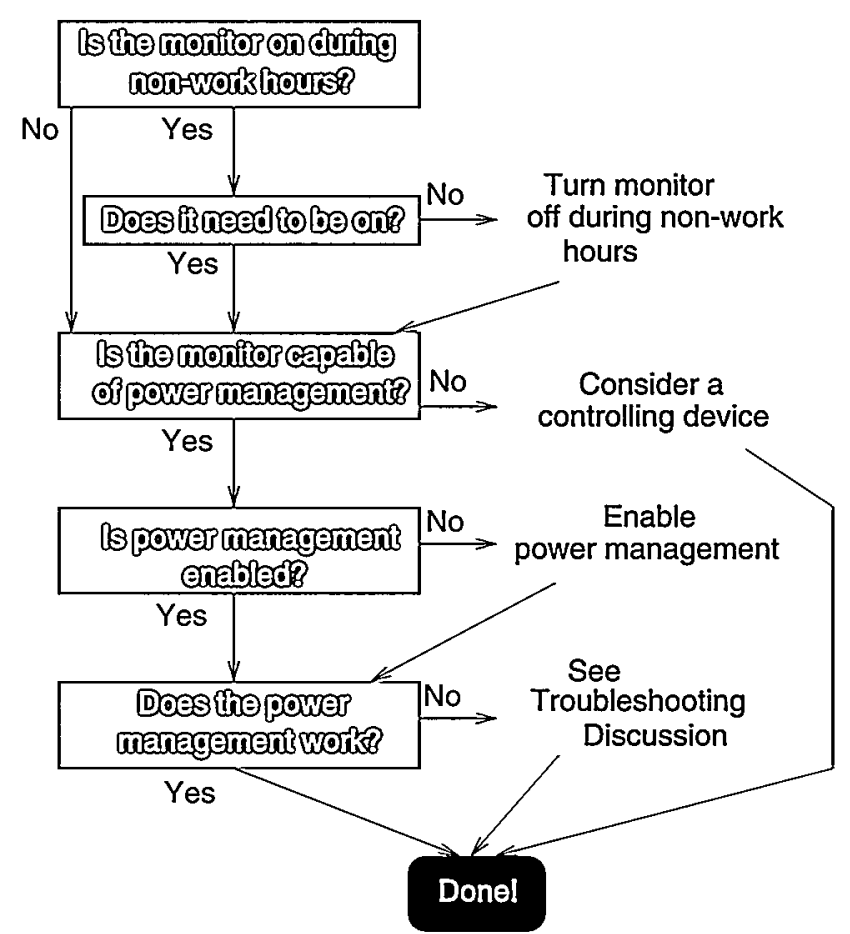




\section{Leaking Electricity and the One-Watt Plan}

\section{A. Meier}

Leaking electricity is the energy consumed by appliances when they are switched off or not performing their principal functions. Field measurements in Florida, California, and Japan show that leaking electricity represents 50-100 watts in typical homes, corresponding to about $5 \mathrm{GW}$ of total electricity demand in the U.S. There are three strategies for reducing leaking electricity: eliminate leakage entirely, eliminate constant leakage and replace with intermittent charge plus storage, and improve efficiency of conversion. These options are constrained by the low value of energy savings - less than $\$ 5$ per saved watt. Some technical and lifestyle solutions are possible. Technical solutions include moving the on/off switch to the high-voltage side of power supply, replacement of existing linear power supplies with more efficient "switcher" power supplies, and development of specialized circuits combined with supercapacitors to limit leakage to the time needed to recharge the supercapacitors. Lifestyle changes include pulling the plug on unused appliances and installing extra switches controlling outlet power.

Virtually all leaking appliances could be redesigned to leak less than 1 watt with no loss in consumer services. We have proposed a combination of non-regulatory actions and incentives to establish a 1-watt per appliance ceiling on leaking electricity. This will cut standby losses by over two-thirds, that is, from about $5 \%$ to W $1 \%$ of residential electricity use, when fully implemented. Even greater savings are achievable if the 1-watt plan is implemented globally, so we have proposed both national and international ini$\underline{\text { Q }}$ tiatives.

$\overline{\mathbf{Z}}$ More information is available at

G http://eetd.lbl.gov/EA/BEA/Projects/Leaking/

\section{Reference}

Rainer, L., S. Greenberg, and A. Meier, You Won't Find These Leaks with a Blower Door: The Latest in "Leaking Electricity" in Homes. In Proceedings of the ACEEE 1996 Summer Study on Energy Efficiency in Buildings, August 25-31, 1996. Washington, DC: American Council for an Energy-Efficient Economy, 1996. Vol. 1, pp. 1.187-191. Also available as Lawrence Berkeley National Laboratory Report No. LBNL-39545.

\section{Analyzing the Energy Use and Costs of Windows}

\section{Y.J. Huang, R. Mitchell (Building Technologies Dept., EETD, LBNL)}

Today's energy-efficient windows can dramatically lower the heating and cooling costs associated with windows while increasing occupant comfort and minimizing glass condensation problems. However, consumers are often confused about how to pick the most efficient windows for their homes. When shopping for glass, they are typically confronted with terms such as U-factors or R-values, Solar Heat Gain Coefficients or Shading Coefficients, and air leakage rates. Furthermore, these properties are based on static evaluation conditions that are very different from the real situation the window will be used in.

The RESFEN computer tool can help consumers and builders pick the most energy-efficient and cost-effective window for a given application. RESFEN performs hourly calculations using a version of the DOE-2 energy analysis simulation program. It calculates the heating and cooling energy use and associated costs as well as the peak heating and cooling demand for specific window products as they will be used. Users define a problem by specifying the house type (single-story or two-story), geographic location, orientation, electricity and gas cost, and building configuration details (such as wall type, floor type, and HVAC systems). Window options are defined by specifying the window's size, shading, and thermal properties (see below). RESFEN calculates the energy and cost implications of the windows compared to unfenestrated walls. The relative energy and cost impacts of two different windows can be compared to each other.

\section{Reference}

Huang, Y.J., R. Sullivan, D. Arasteh, and S. Selkovitz, Residential Fenestration Performance Using RESFEN 3.1. In Proceedings of the Thermal Performance of the Exterior Envelope of Buildings VII Conference, December, 1998, Clearwater Beach, FL (forthcoming).

Input screen for the RESFEN program showing window data.

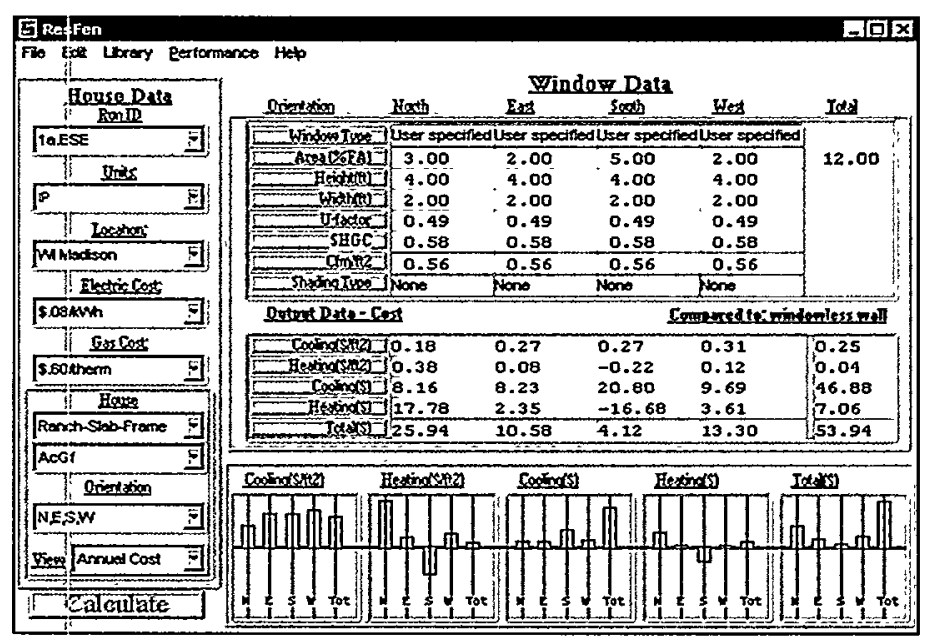




\section{Industrial Energy Analysis and Policies}

Research on energy use and efficiency in the industrial sector throughout the world, especially in the energy-intensive iron and steel, paper and pulp, chemicals, petroleum, and building materials industries. Research into the potential for energy savings from voluntary government programs, such as the Motor Challenge, in the industrial sector.

\section{Energy Intensity in the Iron and Steel Industry}

\section{Price, N. Martin, E. Worrell and J. Farla (Utrecht University), R. Schaeffer (Federal University of Rio de Janeiro)}

In light of the international agreement to establish legally binding targets for overall greenhouse gas emissions reductions, accurate measurements of the energy used in energy-intensive industrial processes are needed to understand past trends, assess the potential for energy-efficiency improvements, and make international comparisons. Our analyses found that there was a general trend toward a reduction in energy used per tonne of steel produced in eight large steel-producing countries (Brazil, China, France,

Energy used to produce a tonne of steel has slowly declined in most countries over the past two decades, although an increase is observed in the energy intensity of steel production in the U.S., Poland, France, and Japan in recent years.

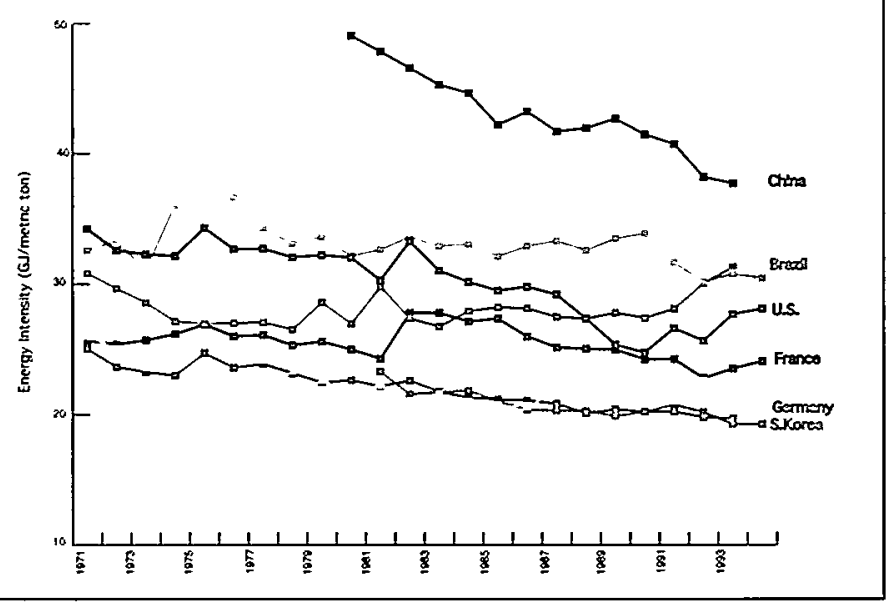

Germany, Japan, S. Korea, Poland, and the U.S.) between 1971 and 1994 (see chart). However, this decreasing trend appears to have reversed in the early 1990s in the U.S., Japan, France, and Poland. Many studies of industrial energy use rely on economic indicators (energy use per value added or gross output) to evaluate energy trends instead of physical measures (energy use per tonne of product output). However, one of our analyses of the energy intensity of steel production found that economic indicators did not track physical developments well in some countries and that while value added based indicators generally reflected the physical energy intensity better than other economic indicators for industrialized countries, large differences occurred in individual years. Using a decomposition analysis based on physical indicators for process type and product mix, we showed that physical energy intensity decreased significantly in the U.S., Germany, and
China between 1980 and 1991. In the U.S., about two-thirds of this decrease was due to efficiency improvements, while the remainder was due to structural changes. A structural/efficiency analysis shows that China, Brazil, Poland, and the U.S. have the largest potential for energy savings in the iron and steel industry.

\section{References}

Price, L., E. Worrell, N. Martin, J. Farla, and R. Schaeffer. Energy Efficiency in the United States Iron and Steel Industry: An International Perspective. In Proceedings of the 1997 ACEEE Summer Study on Energy Efficiency in Industry, July 8 - 11, 1997, Saratoga Springs, NY: American Council for an EnergyEfficient Economy. 1997, pp. 115-123.

Worrell, E., L. Price, N. Martin, J. Farla, and R. Schaeffer. Energy Intensity in the Iron and Steel Industry: A Comparison of Physical and Economic Indicators. Energy Policy, Special Issue on Cross-Country Comparisons of Indicators of Energy Use, Energy Efficiency, and $\mathrm{CO}_{2}$ Emissions, 25 (7-9) 727-744, 1997. Also available as Lawrence Berkeley National Laboratory Report No. LBNL-39782.

Worrell, E., J. Farla, L. Price, N. Martin, and R. Schaeffer. International Energy Efficiency Comparisons and Policy Implications in the Iron and Steel Industry. In The Energy Efficiency Challenge for Europe: Proceedings of the 1997 ECEEE Summer Study on Sustainable Energy Opportunities for a Greater Europe, June 9 - 14, 1997, Spindleruv Mlyn, Czech Republic: European Council for an Energy-Efficient Economy. 1997.

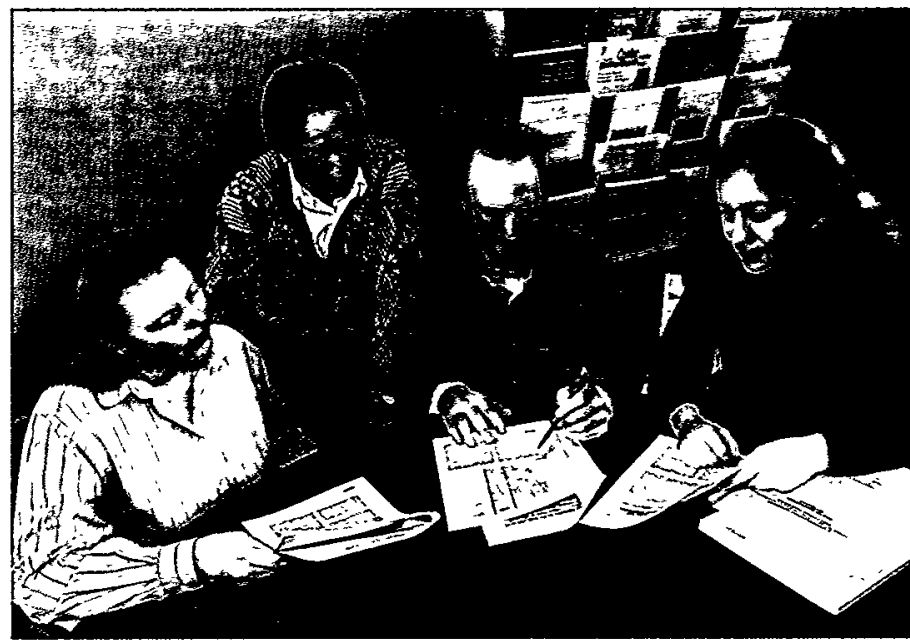

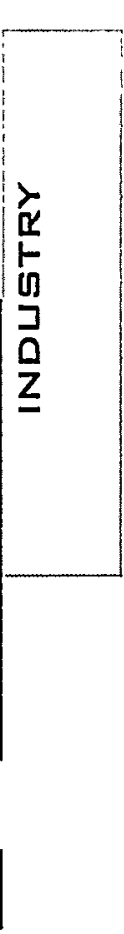




\section{Energy Efficiency in the Pulp and Paper Industry}

\section{Schipper, J. Farla and K. Blok (Utrecht University)}

We developed a method for making cross-country, cross-time comparisons of energy efficiency developments based on the use of physical production data as a measure of activity growth for the manufacturing industry. With this methodology, it is possible to isolate energy efficiency improvement impacts on fuel and electricity consumption from the effects of other changes in the industry.

We found that without improvements in energy efficiency, primary energy consumption from pulp and paper production would have increased by $42 \%$ between 1973 and 1991 in eight industrialized countries studied in this analysis. Because of past improvements in energy efficiency in the sector - averaging 1.6\% over the period — the actual increase between 1973 and 1991 was limited to $16 \%$.

\section{Reference}

Farla, J., K. Blok, and L. Schipper. Energy Efficiency Developments in the Pulp and Paper Industry: A CrossCountry Comparison Using Physical Production Data. Energy Policy, Special Issue on Cross-Country Comparisons of Indicators of Energy Use, Energy Efficiency, and $\mathrm{CO}_{2}$ Emissions, 25 (7-9) 745-758, 1997. Also available as Lawrence Berkeley National Laboratory Report No. LBNL-41140.

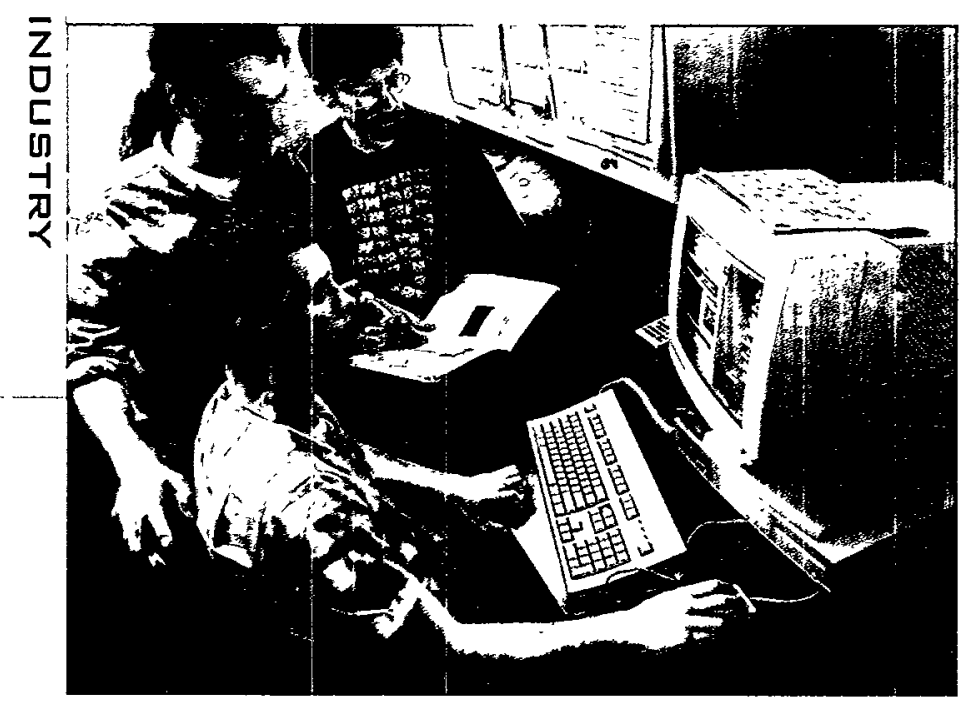

\section{Decomposition Methods for Analyzing Aggregate} Energy Intensity and Carbon Emissions Data

\section{Greening, W.B. Davis, L.J. Schipper, M. Khrushch}

We applied six different methods for decomposition of aggregate energy intensity to the same set of data for the manufacturing sector in ten OECD countries from 1970 to 1992. Based on a comparison of the size of the residual term and the variation of the term over time, we found that the Adaptive Weighting Divisia (AWD) - either in a fixed year or rolling year specification - was most robust, exhibiting the smallest residual term with the least variation.

For the ten OECD countries under examination, the majority of changes in aggregate energy intensity may be explained by changes in energy intensities in individual industrial sub-sectors. However, examination of changes in the production activity mix of each country indicates that (1) shifts in the production mix towards less energy-intensive activities promoted declines in aggregate energy intensity in the U.S., Japan, and Germany, and (2) shifts towards more energy-intensive industries reduced the overall downward trend of energy consumption per unit of output in Norway.

We then applied the AWD method to the decomposition of aggregate carbon intensity from the manufacturing sectors of the same countries. This decomposition examined the same factors influencing changes in aggregate energy intensity (as described above) in addition to two factors which allowed us to analyze carbon emissions - the primary fuel mix used to generate electricity and district heat, and the final fuel mix at the point of end use. Aggregate manufacturing carbon intensities in our ten countries declined by $30 \%-70 \%$ over the study period. As the chart on the next page shows for the U.S., these changes were primarily attributed to declines in subsectoral energy intensities and structural shifts toward less energy-intensive products. Changes in the primary and final fuel mixes worked against such declines in countries where electricity is generated mostly from coal and oil (e.g., the U.S. and Denmark); whereas in the "nuclear" countries (e.g., Sweden and France), changes in the primary and final fuel mixes contributed to significant declines in aggregate carbon intensity.

Analyses such as this provide a better understanding of the effects of increases in average factor productivity on decreases in energy use and carbon emissions. This is a necessary step to the development of policies that promote sustainable, balanced econornic growth, while conserving energy and reducing carbon emissions.

\section{References}

Greening, L.A., W.B. Davis, and L. Schipper. Decomposition of Aggregate Carbon Intensity for the Manufacturing Sector: Comparison of Declining Trends from Ten OECD Countries for the Period 1971 to 1991. Energy Economics 20 (1) 43-65, 1998. Also available as Lawrence Berkeley National Laboratory Report No. LBNL-39741, 1996.

Greening, L.A., W. B. Davis, L. Schipper, and M. Khrushch. Comparison of Six Decomposition Methods: Application to Aggregate Energy Intensity for Manufacturing in Ten OECD Countries, Energy Economics 19 (3) 375-390, 1997. Also available as Lawrence Berkeley National Laboratory Report No. LBNL39738. 

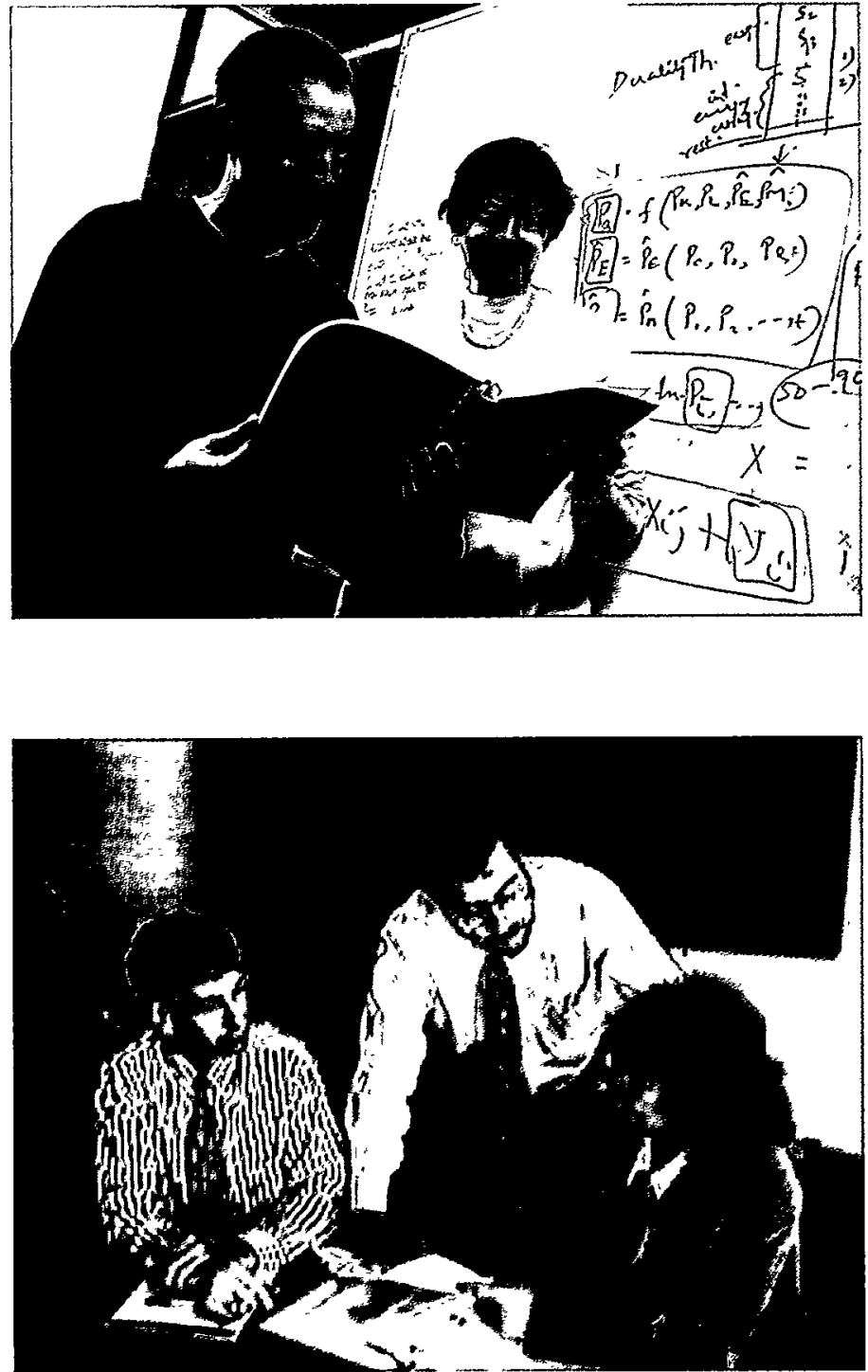

Industrial Energy Use and Energy Efficiency In Developing Countries

\section{Price, N. Martin, E. Worrell, M.D. Levine}

The industrial sector accounts for over $50 \%$ of the energy used in developing countries and this energy use has been growing at an average rate of over $4.5 \%$ per year since 1980 . Based on these trends, developing countries will dominate world industrial energy use by 2020 . A review of energy-intensity trends in four energy-intensive industrial subsectors (iron and steel, chemicals, building materials, and pulp and paper) shows that, in general, energy intensities in developing countries are higher than in industrialized countries due to the use of antiquated equipment and production processes. However, the amount of energy used to produce a tonne of product tends to decline as developing countries invest in new production capacity. LBNL developed three scenarios of future industrial energy use in developing countries which show that growth in industrial energy use is expected to be about $3 \%$ per year through 2020 under business-asusual conditions, but can be reduced to about $1.5 \%$ per year using state-of-the-art or advanced technologies.

\section{Reference}

Price, L., N. Martin, E. Worrell, and M.D. Levine. Industrial Energy Use and Energy Efficiency in Developing Countries. In Proceedings of the 8th National Industrial Energy Technology Conference, April 17-18, 1996, Houston, TX. Also available as Lawrence Berkeley National Laboratory Report No. LBNL39786.

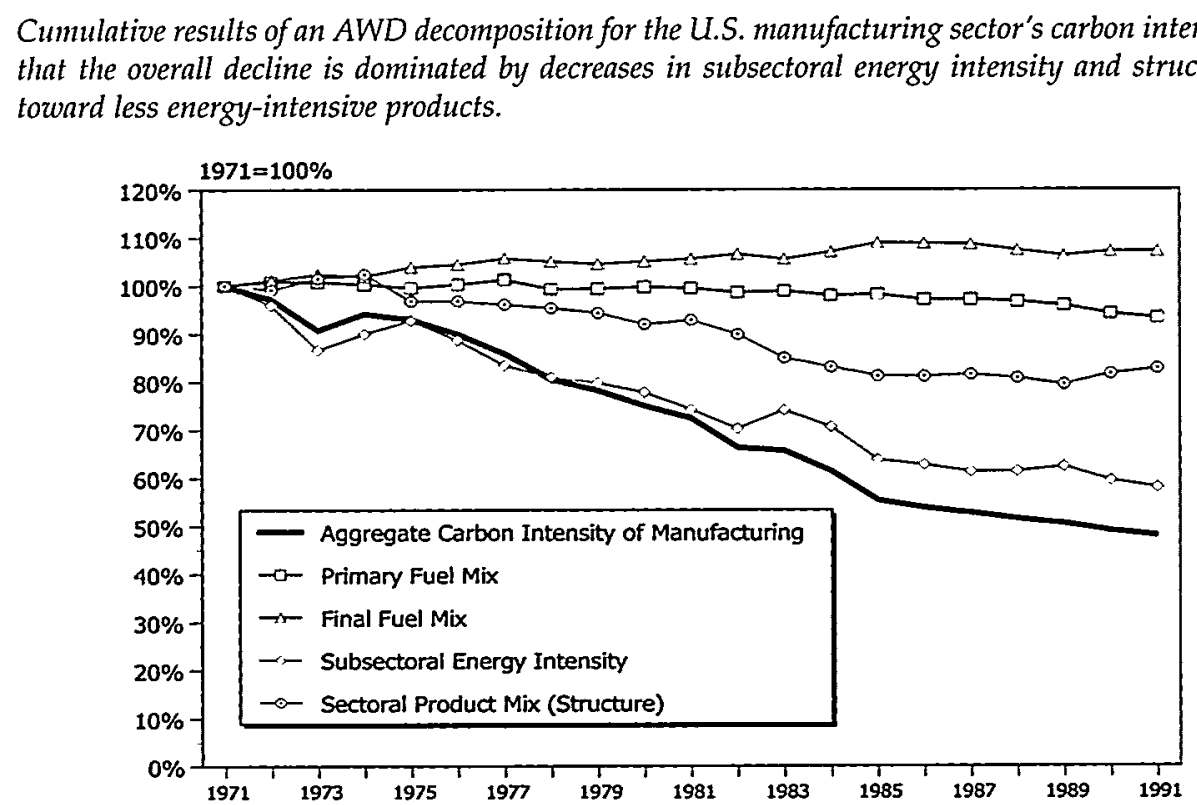




\section{Creating Industry Sector Partnerships}

\section{A. McKane, V. Tutterow}

Many of the barriers to improving energy efficiency in the industrial sector are institutional rather than technological. While continued technological innovation is extremely important to increased industrial productivity, many existing technologies are seriously underutilized by industry because their benefits are not well understood and/or institutional barriers to their adoption have not been adequately addressed. In recent years, we have been working with DOE's Office of Industrial Technologies' Motor Challenge program to create industry sector partnerships as a pathway toward promoting more energy-efficient industrial motor systems.

Electric motor systems account for about $550 \mathrm{TWh}$, or $70 \%$, of all industrial electricity use in the U.S. Of this total, equipment such as pumps, fans, blowers, and air compressor systems represents about $45 \%$, or $230 \mathrm{TWh} / \mathrm{yr}$. Potential savings from more efficient industrial motor systems are very large: a 10\% improvement in overall efficiency - achievable with new and existing technology by 2010 - would save $55 \mathrm{TWh} / \mathrm{yr}$, worth $\$ 1.5$ billion annually to U.S. industry. Most of these savings are attributable to improvements in motor-driven equipment and other parts of the system, rather than the motor itself.

In 1997, two new industry partnerships emerged as the result of our efforts in support of DOE's Office of Industrial Technologies.

Components of a typical compressed air systent. System losses can occur due to inadequate or poorly matched controls, improperly installed or leaking distribution lines, poor maintenance, mis-matching compressors to londs, and/or higher than necessary system pressure.

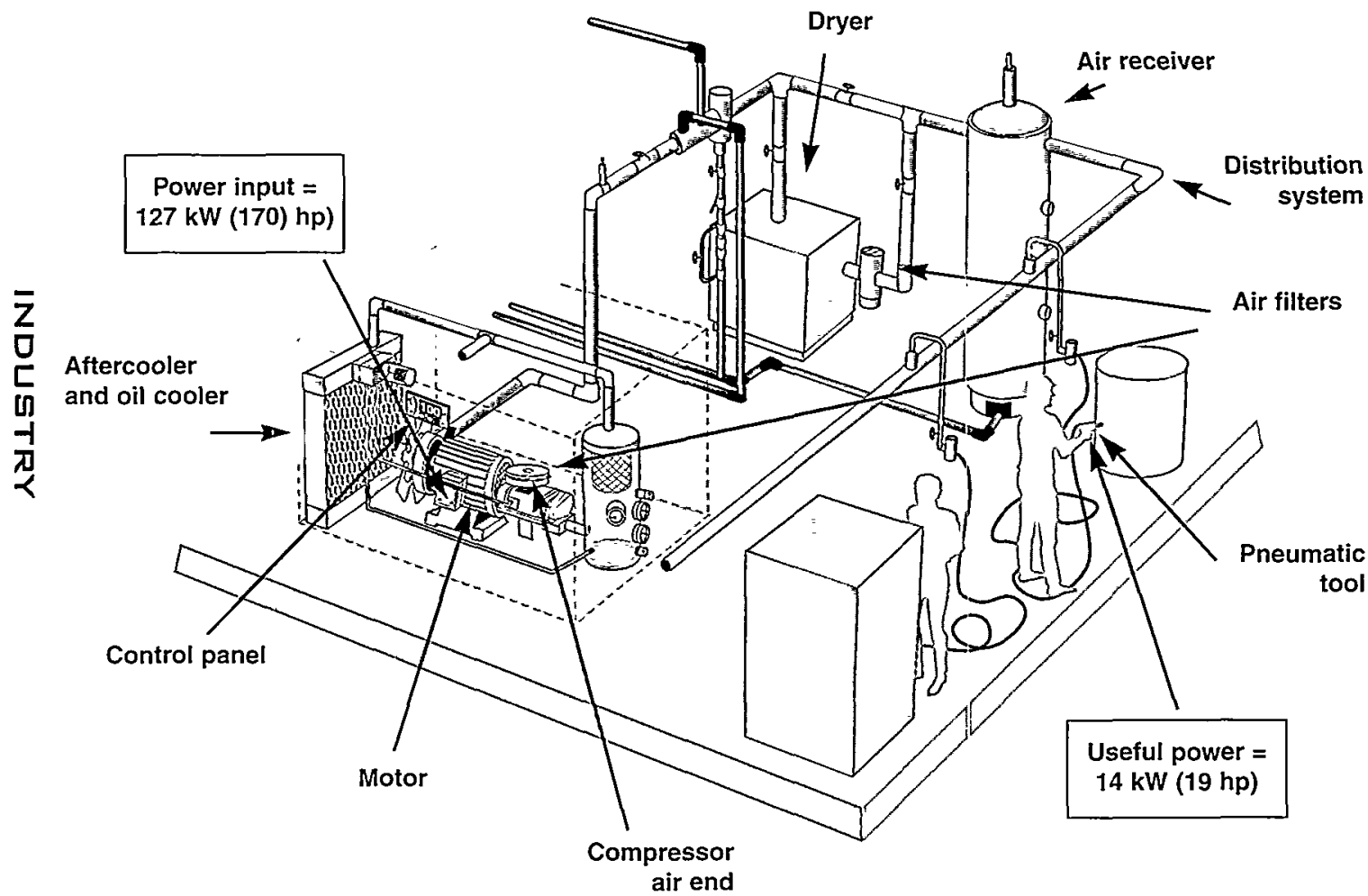

One is organized within a single industry (pulp and paper); the second involves a cross-cutting industrial utility (compressed air). DOE's partnership with the Technical Association of the Pulp and Paper Industry (TAPPI) is designed to help deliver targeted information on efficient motor systems directly to plant personnel. This industry-specific partnership, providing access to TAPPI's 33,000 members world-wide, gives the DOE Motor Challenge Program an important new avenue for achieving savings from improved motor systems--at least 10 TWh annually by 2010 .

The Compressed Air Challenge, another national partnership, aims at improving efficiency of compressed-air systems across many industry sectors, including chemicals, mining, textiles, pulp and paper, glass, plastics, petroleum refining, and automobile and aircraft manufacturing. Industrial compressed air systems, which use an estimated 27 TWh of electricity annually, are frequently oversized and poorly controlled and configured. Even though compressed air - due to inherent inefficiencies in its production - is often the most expensive utility in an industrial plant (see illustration), air is often perceived as "free" by those who use it. A 20 to $50 \%$ improvement in overall system efficiency is achievable and economical in many industrial plants using today's best practices. The primary barrier is a lack of information on the part of plant designers, managers, and end users. The Challenge is designed to:

- raise the awareness of the importance of efficient, effective compressed air systems;

- train industrial plant operating staff on best practices for these systems;

- expand the market for expert services on compressed air system assessments; and

- help build the local market infrastructure to deliver these services.

The Challenge anticipates achieving an average system efficiency improvement of $10 \%$ over current practices by the year 2002 , for an annual energy savings of $2.7 \mathrm{TWh}$.

\section{Reference}

McKane, A.T., P. E. Scheihing, C. Cockrill, and V. Tutterow. U.S. Department of Energy's Motor Challenge: Developed with Industry for Industry. In The Energy Efficiency Challenge for Europe: Proceedings of the 1997 ECEEE Summer Study on Sustainable Energy Opportunities for a Greater Europe, June 9-14, 1997, Spindleruv Mlyn, Czech Republic: European Council for an Energy-Efficient Economy, 1997. 


\title{
$\prod_{\text {ransportation Energy Analysis }}$
}

\begin{abstract}
Research into how vehicle technology, land-use patterns, and travel behavior affect transportation energy use and emissions of greenhouse gases and urban air pollutants.
\end{abstract}

\section{International Trends in Carbon Dioxide Emissions from Passenger Transport}

\section{Schipper}

Since 1970, carbon dioxide emissions from passenger transport have grown in almost every industrialized country. We conducted a comparative analysis of the changes in energy use and carbon dioxide emissions from passenger transport in ten OECD countries. Unlike most previous analyses, we based ours on a newly published international data set covering vehicle activity, passenger travel, and fuel use by mode. We calculated how changes in activity, modal composition, and the energy intensity of each mode contributed to changes in total energy use from travel in the ten countries between 1973 and 1994. Increased travel activity and modal shifts boosted energy use, while reductions in modal energy intensities reduced energy use from automobiles in the U.S. and in air travel throughout the sample of countries. As a result, travel-related energy use increased sharply in every country except the U.S. and Denmark. Using these calculations, we then examined how these changes affected carbon dioxide emissions from travel. Noting that the shifts of fuels within transport have been small, even counting shifts in the fuels used to produce the small amount of electricity used for passenger transport in every country, we found that increased activity and modal shifts raised carbon dioxide emissions from travel in every country except the U.S (see box). Recalling that real prices for road fuels have fallen to near their 1973 levels while energy intensities remain level or are falling slowly, we foresee (in the absence of additional government intervention) continued increases in travel, particularly in cars and airplanes, pushing emissions even higher.

\section{Reference}

Scholl, L., L. Schipper, and N. Kiang. $\mathrm{CO}_{2}$ Emissions from Passenger Transport: A Comparison of International Trends from 1973 to 1992. Energy Policy 24 (1) 17-30. 1996.

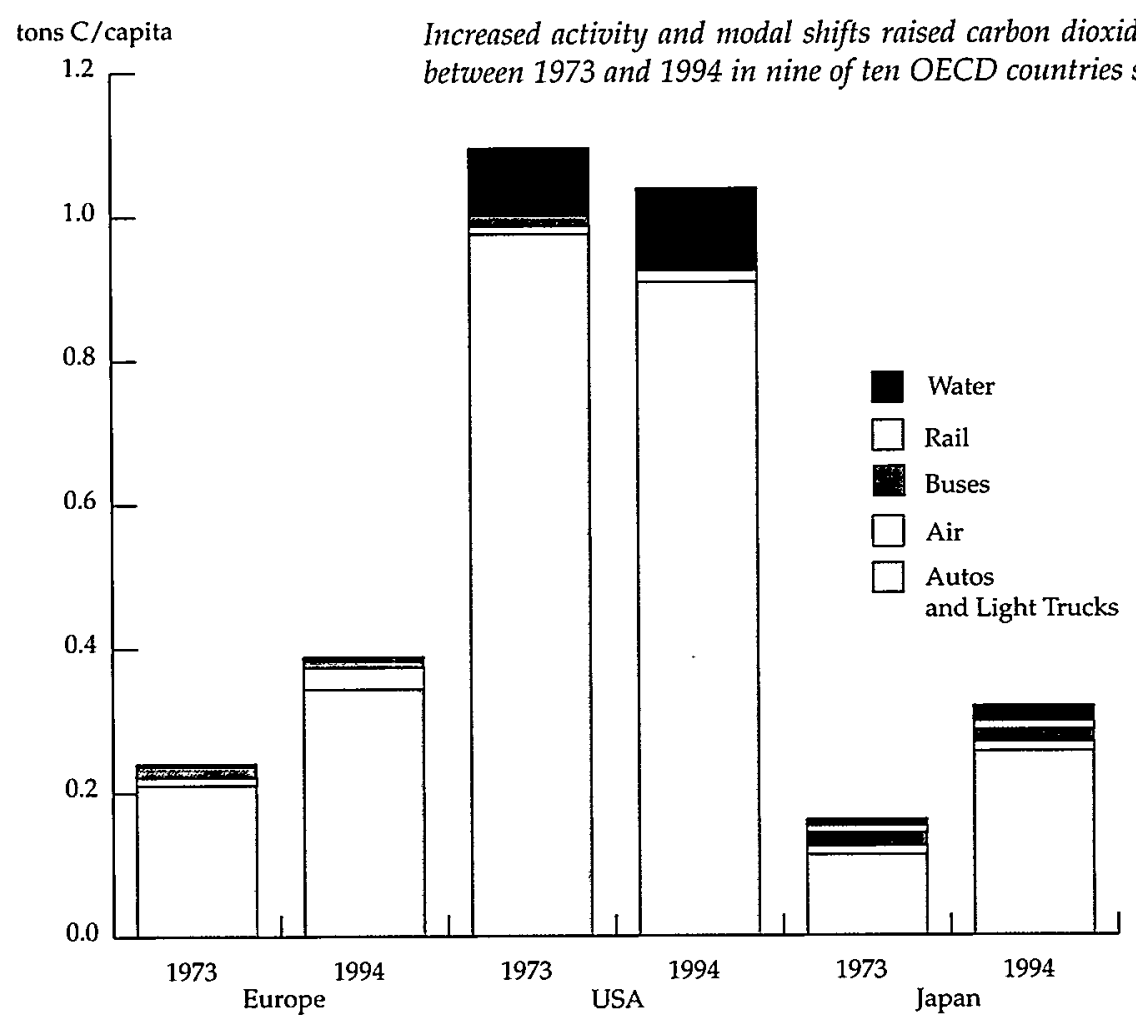




\section{International Trends in Energy Use and Carbon Dioxide Emissions from Freight}

\section{Schipper, L. Price}

Energy use and associated carbon emissions from transportation of freight have increased faster than those from the buildings, industrial, and personal travel sectors in many industrialized countries. Our analysis of trends in the freight sector in ten OECD countries found that domestic freight volumes rose in every country studied and that freight energy use and associated carbon emissions increased markedly. Overall increases in transported goods as well as a dramatic shift toward the use of energy-intensive trucks are the underlying causes of the observed increases. A review of options such as reducing trucking energy intensity, increasing vehicle capacity utilization, shifting from trucking toward shipping and rail, and reducing overall freight activity leads the authors to conclude that the ability to reduce carbon emissions from freight does not look encouraging given recent trends and the fact that energy use for transportation in developing countries is rising rapidly. Use of policies that address the wider environmental problems of freight shipments such as noise, air pollution, and congestion as well as policies that equalize diesel and gasoline taxes and increase road-use fees for trucks could lead to less freight activity and use of more efficient freighthauling vehicles.

\section{Reference}

Schipper, L., L. Scholl, and L. Price. Energy Use and Carbon Emissions from Freight in Ten Industrialized Countries: An Analysis of Trends from 1973 to 1992. Transport Research, Part D: Transport and the Enviromment 2 (1) 57-76, 1996. Also available as Lawrence Berkeley National Laboratory Report No. LBL-38826.

\section{Socioeconomic Factors Affecting Greenhouse-Gas Emissions from Personal Automotive Transportation}

\section{Greening, L. Schipper}

Different subgroups in the population have different levels of greenhouse gas emissions from personal automotive transportation. Socioeconomic characteristics that are associated with higher levels of emissions include greater numbers of vehicles, upper middle to high incomes, educational attainments of college or more, larger family sizes, white collar occupations, and placement of the family unit in the middle stages of the family life-cycle. In general, the characteristics which reflect an affluent life-style are indicative of higher emissions levels.

This is the first time that the statistical technique used here has been utilized with household expenditure data to obtain a ranking of the effects of socioeconomic characteristics on levels of greenhouse gases emissions from personal automotive transportation. This type of analysis can lead to the development of more effective policies for the mitigation of greenhouse gases, including policy-relevant factors that may be addressed with a variety of non-monetary incentives.

\section{Reference}

Greening, L., L. Schipper, R. Davis, and S. Bell. Prediction of Household Levels of Greenhouse-Gas Emissions From I'ersonal Automotive Transportation. Energy-The International Journal 22 (5) 449-460, 1997. Also available as Lawrence Berkeley National Laboratory Report No. LBNL-39770.

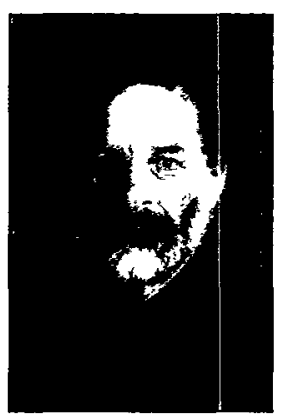




\section{Analysis of Emissions Deterioration of In-Use Vehicles}

\section{T. Wenzel, R. Sawyer (Advanced Technologies Dept., EETD, LBNL)}

Current computer models that forecast air pollutant emissions as the vehicle fleet ages assume that emissions increase dramatically after vehicles reach 50,000 odometer miles. This analysis tested this assumption by examining tailpipe emissions from 220,000 vehicles tested under the Arizona vehicle emission Inspection and Maintenance (I/M) program in 1995. Arizona is one of the first states to use an enhanced I/M testing procedure recommended by the U.S. EPA. The procedure, called the IM240, involves testing vehicles on a treadmill-like device that measures emissions under varying vehicle operating conditions. The procedure was developed to simulate the detailed emissions testing manufacturers perform on their new vehicle models.

The figure shows average hydrocarbon $(\mathrm{HC})$ emissions of passenger cars by vehicle model year and odometer reading (in 1,000mile groupings). The curves indicate that, rather than "kinking" upward when a certain mileage is reached, average vehicle emissions increase at the same rate with increasing mileage even at very high mileages. In addition, older vehicles have higher average emissions than newer vehicles. This is likely due to technological improvements to emissions control technologies over time; however, it is also possible that vehicle aging - independent of mileage accumulation - accounts for some of this emissions increase. The analysis also found that the fraction of vehicles failing the I/M test dominates the overall increase in emissions with increasing mileage. These results will be useful in improving the computer models used to forecast emissions reductions in areas with poor air quality.

\section{Reference}

Wenzel, T., M. Ross, and R. Sawyer. Analysis of Emissions Deterioration of In-Use Vehicles, presentation at the Society of Automotive Engineers' Government/Industry Conference, May 5 - 7, 1997, Washington, DC. Lawrence Berkeley National Laboratory Report No. LBNL-41452, 1997.

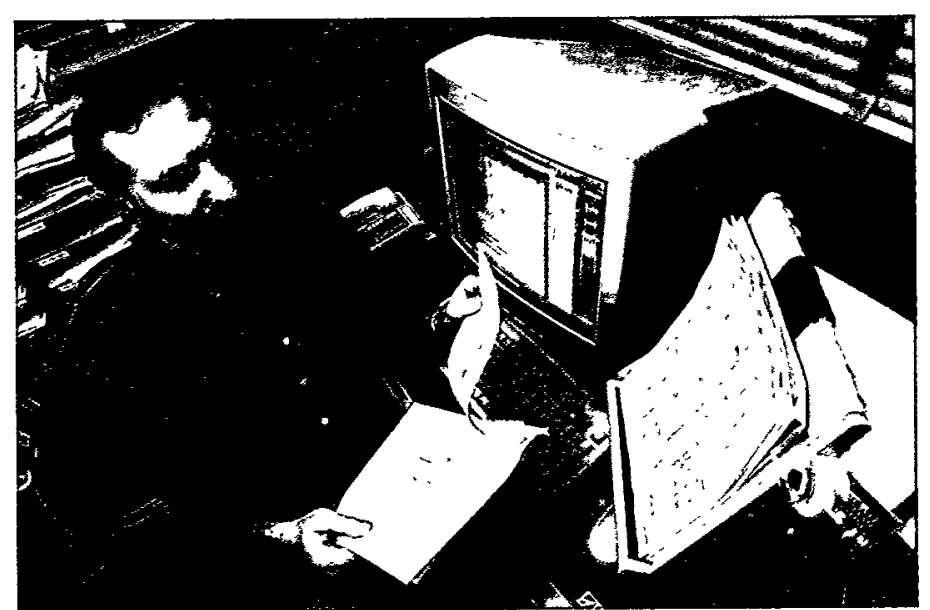

Average HC emissions by vehicle model year (MY) increase linearly with increasing mileage. Average emissions measured in 1995 are higher for earlier model years. More study is needed to determine if the difference in emissions by model year is due to improved technology or simply vehicle aging.

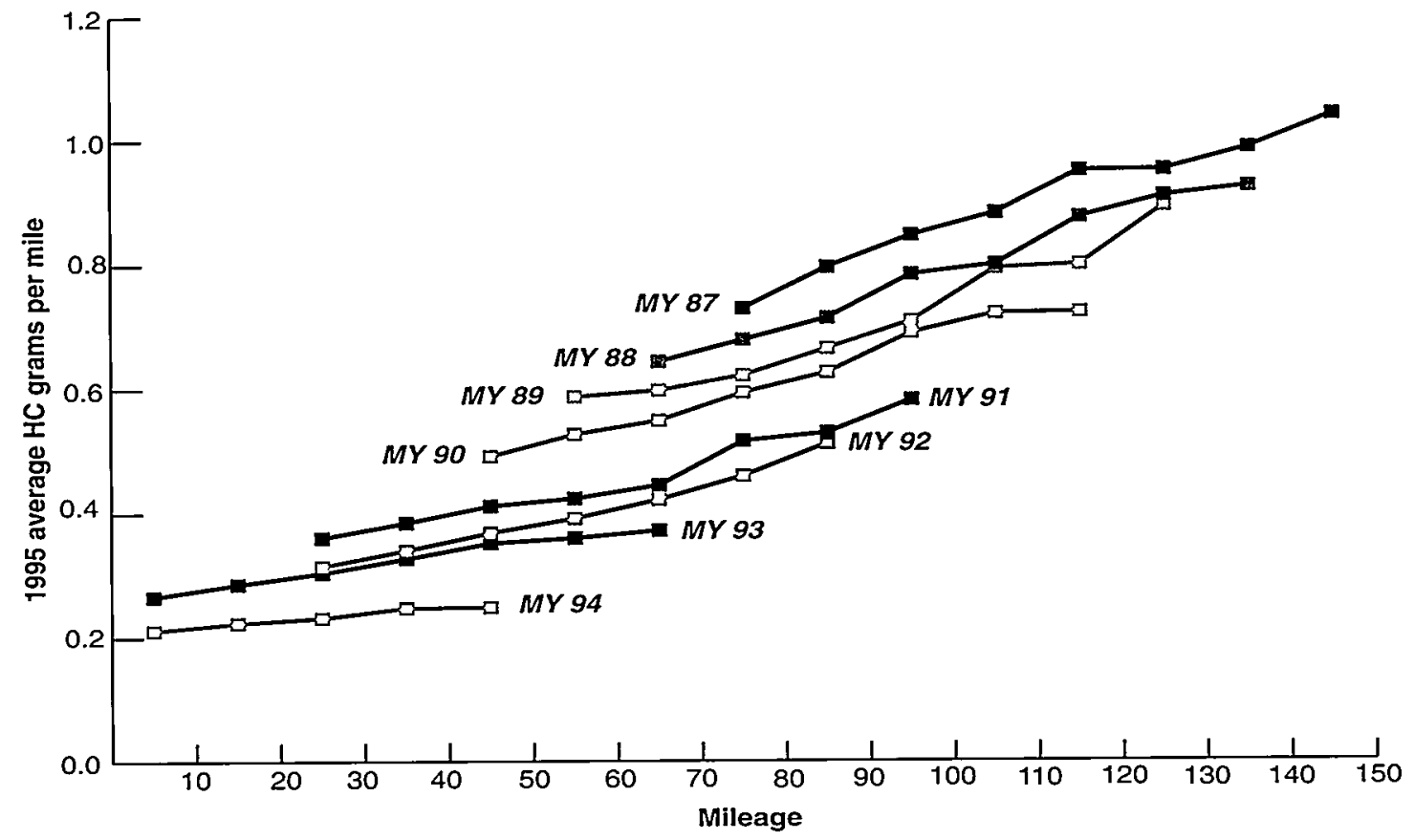




\section{Inspection and Maintenance Failure Rates by Vehicle Model}

\section{T. Wenzel, R. Sawyer (Advanced Teclnologies Dept., EETD, LBNL)}

Previous analysis of vehicle emissions using measurements from roadside remote infrared sensors indicated that emissions vary greatly by vehicle model. This analysis compares vehicle emissions data from three states which use differing measurement techniques in order to determine if test failure rates by model and model year are consistent across states. The California remote sensing data were compared with Inspection and Maintenance (I/M) program data from Arizona, which uses the U.S. EPA-recommended IM240 test procedure, and with Minnesota, which uses the more conventional idle test procedure. Many of the models that were identified by remote sensing as being high emitters had similarly high failure rates in the Arizona IM240 test. The Minnesota data, however, failed to identify these same high emitter models. These results were expected, since remote sensing and IM240 testing capture vehicle emissions over a variety of driving conditions, whereas idle testing does not.

Detailed analysis of the Arizona data revealed that several vehicle models have high failure rates even within the manufacturers' emissions warranty period (5 years or 50,000 miles). The one passenger car model recalled by the EPA in recent years had among the highest failure rates under the Arizona testing; however, several other models had similarly high or even higher failure rates, including some that passed EPA's recall tests. This result suggests that $\mathrm{I} / \mathrm{M}$ data can be used to target specific vehicle models for more detailed testing under EPA's recall testing program.

The analysis also examined the effect of vehicle maintenance on emissions. I/ $\mathrm{M}$ failure rates by model for two testing stations in Arizona were compared. The stations were selected because they had the highest and lowest failure rates of all stations in the Arizona program. It is believed that the difference in failure rate is due to the wide disparity in average income of the two areas served by the stations and that drivers with higher incomes are more likely to properly maintain their vehicles. The figure shows the hydrocarbon $(\mathrm{HC})$ failure rate for 71 passenger car models for each of the two stations, and for all Arizona stations combined, ranked from lowest to highest. Over half of the vehicle models have essentially no failures at either testing station (noted by the solid line). However, virtually all of the models with high overall failure rates have higher failure rates at Station 4 (located in a relatively low income area) than at Station 10 (located in a relatively high income area). These results suggest that cars can be designed to be relatively insensitive to maintenance practices and that vehicle maintenance can affect in-use vehicle emissions of even newer cars.

\section{Reference}

Wenzel, T. and M. Ross. I/M Failure Rates by Vehicle Model, presentation at the Seventh CRC On-Road Vehicle Emissions Workshop. Lawrence Berkeley National Laboratory Report No. L.BNL-41451.

About half of 1991 to 1993 model year (MY) passenger car models have essentially no HC emissions failures within the first 2 to 5 years of driving. However, the models that do fail emissions tests most often have higher failure rates in lower income areas. This suggests that vehicle maintenance can affect in-use car emissions, at least for some car ntodels.

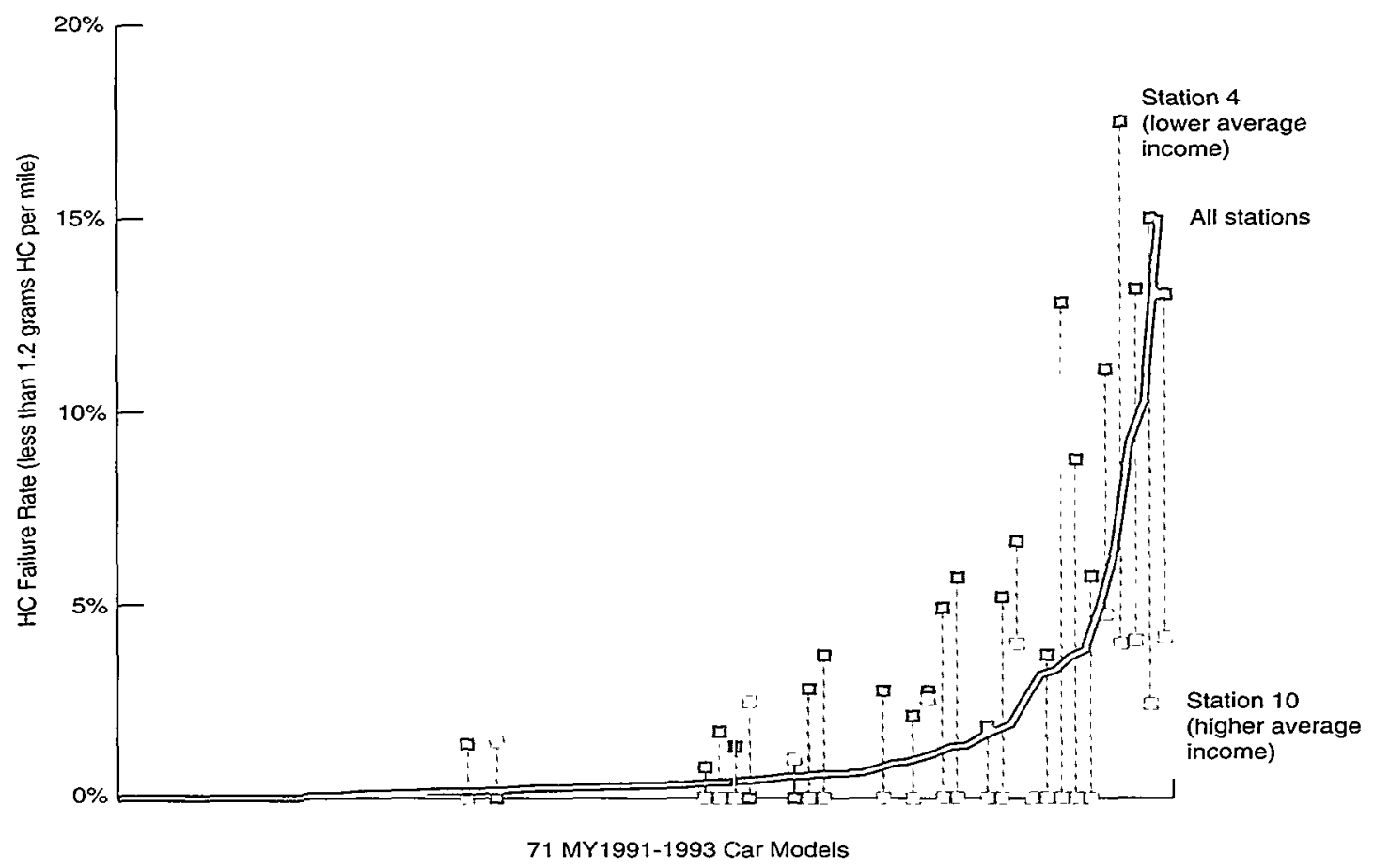




\section{Sponsors}

All work is conducted under U.S. Department of Energy Contract No. DE-AC03-76SF00098. Funding for the work described in this report was provided by:

Assistant Secretary for Energy Efficiency and Renewable Energy, U.S. Department of Energy

Federal Energy Management Program

Office of Building Technologies and State and Community Programs, Office of Building Energy Research

Office of Building Technologies, Office of Codes and Standards

Office of Industrial Technologies, Industrial Energy Efficiency Division

Office of Utility Technologies, Office of Energy Management

Assistant Secretary for Fossil Energy, U.S. Department of Energy

Deputy Assistant Secretary for Coal Technology

Assistant Secretary for Policy, U.S. Department of Energy

Deputy Assistant Secretary for Economic and Environmental Policy

Office of Energy Research, U.S. Department of Energy

Chemical Sciences Division

U.S. Department of Defense, U.S. Army Corps of Engineers, Construction Engineering Research Laboratory

U.S. Environmental Protection Agency

Office of Policy, Planning, and Evaluation, Office of Economy and Environment, Climate Policy and Programs Division

Office of Air and Radiation, Office of Atmospheric Programs, Atmospheric Pollution Prevention Division

U.S. Agency for International Development, Office of Energy and Infrastructure

U.S. Postal Service

$A B$ Volvo

Alternative Energy Development, Inc.

California Institute for Energy Efficiency

Canadian Government

Chevron

Conoco

Danish Energy Agency

Energy Research International

Exxon Company International

Finnish Ministry of Trade and Industry

Ford Motor Co.

Future Resources Associates

International Energy Agency

Korea Energy Economics Institute

National Aeronautics and Space Administration

Oak Ridge National Laboratory

Pacific Northwest National Laboratory

Republic of Venezuela

Resource Management International

Shell Oil Company (Houston)

Shell International Petroleum Company

United Nations Environmental Program, Collaborating Centre on Energy and Environment

Additional support for graduate students to work on LBNL projects came from

Swedish Communications Research Board 